UNIVERSIDAD NACIONAL DE LA PLATA

MAESTRÍA EN SALUD PÚBLICA

\title{
PERCEPCIÓN DE LA CALIDAD DE ATENCIÓN DE LOS USUARIOS DEL CENTRO DE ATENCIÓN PRIMARIA DE LA SALUD “ENTRE RÍOS NORTE”
}

Tesis para obtener el título de MAGISTER EN SALUD PÚBLICA

Tesista

Dra. LILIANA MARIÑO

Directora

Mag. ANA MARÍA BUZZI

Codirector

Dr. GUSTAVO MARÍN

Bragado, Argentina

2019 


\section{AUTORA}

LILIANA ESTER MARIÑO, médica pediatra recertificada por la Sociedad Argentina de Pediatría. Título de grado otorgado por la Universidad Nacional de La Plata. Posgrado en Salud Social y Comunitaria. Diplomatura en capacitación docente para profesionales de la salud.

Desde 1997 se desempeña como pediatra de guardia en el hospital San Luis y en centros de Atención Primaria de la Salud en Bragado, Provincia de Buenos Aires.

Correo electrónico: lilianaester1968@gmail.com

\section{DIRECTORA}

Mag. ANA MARÍA BUZZI, Contador Público: Facultad de Ciencias Económicas de la Universidad Nacional de La Plata. Licenciado en Administración: Facultad de Ciencias Económicas de la Universidad Nacional de La Plata. Especialista en Dirección de Empresas con orientación en Salud (Universidad Austral). Magister en Gestión Actuarial de la Seguridad Social de la Universidad de Buenos Aires. Docente titular de la Facultad de Ciencias Económicas de la UNLP y de la Universidad Nacional de Quilmes (Modalidad virtual). Conferencista, autor de libros y publicaciones en revistas nacionales e internacionales, jurado de concursos y tesis. Especialista externo en la evaluación de la Programación de Proyectos de Investigación UBACYT 2017 y 2018. Docente de postgrado en la Facultad de Ciencias Médicas de la UNLP. Expositor en diversos eventos académicos y profesionales.

\section{CODIRECTOR}

Dr. GUSTAVO MARÍN, Doctor en Medicina (UNLP). Magister en Salud Pública (UNLP). Magister en Economía de la Salud (UNLP). Maestría en Ciencias Políticas (UNLP). Especialista en Farmacología Clínica (CMPBA); Especialista en Gestión Pública (UNTREF). Especialista en Clínica Médica (UBA). Profesor Titular de Salud Comunitaria en la Universidad Nacional de La Plata (UNLP), Argentina. Investigador Adjunto del CONICET. Asistente Extranjero en la Universidad de París VII, Francia. Becario postdoctoral en la Universidad de la Sorbona Paris-Cité. Ex miembro de la Asistencia Pública de París y del Colegio de Médicos de París, Francia. Ex miembro del Programa de Lideres en Salud Internacional -OPS. Autor de 155 publicaciones internacionales indexadas. Director de 10 Proyectos de Investigación del programa de Incentivos del Ministerio de Salud de la Nación. Director de 24 proyectos de Extensión o Voluntariado SPU-Ministerio de Educación ExDirector de Atención Primaria de la Salud de la Provincia de Buenos Aires. Ex-Director de Planificación de la Salud, MLP, Buenos Aires; Ex-Director de Ciencia, Tecnología e Innovación de la Provincia de Buenos Aires. 1er Coordinador del Plan Nacer en Prov. de Buenos Aires. Responsable Provincial del Programa Remediar y Médicos Comunitarios para Buenos Aires. 


\section{INDICE}

1-RESUMEN

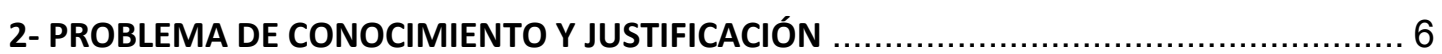

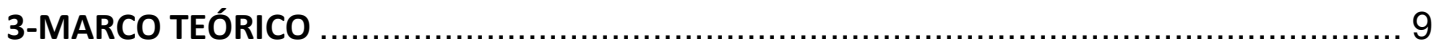

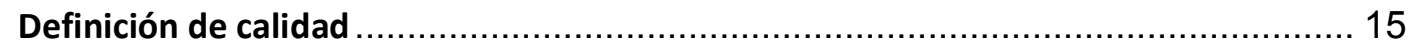

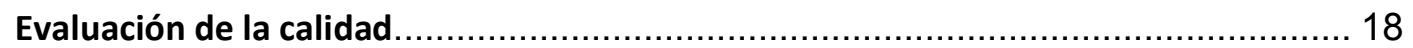

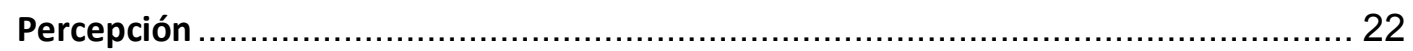

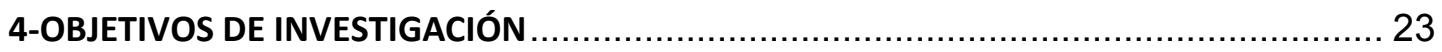

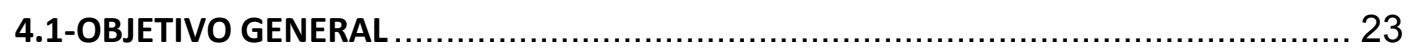

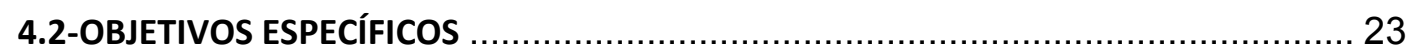

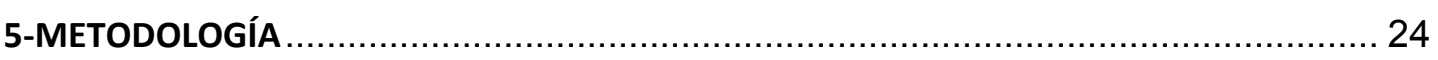

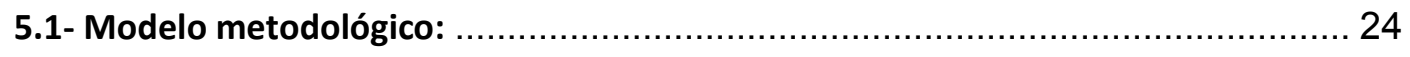

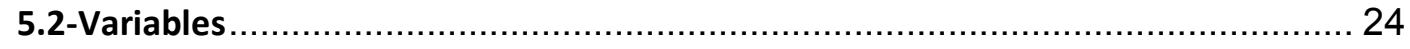

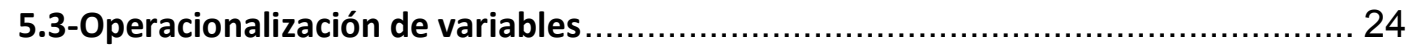

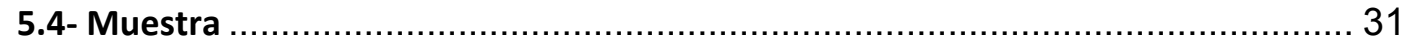

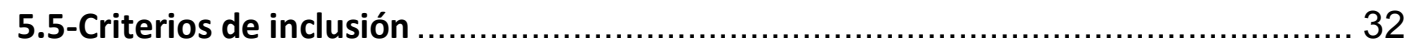

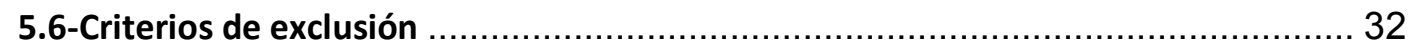

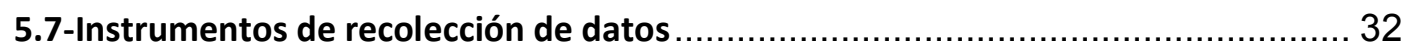

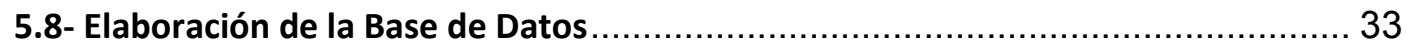

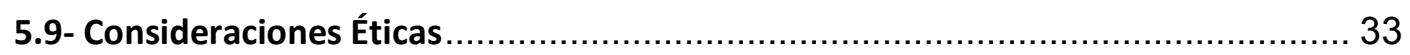

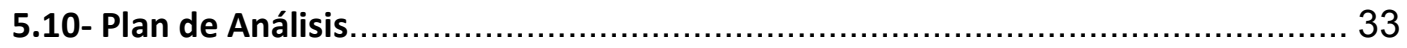

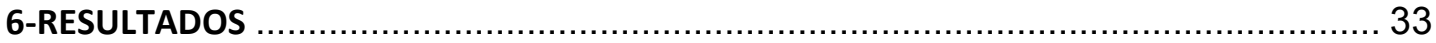

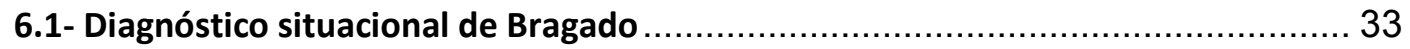

6.2- Análisis de las variables de la entrevista cerrada al usuario interno.................... 34

6.2.1-Análisis variables sociodemográficas de los entrevistados........................... 34

6.2.2-Análisis variables de estructura, proceso y resultado .................................. 35

6.2.3-Análisis de las respuestas según la edad de los entrevistados ...................... 37

6.2.4- Análisis de las respuestas según el género de los entrevistados.................. 39

6.2.5-Análisis de las respuestas según la escolaridad de los entrevistados............. 41

6.2.6 -Análisis de las respuestas según el puesto de trabajo de los entrevistados ... 43

6.2.7- Análisis de las respuestas según la antigüedad de los entrevistados ............ 45

6.2.8- Análisis de las respuestas según las horas de trabajo de los entrevistados .... 47

6.3-Análisis de las variables de la entrevista cerrada usuario externo ....................... 49 
6.3.1-Análisis variables sociodemográficas de los entrevistados

6.3.3-Análisis de las respuestas según el género de los entrevistados

6.3.4-Análisis de las respuestas según la edad de los entrevistados... 54

6.3.5-Análisis de las respuestas según la ocupación de los entrevistados 56

6.3.6-Análisis de las respuestas según la escolaridad de los entrevistados 58

6.3.7-Análisis de las respuestas según el estado civil de los entrevistados 60

6.4-Análisis de las variables de la entrevista abierta al usuario externo 62

6.4.1-Análisis variables sociodemográficas de los entrevistados

6.4.2-Análisis variables de estructura, proceso y resultado 63

6.4.3Análisis de las respuestas según el género de los entrevistados 66

6.4.4-Análisis de las respuestas según la edad de los entrevistados. 66

6.4.5-Análisis de las respuestas según la ocupación de los entrevistados 66

6.4.6-Análisis de las respuestas según la escolaridad de los entrevistados 67

6.4.7-Análisis de las respuestas según el estado civil de los entrevistados 68

6.5-Análisis de las variables del grupo focal.

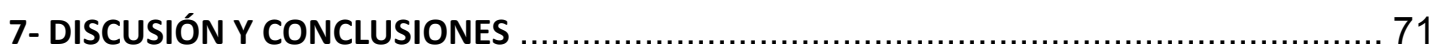

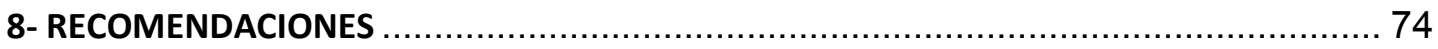

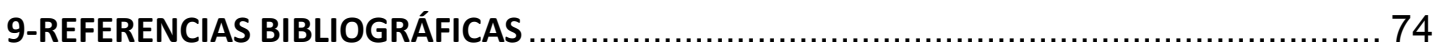

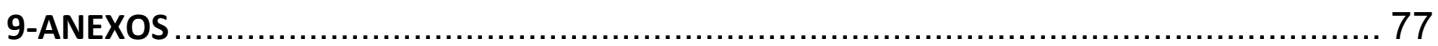




\section{1-RESUMEN}

En el presente trabajo se analizó la calidad de atención en el centro de atención primaria Entre Ríos Norte de la ciudad de Bragado a través de la percepción de los usuarios externos e internos. Se investigó la percepción que tienen los usuarios de las dimensiones de la calidad: estructura, proceso y resultados y la relación de sus respuestas con diferentes características sociodemográficas. Se realizó un estudio transversal analítico, utilizando triangulación metodológica cuantitativa y cualitativa a través de entrevistas cerradas, entrevistas abiertas y grupos focales. La intención fue combinar la metodología cuantitativa que permite generalizar y la cualitativa que posibilita la profundización para obtener mayor información frente a un objeto de estudio complejo, como es, la percepción de la calidad. En este estudio la percepción de los usuarios externos e internos sobre la calidad de la atención, fue muy buena y buena y la satisfacción de ambos usuarios, fue mayor al $80 \%$. 


\section{2- PROBLEMA DE CONOCIMIENTO Y JUSTIFICACIÓN}

El partido de Bragado está ubicado en el centro y noroeste de la provincia de Buenos Aires. Ocupa $2.230 \mathrm{~km}^{2}$, y la densidad de población es de 17,9 hab. $/ \mathrm{km}^{2}$. La creación del partido data del 17 de octubre de 1851. Tiene una población de 41336 habitantes con un índice de masculinidad del $94 \%$ según datos del censo 2010. Existen 14291 hogares de los cuales $59.7 \%$ tiene acceso a la Red Pública de Cloacas, $88.1 \%$ de las viviendas tiene acceso a la Red Pública de Agua Corriente y $62.7 \%$ tiene Gas Natural. La población ocupada es del $46 \%$, la población desocupada $2 \%$ y la población inactiva es $29 \%$. El porcentaje de población con NBI es del $6 \%{ }^{1}$

El sistema de salud de la ciudad de Bragado está integrado por: 1) un hospital municipal con servicios de guardia general y pediátrica, internación, terapia intensiva y consultorios externos de clínica, pediatría, cirugía, traumatología, ginecología, oftalmología, cardiología, diabetes, odontología, salud mental, kinesiología, otorrinolaringología, endocrinología, neurología y neumonología y 2) siete centros municipales de Atención Primaria de la Salud (CAPS) en los barrios periféricos.

El presente estudio se desarrolló en el Barrio Entre Ríos Norte, ubicado en el sector sudeste de la ciudad, que cuenta con una población de 2.122 habitantes (INDEC, según datos del Censo 2010) y está limitado por las calles Catamarca, Maestros Argentinos, Palacios y Ferroviarios Argentinos. (Ver Gráfico N¹).

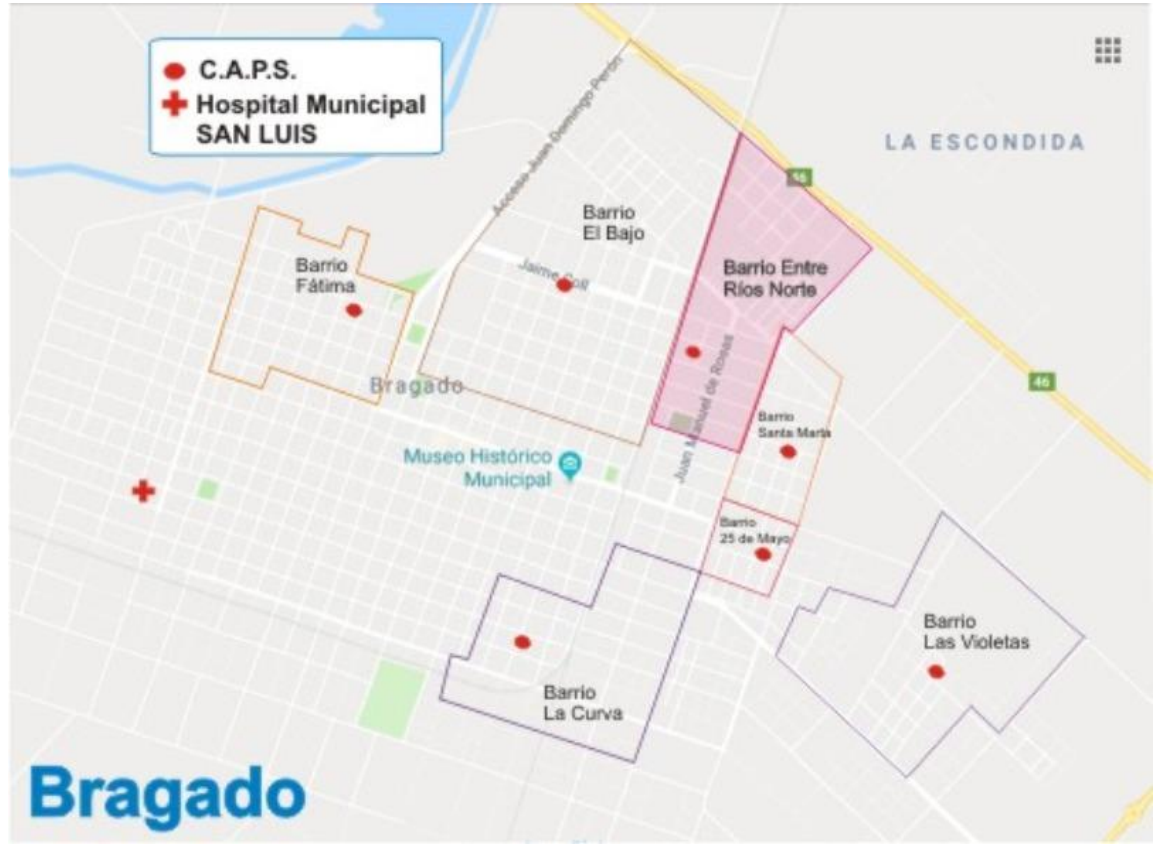

Gráfico Nº1- Áreas programáticas de los centros de salud de Bragado.

\footnotetext{
${ }^{1}$ Fuente: Censo de Población, Hogares y Viviendas 2010 (Consultado en CEPAL/CELADE Redatam+SP).
} 
El Centro de Atención Primaria de Salud (CAPS)“Entre Ríos Norte” atiende a la comunidad en forma gratuita y es de fundamental importancia para el desarrollo de la estrategia que concibe integralmente los problemas de salud-enfermedad de las personas y del conjunto social, a través de la integración de la asistencia, la prevención, la promoción de la salud y la rehabilitación. Tiene como hospital de referencia al Hospital Municipal San Luis ubicado aproximadamente a $4 \mathrm{Km}$. de distancia. Bragado no cuenta con servicio de transporte público local.

El equipo de Salud del CAPS está compuesto por: dos enfermeras, un médico clínico, una pediatra, una ginecóloga, una obstétrica, una fonoaudióloga, un psicólogo, una trabajadora social, una psicopedagoga, una promotora de salud, dos mucamas y dos administrativas. Se implementan programas del Ministerio de Salud de la Nación y de la Provincia como Programa Remediar, Programa de Inmunizaciones, Programa de Médicos Comunitarios, Plan Sumar, etc. La atención se realiza por demanda espontánea y algunos turnos son programados por medio de la promotora de salud. La mayoría de los profesionales tienen una carga horaria de 6 horas por semana distribuidas generalmente en dos horas por día tres veces por semana. Las administrativas y enfermeras cumplen 6 horas por día en turnos rotativos. Las mucamas pertenecen a una cooperativa y cumplen aproximadamente 3 horas por día. La financiación se realiza en forma conjunta entre nación y provincia que proveen los insumos correspondientes a los programas Remediar, Inmunizaciones, Salud Sexual y Procreación Responsable y Programa Médicos Comunitarios y el municipio que absorbe el resto de los gastos (sueldos, insumos, mantenimiento, luz, gas, etc.). El CAPS no cuenta con computadora ni con internet. Las planillas de estadísticas que se completan se envían en un sobre al Centro de Estadísticas que se encuentra en el hospital. La información que se registra en el sistema de salud del municipio de Bragado es la requerida por el Sistema Nacional de Estadísticas de Salud (cantidad de pacientes atendidos por efector, cantidad de egresos hospitalarios, diagnósticos de la planilla C2, etc.). Estos datos no son suficientes para una evaluación de la calidad de atención. Bajo condiciones de desigualdad social y de barreras al acceso, el conocimiento de la percepción de los usuarios con respecto a la calidad de atención de salud aporta información de utilidad para planificar acciones que mejoren las condiciones de salud hacia el logro de una mayor equidad. La finalidad de este estudio fue obtener del entrevistado un conjunto de conceptos y actitudes asociados a la atención recibida o brindada, que aportara información beneficiosa para la institución, para los proveedores de salud y para los usuarios mismos. La entrevista, representa una de las formas más rápidas para evaluar aspectos de la calidad subjetiva de los servicios a un costo relativamente bajo, teniendo en cuenta que el usuario externo no puede valorar los aspectos técnicos de la atención (calidad objetiva). Este estudio combinó la metodología cuantitativa, que permite generalizar, con la cualitativa que posibilita la profundización. Con la combinación de ambas estrategias se logró mayor información frente a un objeto de estudio complejo, como es la percepción de la calidad. La intención fue analizar la realidad desde distintos ángulos y en múltiples dimensiones, propiciando una mayor claridad teórica en la generación de datos y en la elaboración de interpretaciones que potencien la comprensión del fenómeno estudiado.

Para evaluar la calidad subjetiva de la atención en el sistema de salud, debe conocerse la valoración que tienen los usuarios de sus diferentes dimensiones, por ejemplo, las establecidas por Donabedian. La percepción que tengan los usuarios de la estructura, el proceso y los resultados, permitirá mejorar la calidad y acercarse más a sus necesidades y preferencias. Esto se relaciona también con los atributos 5 y 6 de la calidad definidos por Donabedian, que son la aceptabilidad y la legitimidad. En el presente estudio se analizó la percepción de los usuarios externos (UE) e internos (UI) del Centro de Salud Entre Ríos Norte, con respecto a la calidad de atención recibida o brindada. Se identificaron las 
variables dentro de cada dimensión que tuvieron mayor peso para la población, ajustadas por género, edad, educación, estado civil y ocupación en el caso de los usuarios externos y por edad, género, antigüedad laboral, jornada laboral y puesto de trabajo en el caso de los usuarios internos. Como en la actualidad, el municipio no cuenta con datos fidedignos sobre la calidad de la atención en salud, ni con sistemas de evaluación de la calidad, se desconoce el grado de satisfacción de la comunidad y de los trabajadores de los CAPS. Por lo tanto, es necesario realizar estudios que permitan conocer la percepción sobre la calidad de la atención de los usuarios y en cuáles de sus dimensiones, manifiestan mayor o menor satisfacción. La intención de este trabajo fue diseñar una herramienta que permitiera evaluar la calidad de atención en los centros de salud primaria de Bragado y obtener datos confiables. Los resultados de esta investigación podrán utilizarse para establecer estándares de desempeño, planificar acciones, definir procedimientos, normas, etc. Si este estudio se replicara en cada CAPS del municipio, se obtendría información verídica para planificar políticas de salud que mejoren la calidad de la atención. Es imprescindible que los decisores políticos conozcan la percepción de los usuarios internos y externos y tengan en cuenta sus opiniones, a la hora de realizar cambios y planificar en salud.

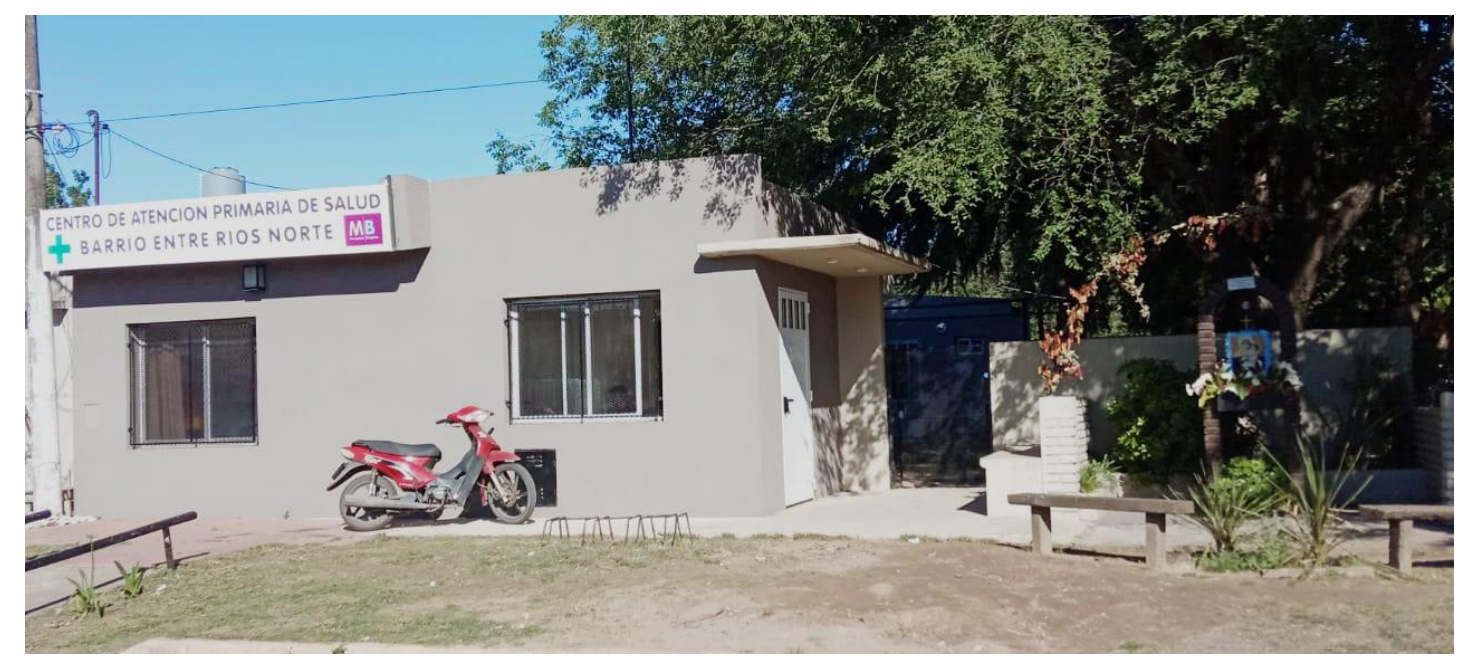

Foto CAPS Entre Ríos Norte 25/10/2019 


\section{3-MARCO TEÓRICO}

Hace años que la mayoría de los países se han puesto de acuerdo en que la salud de la población es un objetivo prioritario. En las últimas décadas, se llevaron a cabo numerosas cumbres de naciones para lograr este fin. Se crearon organizaciones, como la OMS en 1948, con la finalidad de mejorar la salud de las personas. Pero a pesar de tanto esfuerzo no se ha logrado la equidad en salud.

Desde que la OMS definió la meta de Salud para Todos en 1977, las distintas políticas implementadas a lo largo de los años para orientar a los sistemas de salud trataron de cumplir con esa meta social de diversas formas y con diferentes resultados. Observando la situación mundial de desigualdad en salud es posible afirmar que la meta "Salud para Todos" sigue siendo un desafío no logrado cuya solución es impostergable. ${ }^{2}$

La razón de ser del Sistema de Salud es el bienestar de la población y su estado saludable. Una sociedad en la que sus miembros vivan enfermos tiene menos bienes relacionales, baja productividad, aumento de gastos y disminución del rendimiento económico, pero sobre todo presenta menor bienestar subjetivo, satisfacción y felicidad.

Por décadas se creyó que bienestar social era sinónimo de crecimiento económico de los países, pero en los últimos años se ha evidenciado que no sólo los indicadores materiales son relevantes en la vida de las personas, sino que existen otros factores como los bienes relacionales que también tienen gran influencia en la percepción de la satisfacción y la felicidad de las personas. Por eso el estudio del bienestar subjetivo y su medición se han convertido en un desafío para los investigadores. En este contexto los estudios que buscan acercarse a las personas y entender su realidad compleja incorporando aspectos multidimensionales resultan relevantes para disminuir la brecha entre quienes planean las políticas de salud y quienes las reciben. El área de salud en este sentido resulta prioritaria. ${ }^{3}$

Según el Informe sobre la salud de la OMS de 2008 los ciudadanos del mundo en desarrollo, al igual que los de los países ricos, no buscan sólo competencia técnica: también quieren que los proveedores de atención sanitaria sean comprensivos, respetuosos y dignos de confianza. Desean que la atención de salud se organice en torno a sus necesidades, respete sus creencias y tenga presente su situación particular. No quieren que se aprovechen de ellos proveedores sin escrúpulos, ni tampoco que se los considere meros objetivos de los programas de control de enfermedades. Tanto en los países pobres como en los ricos, la gente espera de la atención de salud algo más que intervenciones.

El contacto con el mismo equipo de profesionales a lo largo del tiempo favorece el desarrollo de una relación de confianza entre el paciente y su médico, que genera una interacción más positiva y una mayor comunicación. Al ser más conscientes de las circunstancias en que vive la gente, los profesionales, pueden adaptar la atención a sus

\footnotetext{
2 Paganini, J. M. (2001). Las estrategias para la calidad y eficiencia en salud. Facultad de Ciencias Médicas. INUS. Universidad Nacional de La Plata.

${ }^{3}$ Hamui Sutton Fuentes García Aguirre Hernández Ramírez de la Roche. (2013). Un estudio de satisfacción con la atención médica. Expectativas y experiencias de los usuarios del Sistema de Salud en México. Proyecto de investigación.
} 
necesidades específicas y reconocer los problemas de salud en sus fases iniciales. El interés de todo esto no radica sólo en el fomento de la confianza y satisfacción del paciente, por muy importantes que sean esos dos aspectos, lo fundamental es que ello propicia una mayor calidad y mejores resultados.

Las personas que utilizan la misma fuente de atención médica para la mayor parte de sus necesidades sanitarias tienden a respetar más los consejos que les dan, recurren en menor medida a los servicios de urgencia, requieren menos hospitalizaciones y están más satisfechas con la atención. Los médicos ahorran tiempo de consulta, recurren a menos pruebas de laboratorio, reducen costos y prestan más atención preventiva. ${ }^{4}$

Las estrategias de atención de la salud adoptadas en nuestro entorno otorgan un papel relevante a los servicios de Atención Primaria como forma de asegurar tanto la accesibilidad de todos los ciudadanos a los dispositivos sanitarios, exigencia incuestionable en un sistema basado en la equidad, como la eficiencia de los recursos a través de su adecuada utilización. Se le atribuye también a este nivel asistencial un papel clave como informador influyente en la población que, en último término, persigue modificar conductas hacia lo que se concibe técnicamente como más adecuado para elevar o mantener el estado de salud.

La Atención Primaria de Salud tiene por objeto situar a las personas en el centro de la atención sanitaria para conseguir que los servicios sean más eficaces, eficientes y equitativos. Las características de la atención de salud deben ser la centralidad en la persona, la integralidad e integración y la continuidad de la asistencia, con un punto de acceso sistemático al sistema sanitario para que los pacientes y quienes les atienden puedan entablar una relación duradera basada en la confianza; es una relación directa entre cada individuo, su familia, la propia comunidad y un determinado miembro de la plantilla de salud. ${ }^{5}$

Cada país debería tener como misión, mejorar la calidad de la atención de la salud, utilizando las estrategias adecuadas a su contexto socioeconómico, ya sea, siguiendo lineamientos de organismos internacionales como la OMS, o adaptando a su realidad experiencias exitosas de otros países. Por ejemplo, los Países Bajos que ocupan desde hace algunos años los primeros puestos en las listas de calidad asistencial en Europa. Para lograrlo basaron su modelo asistencial en el establecimiento de hospitales pequeños, la prevención como política prioritaria, medicina ambulatoria, atención a domicilio y reconversión absoluta del concepto de urgencias con una financiación a medias entre el Estado y los ciudadanos. Otro ejemplo de estrategia para mejorar la calidad, es la que lleva a cabo el Sistema de Salud Nacional Del Reino Unido, que posee un sistema de información muy amplio y utiliza parte del mismo para recabar datos sobre la percepción de los usuarios acerca de su satisfacción con los servicios de salud a través de encuestas periódicas. Además, los pacientes tienen disponibles mecanismos para registrar sus quejas, que son resueltas sobre todo a nivel local y la mayor parte dentro de los límites de tiempo establecidos. Con estas medidas lograron que el 92\% de las personas encuestadas en 2009 que habían sido internadas en los hospitales de agudos del NHS en Inglaterra contestaran

\footnotetext{
${ }^{4}$ Informe sobre la salud en el mundo 2008: La atención primaria de salud, más necesaria que nunca. OMS.

${ }^{5}$ Mariño, E. del Salto. (2014). Evaluación de la calidad de atención y satisfacción del usuario que asiste a la consulta en el departamento médico del Instituto Nacional Mejía en el periodo 2012. Universidad Central del Ecuador Facultad de Ciencias Médicas. Maestría de Gestión en salud. Quito.
} 
que la calidad de la atención que habían recibido era buena o mejor. La satisfacción general con el NHS se incrementó entre 1997 y 2007 del 35\% al 51\%. ${ }^{6}$

En las organizaciones que prestan servicios sanitarios y, además, de carácter público, la valoración por las personas que los utilizan adquiere matices especiales. En este caso, la opinión del usuario traduce aquellos resultados que pueden objetivarse a través de indicadores estructurales, de proceso o de resultados técnicos, en el efecto final percibido en el receptor de los servicios, con la particularidad de que éste es el ciudadano que participa, dentro de un sistema solidario, en la configuración y financiación del Sistema Sanitario. ${ }^{7}$

La salud es reconocida como un derecho humano y como tal debe ser garantizada por los estados que de esa manera la conciben, a través de la disponibilidad de servicios de salud, la creación de condiciones de trabajo saludables y seguras, el acceso a una vivienda adecuada y a alimentos nutritivos. El Comité de Derechos Económicos, Sociales y Culturales de las Naciones Unidas, que supervisa la aplicación del Pacto Internacional de Derechos Económicos, Sociales y Culturales, adoptó en el año 2000 una Observación general sobre el derecho a la salud, resaltando que este debe abarcar cuatro elementos:

- Disponibilidad: Se deberá contar con un número suficiente de establecimientos, bienes y servicios públicos de salud, así como de programas de salud.

- Accesibilidad: Los establecimientos, bienes y servicios de salud deben ser accesibles a todos dentro de la jurisdicción del Estado Parte. No discriminación. Accesibilidad física. Accesibilidad económica (asequibilidad). Acceso a la información.

- Aceptabilidad: Todos los establecimientos, bienes y servicios de salud deberán ser respetuosos de la ética médica y culturalmente apropiados, a la par que sensibles a los requisitos del género y el ciclo de vida.

- Calidad: Los establecimientos, bienes y servicios de salud deberán ser apropiados desde el punto de vista científico y médico y ser de buena calidad. Ello requiere, entre otras cosas, personal médico capacitado. ${ }^{8}$

Los sistemas de salud, así como las políticas, programas, planes y declaraciones, tanto de los gobiernos como de los organismos internacionales, organizaciones intermedias, como ONG y entidades académicas, se enfocan, actualmente, hacia el acceso universal y la atención de buena calidad, lo que puede ser englobado en el concepto de equidad (Mattioli, 2011). Este concepto es definido por John Rawls en su libro Teoría de la Justicia como "Todos los bienes sociales primarios, libertad, igualdad de oportunidades, renta, riqueza y las bases del respeto mutuo- han de ser distribuidos de un modo igual, a menos

${ }^{6}$ Laura Lima Quintana; Mónica Levcovich; Ana Rita Diaz Muñoz. (2012). Las reformas de los sistemas de salud del Reino Unido, Estados Unidos y Países Bajos de la década del '90 al siglo XXI. Buenos Aires: Fundación Sanatorio Güemes.

${ }^{7}$ Alfaro Latorre, M. Etreros Huerta, J. Ruiz Martínez, A. Sendagorta Camino, A. Terol García, E. (2001). Encuesta de satisfacción de los usuarios con los servicios de Atención Primaria 2000. Madrid: Ministerio de Sanidad y Consumo Instituto Nacional de la Salud.

${ }^{8}$ Tesis para obtener el título de Magíster en Salud Pública. Eduard Wanderley Mongui Palacios Director Dra. Adriana Moiso. La Plata, Argentina 2015. 
que una distribución desigual de uno o de todos los bienes redunde en beneficio de los menos aventajados." 9

La equidad en el sistema de salud, según el Dr. José M. Paganini, se define como "las prioridades, políticas, planes, programas y estrategias, tanto a nivel nacional como local e institucional, destinadas a resolver las desigualdades del acceso al conocimiento por diferencias socioeconómicas, educacionales, sociales, étnicas, de género, y a la atención de la salud tanto en la accesibilidad, continuidad, calidad y humanización." Como el propósito de la equidad es llegar a toda la población con todos los recursos, esta amplia definición requiere que todos los niveles y los componentes e instituciones del sistema de salud deban contribuir a la equidad y calidad del sistema. Ello significa que toda política de salud colectiva debe orientar los recursos y sus componentes teniendo en cuenta las "necesidades" de la población, tanto en la promoción de la salud como en la prevención y el tratamiento de las enfermedades, con la mayor "calidad" posible, sin ningún tipo de limitación económico-social. ${ }^{10}$

Para lograr un sistema de salud equitativo es primordial mejorar la calidad de atención. En Argentina, la salud es un derecho que debe garantizar el Estado, por eso el sistema público de salud está organizado en torno al principio de cobertura universal, lo cual implica que toda persona que habite el suelo argentino, por ese sólo hecho, puede acceder a las prestaciones en salud brindadas por el sector público. Este sector, coexiste con el sector privado y el de la Seguridad Social (que, además, cuenta con varios subsistemas y un sinnúmero de entidades financiadoras), a los cuales se puede acceder por medio de una contratación en el sector privado o a partir de la condición de trabajador en relación de dependencia o autónomo, a través de aportes a la Seguridad Social. Además, es un país federal, por lo que existe una fragmentación territorial del sistema de salud, correspondiendo a cada provincia asumir la responsabilidad de garantizar la salud de sus habitantes. Un estudio de la Dra. Mercedes Laurenza sobre calidad en el sistema de salud argentino describe que, "La fuerte fragmentación con superposición en las coberturas $e$ inequidades a lo largo del territorio, que cristalizan y al mismo tiempo reproducen las inequidades socioeconómicas preexistentes, provocan en el ciudadano niveles variables de gasto de bolsillo y acceso a prestaciones de diferente calidad según tipo de cobertura y ubicación geográfica". ${ }^{11}$

El documento de la OPS "Salud Pública en las Américas" del año 2002 definió las funciones esenciales de la salud pública, entre ellas, la Función Esencial N 9 "Garantía y mejoramiento de la calidad de los servicios de salud individual y colectiva." En 2010, en la ciudad de La Plata se realizó "La Segunda Jornada de Evaluación de las Funciones Esenciales de Salud Pública de la Provincia de Buenos Aires. Como resultado se observó que la Función Esencial $\mathrm{N}^{\circ} 9$ obtuvo sólo 0,47 puntos ocupando el 70 lugar en el ranking, por debajo del valor de referencia que era 0,55 puntos. El indicador 1 de la Función: "Definición de estándares y evaluación para el mejoramiento de la calidad de los servicios de salud individuales y

\footnotetext{
${ }^{9}$ La Salud y la Equidad. Fundamentos conceptuales, definiciones, propuestas de acción. José María Paganini. INUS. Facultad de Ciencias Médicas UNLP.

${ }^{10}$ Paganini José María: Las Ciencias de la Salud Colectiva. Relaciones Lógicas Sistémicas para la equidad y calidad. INUS, 2016.

11 Dra. Mercedes Laurenza. Calidad de la atención de la salud desde la perspectiva del paciente. Análisis de los resultados de una encuesta realizada en centros de atención primaria del ámbito público. www.itaes.org.ar/biblioteca/5-2013/ITAES-5-2013investigacion.pdf
} 
colectivos" logró una puntuación alta de 0,68 , pero fue el único. En cambio, el indicador 2: "Mejoría de la satisfacción de los usuarios con los servicios de salud" obtuvo 0,42. El indicador 3: "Sistema de gestión tecnológica y de evaluación de tecnologías en salud para apoyar la toma de decisiones en salud pública" 0,35 y el 4 "Asesoría y apoyo técnico a los niveles subprovinciales de salud y para asegurar la calidad de los servicios" 0,43. Todos, menos el primero, estuvieron por debajo del valor de referencia. Estos indicadores dejaron a la vista las debilidades que presentaba el sistema de salud de la provincia de Buenos Aires y demostraron que no cumplía con la función esencial $\mathrm{N}^{\circ} 9$. Usar estos resultados para corregir las falencias mejoraría la calidad del sistema de salud provincial.

Para obtener una atención sanitaria de calidad la Organización Panamericana de la Salud emitió en 2007, la Resolución "Política y Estrategia Regional para la Garantía de la Calidad de la Atención Sanitaria, incluyendo la Seguridad del Paciente", donde delineó las acciones regionales en base a seis estrategias:

-Introducir y fortalecer la cultura de la evaluación, la mejora continua y la seguridad del paciente entre los profesionales.

-Identificar líderes nacionales que actúen de forma proactiva y realicen acciones relativas a la calidad de atención y seguridad del paciente.

- Involucrar en la calidad a los niveles de gobierno y gerenciales, al mismo tiempo que a los niveles de ejecución.

-Realizar un trabajo interdisciplinario.

-Promover la participación activa de los profesionales para la gestión de la calidad.

-Incorporar la participación del paciente, la familia y la comunidad en la toma de decisiones y en la promoción del autocuidado. ${ }^{12}$

La participación del paciente y la participación social en el sistema de salud, requiere como condición primordial el respeto al derecho de autonomía del paciente que puede decidir sobre su salud. El derecho de autonomía es un derecho parcialmente conquistado y todavía está pendiente, el cambio cultural que logre imponerlo. Por mucho tiempo los médicos asumieron la tutela del paciente, permitiéndole sólo la autonomía para elegir al proveedor de servicios, pero no de arbitrio sobre lo que puede y debe ser hecho por la medicina a su cuerpo y mente. Con respecto a este tema, Joaquim Clotet, filósofo destacado en ética y bioética, enunció "El énfasis social y político por el reconocimiento de los derechos fundamentales de las personas, sin distinción de clase, sexo y edad, está también repercutiendo en el mundo de la medicina. Ésta no permanece ajena al lenguaje de reivindicación de los derechos. Expresiones como: consentimiento informado, principios de independencia o de respeto a la autonomía del paciente son nuevos en la ética médica, desconocidos por la tradición hipocrática y fruto del influjo de las ideas sociales y políticas en la teoría y praxis médica". ${ }^{13}$ Actualmente, aunque se ha reconocido el derecho de autonomía del paciente, persiste cierta resistencia de parte de los profesionales de la salud

12 Organización Panamericana de la Salud. Calidad en la Atención y Seguridad del Paciente. [En línea] septiembre de 2011.

http://new.paho.org/hq/index.php?option=com content\&task=view\&id=3412\&ltemid=155 $\underline{7}$

${ }^{13}$ Clotet, J. (1993). Por Qué Bioética, in Bioética. Revista Publicada por el Consejo Federal de Medicina, Brasilia, Vol. 1, N. 1. p. 16. 
a compartir el poder de decisión y a consensuar con el paciente las prescripciones. Se necesita más tiempo y esfuerzo para cambiar el modelo paternalista de quien es legítimamente un co-prestador del servicio, puesto que no puede haber rehabilitación o prevención adecuadas sin la cooperación inteligente del paciente y de sus familiares. Por lo tanto, la mejora de la calidad implica que el paciente, pueda reasumir el derecho de opinar y escoger entre procedimientos alternativos, concientizado del riesgo que incluye cada uno de ellos y predispuesto a colaborar, con su capacidad de discriminación, en el propio proceso de diagnóstico y terapia.

La $27^{\circ}$ Conferencia Sanitaria Panamericana de la OPS (2007) también definió que las causas de la falta de calidad son múltiples, e involucran fallos tanto a nivel sistémico como a nivel de la prestación de servicios de salud individual.

A nivel sistémico contribuyen a la mala calidad: 1) la falta de posicionamiento de la calidad en las prioridades, y agenda de reforma del sector salud; 2) la deficiencia de los marcos reguladores de la calidad tales como las normas y estándares técnicos, los sistemas de acreditación, certificación, y habilitación, y el limitado conocimiento de derechos y deberes de los pacientes; 3 ) la insuficiencia o falta de recursos materiales, humanos y financieros; 4) la falta de sistemas de información para la gestión adecuada de los recursos; 5) las transferencias financieras o mecanismos de pago a prestadores no vinculados a nivel de desempeño y resultados en salud; y 6) la formación de pregrado y postgrado con bajos estándares técnicos, éticos y humanos.

A nivel de la prestación de servicios de salud individual, son causas de mala calidad: 1) la desmotivación de los trabajadores de la salud; 2 ) la debilidad en materia de competencias y destrezas técnicas; 3) la ausencia de trabajo en equipo y de relaciones de confianza adecuadas; 4) la atención bajo un modelo paternalista que no involucra al usuario en la toma de decisiones; 5) las condiciones de trabajo inadecuadas; y 6) la inexistencia de carrera profesional y programas de actualización profesional.

Las investigaciones realizadas actualmente, para mejorar la calidad de la atención de salud, identificaron, según Paganini José María, cuatro estrategias fundamentales con relación directa a cambios positivos hacia la calidad. Ellas son: la capacitación, la autoevaluación, la participación y la gestión estratégica integral. ${ }^{14}$ En la Gestión Integral de Calidad, se desarrollan procesos de mejora de la calidad que involucran a los trabajadores, los usuarios y la sociedad. La calidad implica un valor de la cultura organizacional de las instituciones de salud y se expresa en mejores niveles de salud y satisfacción de los usuarios. Sus objetivos son: lograr la satisfacción y participación ciudadana de los usuarios, la satisfacción y el desarrollo de las personas que brindan los servicios de salud, fomentar una cultura de calidad basada en valores, implementar procesos de garantía y mejoramiento de la calidad en todos los niveles.

La Gestión Integral de Calidad constituye una propuesta moderna para la gestión de salud que requiere:

- Una visión integral del establecimiento de salud y el análisis permanente y objetivo de sus resultados, procesos y estructuras;

- Una conducción en equipo con una visión estratégica y amplia de la realidad y del contexto de la institución;

- El desarrollo de sistemas de información para la gestión estratégica;

- La capacitación continua de todo el personal y

${ }^{14}$ La gestión integral de la calidad, una estrategia para la equidad en salud. Prof. Dr. José María Paganini. Director Centro INUS, UNLP. Presidente del CENAS. 
- El uso y actualización de normas, estándares y protocolos basados en la evidencia.

La atención de calidad en salud no depende exclusivamente de colocar en los centros de salud la mejor tecnología y el personal más calificado, sino de involucrar a todos los elementos que intervienen en la prestación de servicios de salud y con el compromiso ético de brindar una prestación de excelencia, porque sólo una organización que ha definido en sus valores supremos generar productos y servicios de calidad para el desarrollo social, estará realmente comprometida en la consecución de sus objetivos.

\section{Definición de calidad}

La calidad es una construcción histórico cultural, específica de cada sociedad y de cada institución En ella juegan un importante papel los factores subjetivos o psicosociales (creencias, idiosincrasias, valores, etc.).

Según la OMS, la calidad es "un alto nivel de excelencia profesional. Uso eficiente de los recursos, un mínimo de riesgos para los pacientes. Un alto grado de satisfacción por parte del paciente. Impacto final en la Salud." 15

El concepto de calidad, surgió de la industria y luego fue adaptado a los servicios de salud. El Dr. Joseph Juran, considerado como uno de los gestores de la revolución de la calidad en Japón, mencionado por Passos Nogueira, expresa dos conceptos experimentales y uno de síntesis de la calidad. Los experimentales son los siguientes: "La calidad consiste en las características del producto que van al encuentro de las necesidades de los clientes y de esa forma proporcionan satisfacción en relación al producto" y "La calidad es la ausencia de defectos". El concepto de síntesis se resume en: "La calidad es definida como la adecuación al uso". Esta definición ofrece la posibilidad de medir la calidad en grados de adecuación al uso y no las alternativas del todo o nada, determinándose de esta manera no sólo el grado de calidad, sino el conjunto de necesidades humanas como las psicológicas, tecnológicas, éticas, etc. ${ }^{16}$ Su enfoque de la eficiencia organizacional involucra crear conciencia respecto de la necesidad de implementar mejoras, integrar la mejora de calidad a todas y cada una de las actividades, proporcionar capacitación en relación con los métodos de calidad, establecer resolución de problemas en equipo y reconocer los resultados. Hace hincapié en la necesidad de mejorar la totalidad del sistema. Para mejorar la calidad, los miembros de la organización deben desarrollar técnicas y habilidades, y saber cómo aplicarlas. Su definición de calidad va más allá del producto o del momento en que se brinda un servicio. Para el doctor Juran, la calidad es un concepto que es preciso encontrar en todos los aspectos del negocio, y los líderes deben guiar la administración de la empresa en función de la calidad. En el texto "Juran on Leadership for Quality: An Executive Handbook", postula tres principios fundamentales: el liderazgo de primer nivel, la educación continua y la planificación anual para mejoría de la calidad y reducción de costos. Esta trilogía aprovecha tres procesos administrativos: planificación de la calidad, control de la calidad y mejora de la calidad.

Por otra parte, Edwards Deming, estadístico estadounidense y profesor universitario, también citado por Passos Nogueira, fundamenta su definición de calidad para la industria,

${ }^{15}$ Carol M. Gilmore, Humberto Novaes. (1996). Gerencia de la calidad. Washington, D.C.: Organización Panamericana de la Salud.

16 Passos Nogueira, R. (1997). Perspectivas de la gestión de Calidad Total en los Servicios de Salud. Serie Paltex Salud y Sociedad. 2000. N4. 
determinando por un lado, el importante papel que tiene el consumidor como evaluador de la calidad y por otro, la problematización pedagógica de su significado, remitiendo esta última a una serie de indagaciones que estimulan la capacidad de reflexión de las personas, es decir, la calidad de un servicio se manifiesta al emitir un juicio que emana de la facultad de opinar. De la lectura del clásico libro de Deming, puede inferirse desde su punto de vista, que lo más importante no es llegar a contar con una completa teoría de la calidad sino introducir en las empresas esa forma de discusión que abarca todos los aspectos relacionados directa o indirectamente con las características objetivas de los productos, los cuales determinan el grado de satisfacción de los clientes. El doctor Deming, quien describió su trabajo como "administración de la calidad", consideraba que el consumidor es el factor más importante en la generación de productos o en el ofrecimiento de servicios. Tener en cuenta la voz del consumidor y luego utilizar la información obtenida para mejorar los productos y servicios, es parte integral de sus enseñanzas. Para él, la calidad debe definirse en términos de la satisfacción del cliente. Este enfoque en el cliente implica que la calidad de un producto o servicio es multidimensional, y también que hay diferentes grados de calidad, un producto que satisface por completo al cliente $A$ tal vez no satisfaga al cliente B. Las filosofías del doctor Deming hacen gran hincapié en la participación de la administración, la mejora continua, el análisis estadístico, la fijación de metas y la comunicación.

Donabedian (1984) ${ }^{17}$ definió la calidad como la obtención del máximo beneficio para el usuario mediante la aplicación del conocimiento y tecnología más avanzada tomando en cuenta los requerimientos del paciente, así como las capacidades y limitaciones de recursos de la institución de acuerdo con los valores sociales imperantes. Esta definición tiene como eje al usuario, teniendo en cuenta sus necesidades y los beneficios que pueda obtener, sin perder de vista la competencia técnica y recursos necesarios para la atención, así como la importancia de los valores, que le confieren un enfoque holístico.

La preocupación por la calidad, si bien siempre estuvo presente en el ejercicio de la medicina, en la actualidad y desde los años noventa, se ha instalado como un tema de importancia estratégica para la transformación de los sistemas sanitarios (Petracci, Manzelli, Pecheny, Necchi, Cerrutti, 2004). Conceptualmente se trata de un término dinámico, dado que articula ámbitos institucionales diversos como la cultura de una organización, el clima laboral de los servicios de salud, la respuesta a los problemas de los pacientes y la perspectiva de los usuarios sobre la atención recibida. A su vez es un concepto polisémico, dado que su sentido varía según el enunciador sea la comunidad científica, los profesionales, los usuarios de los servicios de salud o la opinión pública. Para Donabedian (1990), se trata de un término multidimensional en el que se conjugan diferentes atributos que denominó los siete pilares de la calidad en salud: 1. Eficacia: la capacidad del cuidado, asumiendo su forma más perfecta de contribuir a la mejoría de las condiciones de salud; 2. Efectividad: en cuanto a que las mejoras posibles en las condiciones de salud son de hecho obtenidas; 3 . Eficiencia: la capacidad de obtener la mayor mejoría posible en las condiciones de salud al menor costo posible; 4. Optimización: la más favorable relación entre costos y beneficios; 5 . Aceptabilidad: conformidad con las preferencias del paciente en lo que concierne a la accesibilidad, relación médico-paciente, las comodidades, los efectos y el costo del cuidado prestado; 6 . Legitimidad: conformidad con preferencias sociales en relación a todo lo anteriormente mencionado; 7. Equidad: igualdad en la distribución del cuidado y de sus efectos sobre la salud.

\footnotetext{
${ }^{17}$ Donabedian, A. (1984). La Calidad de la atención médica, definición y métodos de evaluación. Editorial La Prensa Médica Mexicana.
} 
El atributo de la aceptabilidad, refiere justamente a la conformidad de los deseos y expectativas individuales de las personas con las prestaciones recibidas. La perspectiva de los usuarios/pacientes es también recuperada como un elemento central por la perspectiva de la garantía de la calidad, desde la cual se busca obtener información y en función de esa información reajustar los procesos de atención de la salud (Donabedian, 2001). En este sentido el autor define diferentes roles asumidos por los pacientes respecto de la calidad: son definidores de la misma; evaluadores; informantes; coproductores de la atención, trabajando junto con los profesionales con capacidad de ser reformadores de la atención médica; ejecutores de la garantía de calidad; controladores de los prestadores y reformadores del servicio de salud.

Las organizaciones que decidan mejorar la calidad de sus servicios, deberán interesarse por conocer qué esperan sus usuarios, qué entienden estos por calidad, porque a medida que cumplan con las expectativas de los usuarios, lograrán aumentar la satisfacción de estos con la atención de salud. Deberán replantear su manera de trabajar pasando del modelo de atención tradicional, donde la calidad se establece por la definición y percepción de los directivos y planificadores de la organización, que es muy diferente a la de los pacientes, al nuevo modelo que reconoce la importancia que tiene la opinión de los pacientes y de los prestadores del servicio.

Parasuraman 1993, mencionado por Mélida Rosario Bravo Tapia, establece una relación entre las percepciones y las expectativas de los usuarios con respecto al servicio, concluyendo que mientras la percepción sea mejor que las expectativas, más alto será el nivel de calidad percibido, es decir plantea que la diferencia entre las expectativas del usuario antes de recibir el servicio y la calidad percibida una vez que este se le brindó, es uno de los factores que mejor explica la calidad de los servicios. La calidad del servicio tiene carácter subjetivo debido en gran parte a las relaciones interpersonales que se establecen entre los proveedores de la atención y los usuarios de la misma, pero también a las facilidades y comodidades que en conjunto intentan dar respuesta a las necesidades, deseos y expectativas de los usuarios y que son capaces de satisfacerlos. Parasuraman menciona cinco dimensiones de la calidad a tener en cuenta en la diferenciación entre las percepciones y expectativas de calidad de servicio que manifiesta el usuario: Tangibilidad, Confiabilidad, Sensibilidad, Seguridad y Empatía. Cada uno de estos cinco componentes engloba aspectos del servicio, que los usuarios perciben y que les permiten evaluar la calidad de servicio en el momento en que la reciben, aún sin conocer aspectos técnicos del proceso.

Numerosos autores han postulado las dimensiones que abarca la calidad, siendo la clasificación más conocida la de H. Palmer que incluye:

-Efectividad: Capacidad de un determinado procedimiento o tratamiento en su aplicación real para obtener los objetivos propuestos.

-Eficiencia: La prestación de un máximo de unidades comparables de cuidados por unidad de recursos utilizada.

-Accesibilidad: Facilidad con que puede obtenerse la asistencia frente a barreras económicas, organizativas, culturales, etc.

-Aceptabilidad: Grado de satisfacción de los usuarios respecto a la atención.

-Competencia profesional: Capacidad del profesional para la mejor utilización de sus conocimientos a fin de proporcionar cuidados y satisfacción a los usuarios. 
La orientación hacia la calidad exige procedimientos para evaluar la eficiencia, la efectividad y la seguridad de las intervenciones preventivas, de apoyo y curativas, pero también la satisfacción de los prestadores y usuarios.

\section{Evaluación de la calidad}

A partir de los trabajos de Avedis Donabedian, se inició la evaluación de la calidad de la atención médica, con base en la teoría de sistemas, mediante el análisis de la estructura disponible para otorgar la atención, el proceso mismo de la atención y sus resultados. Posteriormente, Donabedian dio a conocer una división clásica de indicadores que se deben utilizar para medir el nivel de calidad de la asistencia médica. Para ello los clasificó en: indicadores de estructura, indicadores de proceso e indicadores de resultado.

Los indicadores de estructura son todos aquellos atributos materiales y organizacionales relativamente estables. Parten del condicionamiento para verificar si los recursos están disponibles y organizados para facilitar la atención de los servicios de salud.

Los indicadores de proceso se refieren a aquello que el profesional médico y demás proveedores son capaces de hacer por los pacientes, y a la interrelación con las actividades de apoyo diagnosticadas, así como las actitudes, habilidades, destrezas y la técnica con que lo llevan a cabo, incluido aquello que los pacientes son capaces de hacer por sí mismos.

Los indicadores de resultado son los referidos a la variación de los niveles de salud y a la satisfacción del paciente con la atención recibida, la cual otorga a esto último una importancia mayor, dada por la necesidad cada vez más creciente de satisfacer las expectativas del usuario mediante un servicio de mayor calidad.

El uso de los resultados como criterio para estimar la calidad de la atención médica ofrece innumerables ventajas porque generalmente son fáciles de cuantificar y tienden a ser más concretos. Podemos cuantificar la mortalidad, la morbilidad, las internaciones, el porcentaje de pacientes tratados y curados, etc. Sin embargo, esta aparente validez de los resultados no es absoluta cuando lo que queremos medir es la satisfacción del usuario. La medición de conceptos que no pueden definirse con tanta precisión puede resultar difícil. En general, los indicadores de resultados, son útiles para dar validez a la eficacia y calidad.

Otra forma de evaluar la calidad consiste en examinar el proceso de atención. En este sentido lo que interesa no es el poder de la tecnología médica de alcanzar los resultados previstos, sino determinar si se ha aplicado una "buena" atención médica. Esta comprende desde la confección de la historia clínica, el examen físico, pruebas diagnósticas, justificación del diagnóstico y tratamiento, las medidas preventivas implementadas y la continuidad de la atención. Este enfoque requiere que se especifiquen con gran detenimiento las dimensiones, valores y las normas que se usarán en la evaluación. Las estimaciones de calidad obtenidas de esta manera son más pertinentes, aunque menos definitivas que los resultados.

Otra manera de abordar la evaluación es estudiando la estructura que se basa en aspectos tales como la adecuación de las instalaciones y los equipos, idoneidad del personal médico y su organización, los procesos administrativos y el funcionamiento de programas e instituciones que prestan atención médica. Cada uno de estos abordajes de la evaluación de la calidad presenta ventajas y deficiencias, y requerirán del investigador la elaboración de una metodología precisa para lograr la información más exacta y confiable posible. 
El enfoque para evaluar la calidad determina qué métodos se utilizarán para recoger la información requerida. Donabedian establece 4 métodos para evaluar calidad:

1-Historias Clínicas: son los documentos de los que se parte para la mayoría de los estudios sobre el proceso de atención médica. Sin embargo, adolecen de varias limitaciones, porque no son fácilmente accesibles y pueden faltar datos en su confección.

2- La observación directa de las actividades del médico por un colega calificado. La principal limitación sería que el médico actuara diferente al saber que lo están observando.

3- Enfoque sociométrico, según el cual, cuando los médicos buscan atención para ellos y sus familias expresan con sentido críticos opiniones válidas sobre la capacidad de sus colegas de brindar atención de alta calidad.

4- Autorreferencial: se comprobó que la gente suele ser bastante perspicaz cuando juzga la eficacia de las organizaciones en las que trabaja. ${ }^{18}$

En cada una de las dimensiones (estructura, proceso y resultados) se pueden encontrar atributos o requisitos de calidad que caracterizan al servicio de salud. (Hidalgo Jara, 2002). Para evaluar la calidad de la atención es importante tener en cuenta los atributos que requiere una buena atención de salud. Estos son:

-Oportunidad: Respuesta a una necesidad de salud en un tiempo que implique menor riesgo y mayor beneficio para la persona o la población

-Eficacia: Uso correcto de las normas, protocolos y procedimientos en la gestión y prestación de servicios de salud individual y colectiva

-Integralidad: Acciones dirigidas a la persona, su familia, la comunidad y el ambiente en un proceso que contiene los momentos de promoción de la salud, prevención, recuperación y rehabilitación de la salud.

-Accesibilidad: Condiciones necesarias para que las personas puedan obtener servicios de salud individual y colectiva, disminuyendo las barreras geográficas, socioeconómicas, organizativas y culturales.

-Seguridad: Condiciones en el establecimiento que garanticen a los usuarios, acceso a servicios sanitarios básicos para prevenir riesgos en él y en el medio ambiente.

-Respeto al usuario o buen trato: La forma amable, cordial y empática, que se pone de manifiesto durante el proceso de atención-interacción entre el proveedor y el usuario, donde prima el respeto a sus derechos y la valoración de su cultura y condiciones individuales.

-Información completa: Provisión de contenidos, veraces, oportunos y entendibles por las personas o público, que le permite tomar decisiones sobre su salud.

Tomando en cuenta un estudio que refiere que el trato respetuoso junto con la información y el apoyo social tienen una asociación significativa inversa con el nivel educacional (Puentes Rosas 2006), se demuestra, que las personas que tienen mejor nivel de educación,

18 Donabedian, A. (1992). Evaluación de la calidad de la atención médica. Investigación sobre Servicios de Salud: una antología. Publicación científica N534 OPS, Capítulo 33; pág.382, 389. 
buscan una mejor atención y son más exigentes. En cambio, las personas de poco nivel educativo suelen estar más conformes con la información y por lo tanto con la atención.

En un texto editado en 1992 por consultores de la Organización Panamericana de la Salud que abordó los fundamentos de la garantía de calidad para fines de acreditación hospitalaria, el derecho a una información completa, se explicita en los siguientes términos: "El paciente tiene el derecho de participar, razonablemente informado, en las decisiones relacionadas con su tratamiento de salud. Hasta donde sea posible, esto debe ser basado en una explicación clara y concisa de su condición y de todos los procedimientos técnicos implícitos, incluyendo la posibilidad de cualquier tipo de riesgo de muerte o de reacciones serias, de problemas relacionados con su recuperación y su posible alta satisfactoria. El paciente no deberá estar sujeto a ningún procedimiento sin su consentimiento voluntario, competente y sano, o el consentimiento de su representante legal autorizado. Cuando existan alternativas médicas significativas para su tratamiento, estas también deberán ser informadas al paciente."

-Trabajo en equipo: Personas con visión compartida que asumen responsabilidades y compromisos, complementan capacidades y desarrollan sus potencialidades para el logro de resultados.

-Participación social: Mecanismos y procesos que permiten a la población organizada intervenir y tomar decisiones respecto a las prioridades, políticas y estrategias sanitarias.

-Satisfacción del usuario externo: Es el balance favorable entre lo que la persona o población espera de los servicios de salud y su percepción acerca de lo que recibe de ellos.

-Satisfacción del usuario interno: Es el balance favorable entre lo que el usuario interno espera de la organización y lo que percibe de ella. En relación a las expectativas del trabajador, se intenta explorar la satisfacción del personal, incluyendo el sentido de pertenencia e identificación institucional; la motivación, el autodesarrollo y las cargas de trabajo; los recursos mínimos necesarios para desempeñar adecuadamente sus actividades; incentivos laborales (políticas de promoción); reconocimiento social y profesional; incentivos económicos y finalmente clima laboral, el cual implica seguridad de empleo, coordinación, comunicación, información, respeto, liderazgo, bienestar y confort. ${ }^{19}$

La "Encuesta de Satisfacción del Personal de Salud" pretende recoger información sobre las percepciones que tienen los trabajadores de su ambiente de trabajo y que se traduce generalmente en la satisfacción o insatisfacción en relación a lo que espera de la organización y lo que percibe de ella. El conocimiento y la comprensión del nivel de satisfacción del "usuario o cliente interno" constituye un factor fundamental en la gestión y desarrollo de las empresas e instituciones debido a las implicancias que guarda con los temas de comportamiento organizacional, cultura de calidad, relaciones interpersonales que conllevan, entre otros aspectos, al éxito en la obtención de los resultados de la calidad de la atención. El personal de salud siente mayor satisfacción personal y profesional con su trabajo cuando puede ofrecer atención de buena calidad y sentir que su labor es valiosa. Con la evaluación de la satisfacción de los trabajadores se pretende conocer qué logros está alcanzando la organización en relación con las personas que la integran. Este conocimiento permitirá plantear objetivos concretos, relativos al grado de satisfacción laboral del

${ }^{19}$ Edgar del Salto Mariño. (2014). Evaluación de la calidad de atención y satisfacción del usuario que asiste a la consulta en el departamento médico del Instituto Nacional Mejía en el periodo 2012. Facultad de Ciencias Médicas Maestría de Gestión en Salud. Quito. 
personal, y desplegar las acciones necesarias para alcanzarlo. Otorgar a los trabajadores de salud la autoridad para resolver problemas y mejorar los servicios, como se hace en muchos de los métodos para mejorar la calidad, eleva la moral ${ }^{20}$. La percepción de los usuarios internos sobre la calidad de la atención que ofrece su lugar de trabajo es válida para la evaluación de la misma.

En la actualidad se es competitivo como organización o como persona si se está entre los que, de acuerdo a criterios del mercado, proporcionan mayor satisfacción al cliente. De tal forma que la calidad de los servicios de salud pasa a constituir una exigencia que se extiende progresivamente desde una perspectiva tradicionalmente centrada en la institución a otra que incorpore la perspectiva de los usuarios y trabajadores de los servicios, que los enfoques gerenciales denominan usuarios externos e internos respectivamente. El carácter subjetivo de la calidad del servicio se caracteriza por su incertidumbre, variabilidad y dificultad de medición, no obstante, se han diseñado diferentes técnicas e instrumentos que buscan medirla. La satisfacción del usuario se puede evaluar de dos maneras diferentes. A través de métodos, técnicas e instrumentos cuantitativos que supuestamente aseguran mayor objetividad debido a la homogeneidad de los instrumentos utilizados, o a través de métodos y técnicas cualitativas que permiten abordajes en profundidad de los problemas de calidad percibidos por los usuarios, así como de sus potenciales soluciones. La crítica que puede hacerse a los métodos cuantitativos, es su aparente superficialidad, donde los problemas y las causas fundamentales muchas veces no emergen o quedan encubiertos.

Las encuestas, como método de investigación, es el más utilizado para conocer la satisfacción de los usuarios con los servicios recibidos, midiendo la percepción de los que han sido atendidos en los servicios de salud, que no representa la opinión general de la comunidad sobre el sistema sanitario. Si bien los métodos cualitativos pueden aportar información más exhaustiva sobre esta condición básicamente subjetiva, son complejos y exigen amplia preparación y experiencia en su manejo. Es importante reconocer que los métodos cualitativos difícilmente pueden producir por sí solos la información capaz de ser generalizada a espacios institucionales extensos y deben ser asumidos como modalidades complementarias que permiten profundizar la información sobre problemas previamente detectados por métodos cuantitativos. A fin de vencer estos obstáculos, los investigadores están explorando diferentes maneras de medir y analizar la satisfacción del usuario.

En nuestra región, países como Brasil, Chile, México, Cuba, entre otros, han desarrollado cuestionarios validados para estimar la satisfacción de los pacientes y/o usuarios de los establecimientos de salud, tanto del ámbito público como privado. En Argentina, si bien el desarrollo de encuestas de satisfacción es común en los establecimientos de salud, no fue hasta el año 2009 que comenzó a implementarse un cuestionario validado para medir la calidad percibida por los pacientes en el nivel de atención ambulatoria. El mismo es desde entonces, instrumentado por el Programa de Indicadores de Calidad de la Atención Médica (PICAM)2, que forma parte del Instituto Técnico para la Acreditación de Establecimientos de Salud (ITAES) y la Sociedad Argentina para la Calidad de la Atención de la Salud (SACAS), aplicándose tanto en establecimientos privados como públicos.

Donabedian estableció que la calidad de los servicios de salud puede ser evaluada en tres diferentes planos: a) en la visión de los prestadores de servicios, b) en la visión de los usuarios y c) en la de las prioridades consideradas por la sociedad en general. Los juicios de calidad formulados en esos tres planos pueden coincidir más o menos, o discrepar entre sí

20 Jara, D. R. (2002). Encuesta de Satisfacción del Personal de Salud. Dirección General de Salud de las Personas. Dirección de Garantía de la Calidad y Acreditación. Lima, Perú. 
en relación a ciertos actos de salud concretos, debido a que puede evaluarse en forma distinta el peso que debe ser atribuido a cada uno de esos tres factores. La evaluación de la calidad desde el punto de vista de los usuarios se realiza generalmente a través de las encuestas de satisfacción. La evaluación de las prioridades de la sociedad en general se lleva a cabo a través de la evaluación de las políticas públicas de salud. La evaluación de la calidad por los prestadores de salud requiere de parte de estos, autocrítica y reflexión sobre las prerrogativas médicas y el modelo de atención paternalista. No se puede cambiar la esencia o calidad de los servicios sin replantear las funciones y tareas que los médicos están habituados a ejercer y sin su cooperación. El desafío del nuevo paradigma de la calidad requiere que los médicos compartan habilidades de trabajo en grupos de discusión (equipos de calidad interdisciplinarios) como base para una mejor articulación en el momento de operar la división técnica del trabajo en las unidades y que compartan responsabilidades técnico-gerenciales en la determinación y evaluación de normas de conducta para el mejor desempeño de los servicios.

\section{Percepción}

Para analizar la percepción de los usuarios primero debemos definirla. La percepción es el proceso que permite al organismo, a través de los sentidos, recibir, elaborar e interpretar la información proveniente de su entorno. El proceso de la percepción es de carácter inferencial y constructivo, generando una representación interna de lo que sucede en el exterior. Para ello se usa la información que llega a los receptores y se va analizando paulatinamente, así como la información que viene de la memoria tanto empírica como genética y que ayuda a la interpretación y a la formación de representaciones. Con base en la percepción, se constituye la experiencia y se formulan opiniones, que pueden definirse como el estado de creencia de los individuos y la colectividad respecto a determinado asunto e implica un juicio de valor. Su validez lógica como verdad no se fundamenta en el grado de conocimiento o en la prueba científica, sino en la participación como miembro de cierto grupo social. La opinión se elabora como relato, de manera discursiva, e implica un esfuerzo de ordenación de la percepción y la experiencia para ser aprehendida, y transmitida en estructuras narrativas a través del lenguaje.

La Gestalt define la percepción como un proceso de extracción y selección de información relevante encargado de generar un estado de claridad y lucidez consciente que permita el desempeño dentro del mayor grado de racionalidad y coherencia posibles con el mundo circundante. Se puede afirmar que, de la enorme cantidad de datos arrojados por la experiencia sensorial (luz, calor, sonido, impresión táctil, etc.), los sujetos perceptuales toman tan sólo aquella información susceptible de ser agrupada en la conciencia para generar una representación mental. La percepción, no está sometida a la información proveniente de los órganos sensoriales, sino que es la encargada de regular y modular la sensorialidad. El hecho de recibir de manera indiscriminada datos de la realidad implicaría una constante perplejidad en el sujeto, quien tendría que estar volcado sobre el inmenso volumen de estímulos que ofrece el contacto con el ambiente. Inicialmente, la percepción determina la entrada de información, y en segundo lugar, garantiza que la información retomada del ambiente permita la formación de abstracciones (juicios, categorías, conceptos, etc.).

No existe un punto de vista externo al individuo que sea objetivamente válido para la determinación de su bienestar, sólo es posible mediante una representación de las percepciones de dicho individuo. La evaluación en términos de satisfacción introduce un cuerpo más complejo de variantes y de información útil para identificar dimensiones que 
afectan el bienestar individual como para contrastar esa información con indicadores objetivos.

La satisfacción se relaciona con la ponderación de los diversos ámbitos de la experiencia. Es resultado de un conjunto de procesos que encuentran su síntesis en un segundo momento de significación, mediante un proceso reflexivo. Las percepciones no son un reflejo directo de la realidad y están influidas por patrones culturales.

Algunas de las dificultades que enfrentan los investigadores cuando intentan medir las percepciones son: que están sujetas a ambigüedades de interpretación, a sesgos de autocomplacencia, están afectadas por expectativas y aspiraciones, también están influidas por factores personales indescifrables y pueden ser inconsistentes con las decisiones que toman los individuos. Por consiguiente, las percepciones no son un reflejo directo de la realidad y no pueden utilizarse como sustituto de la información objetiva. Entre los numerosos factores que influyen en las percepciones están las diferencias ideológicas y de interpretación de las preguntas, y las diferencias de gustos y objetivos. A pesar de las limitaciones, al comparar las percepciones con los indicadores objetivos, las opiniones que la gente tiene sobre su bienestar tienden a reflejar correctamente las afectaciones positivas y negativas que experimentan internamente o que expresan físicamente. ${ }^{21}$

\section{4-OBJETIVOS DE INVESTIGACIÓN}

\section{1-OBJETIVO GENERAL}

Averiguar la percepción de la calidad de atención de los usuarios internos y externos del CAPS Entre Ríos Norte.

\section{2-OBJETIVOS ESPECÍFICOS}

-Conocer la percepción de los usuarios internos y externos sobre la calidad de la estructura del centro de salud Entre Ríos Norte.

-Estimar la percepción de los usuarios internos y externos sobre la calidad de los procesos de atención del CAPS Entre Ríos Norte.

- Valorar la percepción de los usuarios internos y externos sobre la calidad de los resultados y el nivel de satisfacción logrados por la atención del centro de salud.

-Analizar el grado de correlación entre la percepción de la calidad de atención de los usuarios externos y características de los mismos tales como edad, género, estado civil, escolaridad y ocupación.

-Determinar la relación entre las características de los usuarios internos tales como edad, género, escolaridad, antigüedad, jornada laboral y puesto de trabajo y su percepción sobre la calidad de la atención.

21 Hamui Sutton Fuentes García Aguirre Hernández Ramírez de la Roche. (2013). Expectativas y experiencias de los usuarios del Sistema de Salud en México: Un estudio de satisfacción con la atención médica. Universidad Nacional Autónoma de México. 


\section{5-METODOLOGÍA}

\section{1- Modelo metodológico:}

- Tipo de estudio: se realizó un estudio transversal analítico, utilizando triangulación metodológica cuantitativa y cualitativa. El estudio cuantitativo permitió recopilar información estadística para analizar el bienestar subjetivo, así como el grado de satisfacción del usuario con la atención recibida o prestada de acuerdo a su espacio de experiencias y horizonte de expectativas en cada evento de atención de salud. El método cualitativo, permitió conocer las percepciones, motivaciones, historias de vida, representaciones sociales de los usuarios con respecto a la atención médica, información, que en su conjunto permitió evaluar, directa e indirectamente, la calidad de la atención percibida.

- Plan de análisis de los resultados: análisis cuantitativo de los datos volcados de las entrevistas cerradas: estadística descriptiva. Determinación de medidas de tendencia central y cálculo de proporciones para las variables cualitativas.

Análisis cualitativo: análisis del discurso, encontrar coincidencias, frases entre comillas de las entrevistas abiertas y grupos focales.

- Instrumentos de recolección: entrevistas cerradas a ambos usuarios, grupos focales con los usuarios internos y entrevistas abiertas a los usuarios externos.

- Unidad de análisis: usuarios externos que consultaron al centro de salud y que se habían atendido en el mismo previamente y los usuarios internos que incluyó a todos los trabajadores del centro de salud.

- Fuente de datos: primaria

\section{2-Variables}

-Percepción de la calidad de atención y de sus dimensiones: estructura, procesos y resultados.

-Variables sociodemográficas de usuarios externos: edad, género, escolaridad, estado civil y ocupación. De usuarios internos: edad, género, escolaridad, antigüedad, jornada laboral y puesto de trabajo.

\section{3-Operacionalización de variables}

A- Percepción de la calidad de atención: es la valoración subjetiva del usuario positiva o negativa de la calidad de la atención recibida o prestada. La percepción es el juicio de valor del usuario sobre la prestación recibida o realizada en el centro de salud y que expresa a través de su conformidad o disconformidad.

\section{B- Dimensiones de la calidad}

Estructura: son todos los atributos materiales y organizacionales relativamente estables, así como los recursos humanos y financieros disponibles en los sitios en los que se proporciona atención.

1. Accesibilidad geográfica: estado de las calles y veredas de acceso al CAPS.

2. Accesibilidad administrativa: horario de atención y modalidad para solicitar turnos. Dificultad para obtener turnos. Oferta de prestaciones: cantidad de disciplinas relacionadas con la salud disponibles (clínica, pediatría, ginecología, psicología, 
odontología, Estimulación Temprana, etc.). Cantidad de turnos por especialidad y frecuencia semanal de atención.

3. Edificio: ventilación, calefacción, iluminación, estado del edificio, comodidad de la sala de espera, tamaño y distribución de los consultorios.

4. Limpieza: higiene de los ambientes (pisos, muebles, baño) e instrumental.

5. Insumos: administrativos (lapiceras, recetarios, hojas, cuadernos, etc.), de limpieza (cloro, desinfectantes, rejilla, trapo de piso, etc.), descartables (gasas, alcohol, vendas, yodo-povidona, jeringas, etc.). Material gráfico para actividades de prevención: afiches, folletos, revistas.

6. Instrumental médico: camillas, estetoscopio, otoscopio, colposcopio, balanza, pediómetro, etc.

7. Sistema de información: recopilación de datos y su análisis para obtener información pertinente y oportuna para la toma de decisiones de los profesionales y de los gestores del CAPS.

8. Valores: Amabilidad: comportamiento o acto caritativo, solidario o afectuoso del personal del CAPS con los usuarios externos, que incluye actitudes como la simpatía, la generosidad, la compasión y el altruismo. Respeto al usuario: trato cordial y empático que se pone de manifiesto durante el proceso de atención entre el proveedor y el usuario.

9. Tiempo de atención: tiempo mínimo de consulta que requiere el paciente para satisfacer su demanda. De acuerdo a la bibliografía consultada, el promedio de duración de la consulta médica en los consultorios clínicos oscila actualmente entre 10 y 15 min. La consulta psicológica es de 40 minutos. Fonoaudiología y psicopedagogía 30 minutos.

10. Sistema de gestión: administración de los recursos de la organización, es un conjunto de reglas y principios relacionados entre sí de forma ordenada, para contribuir a la gestión de procesos generales o específicos de una organización. Permite establecer una política, objetivos y alcanzar dichos objetivos.

11. Implementación de Programas de salud nacionales o provinciales: son instrumentos para operacionalizar las políticas de salud a través de la planeación, ejecución y evaluación de acciones de promoción, prevención, tratamiento y recuperación de la salud. Organización de estructura y procesos internos que permitan llevar a la práctica los programas definidos por otras jurisdicciones. Según el área geográfica de aplicación, un programa de salud puede ser nacional, provincial o municipal.

12. Resolución de conflictos: normas o protocolos establecidos para resolver los conflictos que se presenten entre los trabajadores del centro de salud.

13. Oferta de prestaciones: diferentes profesionales que prestan servicio en el CAPS como médico, psicólogo, asistente social, psicopedagoga, fonoaudióloga, etc.

Procesos: Se refiere a lo que los médicos y proveedores son capaces de hacer por los pacientes, la interrelación con las actividades de apoyo diagnosticadas, además de las actitudes, habilidades, destreza y técnica con que se llevan a cabo.

1. Claridad de las indicaciones médicas: compromiso y acciones del profesional en lograr la comprensión del paciente de sus prescripciones verbales o escritas.

2. Entrega de medicamentos: proveer los medicamentos necesarios para realizar el tratamiento o el método anticonceptivo prescripto.

3. Trabajo interdisciplinario: el trabajo en equipo interdisciplinario requiere un grupo de profesionales de distintas especialidades que trabajen juntos para asegurar la utilización integrada de las diferentes disciplinas en la planificación y la toma de decisiones para resolver un mismo problema. Reuniones de los profesionales del CAPS donde complementan capacidades y desarrollan sus potencialidades para lograr los objetivos propuestos. 
4. Trabajo en red: participación en redes intersectoriales establecidas formalmente. Por ejemplo, trabajar en forma conjunta en ciertos objetivos con educación, desarrollo social, medio ambiente, etc.

5. Seguimiento del paciente: El seguimiento médico es un proceso de atención sanitario que continúa a una intervención diagnóstica o terapéutica, con el objetivo de finalizar el episodio de atención iniciado para conseguir su completa recuperación, o de mantener un estado de salud satisfactorio en enfermedades crónicas. Se realiza a través de turnos programados, citaciones por la promotora de salud, acompañamiento de la trabajadora social al paciente para el cumplimiento del control o tratamiento.

6. Actividades de prevención: Comprende las actividades de promoción de la salud, educación sanitaria y prevención de las enfermedades dirigidas al individuo, la familia y la comunidad. Se realizan a través de charlas educativas en la sala de espera a cargo de un profesional o la promotora de salud, talleres en la comunidad para transmitir información sobre hábitos saludables o medidas preventivas, actividades planificadas en las escuelas para promover hábitos saludables en los niños, etc.

7. Participación social: mecanismos y procesos que permiten a la comunidad organizada intervenir y tomar decisiones respecto a sus prioridades en salud.

Resultados: Se definen como la variación de los niveles de salud de la población atendida, la satisfacción del paciente por la atención recibida y la satisfacción del usuario interno con su trabajo.

1. Resolución del problema de salud o motivo de consulta: a través de la percepción del usuario externo sobre sí obtuvo una respuesta del centro de salud a su requerimiento. Percepción del usuario interno si el centro de salud resuelve la mayoría de las consultas que atiende.

2. Mejoría del estado de salud: percepción del usuario externo sobre si se siente mejor, igual o peor que antes de la atención en el centro de salud. Percepción del usuario interno si la salud de la población que acude al CAPS solicitando prestaciones ha mejorado después de recibirlas.

3. Satisfacción del usuario externo: es el balance entre lo que la persona espera (expectativas) de los servicios de salud y su percepción acerca de lo que recibe.

4. Satisfacción del usuario interno: es el balance entre lo que el trabajador espera (expectativas) de la organización y lo que percibe de ella.

c- Variables sociodemográficas: se definen como cualquier evento, circunstancia o característica que puede adoptar diferentes valores en una población. Son indicadores sociales, económicos y demográficos que permiten segmentar la población en grupos homogéneos.

Usuario Externo: persona que solicita una prestación de salud.

1. edad: años

2. género: masculino o femenino.

3. ocupación: trabajo o labor principal.

4. escolaridad: nivel de educación alcanzado.

5. estado civil: situación personal en que se encuentra o no una persona física en relación a otra, con quien se crean lazos jurídicamente reconocidos sin que sea su pariente, constituyendo con ella una institución familiar, y adquiriendo derechos y deberes al respecto.

Usuario Interno: trabajador del centro de salud

1. edad: años

2. género: masculino o femenino.

3. antigüedad laboral: periodo de tiempo que un trabajador lleva vinculado a una organización. 
4. jornada laboral: número de horas que el trabajador está obligado a trabajar efectivamente.

5. escolaridad: nivel de educación alcanzado.

6. Puesto de trabajo: se define como el lugar o área ocupado por una persona dentro de una organización, empresa o entidad donde se desarrollan una serie de actividades las cuales satisfacen expectativas, que tienen como objetivo, garantizar productos, servicios y bienes en un marco social. Para este trabajo se los clasifica en profesionales y no profesionales.

\begin{tabular}{|c|c|c|}
\hline INDICADORES & UNIDAD DE ANÁLISIS & FUENTE DE INFORMACIÓN \\
\hline Accesibilidad geográfica & usuarios externos e internos & $\begin{array}{l}\text { UE*: entrevistas abiertas cerradas } \\
\text { UI*: entrevistas cerradas y grupos focales }\end{array}$ \\
\hline Accesibilidad administrativa & usuarios externos e internos & $\begin{array}{l}\text { UE: entrevistas abiertas y cerradas } \\
\text { UI: entrevistas cerradas y grupos focales }\end{array}$ \\
\hline Edificio & usuarios externos e internos & $\begin{array}{l}\text { UE: entrevistas abiertas y cerradas } \\
\text { UI: entrevistas cerradas y grupos focales }\end{array}$ \\
\hline Limpieza & usuarios externos e internos & $\begin{array}{l}\text { UE: entrevistas abiertas y cerradas } \\
\text { UI: entrevistas cerradas y grupos focales }\end{array}$ \\
\hline Insumos & usuario interno & UI: entrevistas cerradas \\
\hline Instrumental médico & usuario interno & UI: entrevistas cerradas y grupos focales \\
\hline Sistema de información & usuario interno & UI: entrevistas cerradas y grupos focales \\
\hline Amabilidad y respeto al usuario & usuarios externos e internos & $\begin{array}{l}\text { UE: entrevistas abiertas y cerradas } \\
\text { UI: entrevistas cerradas }\end{array}$ \\
\hline Tiempo de atención & usuarios externos e internos & $\begin{array}{l}\text { UE: entrevistas abiertas y cerradas } \\
\text { UI: entrevistas cerradas y grupos focales }\end{array}$ \\
\hline Gestión del CAPS & usuario interno & UI: entrevistas cerradas y grupos focales \\
\hline Programas de salud & usuario interno & Ul: grupos focales \\
\hline Oferta de prestaciones de salud & usuarios externos e internos & $\begin{array}{l}\text { UE: entrevistas abiertas y cerradas } \\
\text { UI: grupos focales }\end{array}$ \\
\hline Resolución de conflictos & usuarios internos & UI: entrevistas cerradas y grupos focales \\
\hline Claridad en las indicaciones & usuarios externos & UE: entrevistas abiertas y cerradas \\
\hline Entrega de medicamentos & usuarios externos & UE: entrevistas abiertas y cerradas \\
\hline Trabajo interdisciplinario & usuarios internos & UI: entrevistas cerradas y grupos focales \\
\hline Trabajo en red & usuarios internos & UI: entrevistas cerradas y grupos focales \\
\hline Seguimiento del paciente & usuarios internos y externos & $\begin{array}{l}\text { UE: entrevistas abiertas } \\
\text { UI: grupos focales y entrevistas cerradas }\end{array}$ \\
\hline Actividades de prevención & usuarios internos y externos & $\begin{array}{l}\text { UE: entrevistas abiertas } \\
\text { UI: grupos focales y entrevistas cerradas }\end{array}$ \\
\hline
\end{tabular}




\begin{tabular}{|l|l|l|}
\hline Participación social & usuario externo & UE: entrevistas abiertas y grupos focales \\
\hline $\begin{array}{l}\text { Resolución del problema de } \\
\text { salud o motivo de consulta }\end{array}$ & usuarios externos e internos & $\begin{array}{l}\text { UE: entrevistas abiertas y cerradas } \\
\text { UI: entrevistas cerradas }\end{array}$ \\
\hline Mejoría del estado salud & usuarios externos e internos & $\begin{array}{l}\text { UE: entrevistas abiertas y cerradas } \\
\text { UI: entrevistas cerradas }\end{array}$ \\
\hline Satisfacción & usuarios externos e internos & $\begin{array}{l}\text { UE: entrevistas abiertas y cerradas } \\
\text { UI: entrevistas cerradas y grupos focales }\end{array}$ \\
\hline
\end{tabular}

*UE: usuario externo *UI: usuario interno

Variables de la entrevista abierta al usuario externo:

\begin{tabular}{|c|c|}
\hline PREGUNTA & VARIABLE INVESTIGADA \\
\hline Edad, género, ocupación, escolaridad y estado civil & Variables sociodemográficas \\
\hline ¿Cómo calificaría a este centro de salud? & Calidad resultados: satisfacción U E \\
\hline ¿Qué opina del estado de las calles y veredas para llegar hasta acá? & Calidad estructura: accesibilidad geográfica. \\
\hline ¿Qué opina del edificio, la sala de espera? ¿Qué cambiaría? & Calidad estructura: edificio \\
\hline ¿Es fácil o difícil sacar un turno? ¿Para quién? & $\begin{array}{l}\text { Calidad estructura: accesibilidad } \\
\text { administrativa. }\end{array}$ \\
\hline ¿Le parece limpio? & Calidad estructura: limpieza \\
\hline $\begin{array}{l}\text { ¿El personal y los profesionales son amables? ¿Son respetuosos? ¿Lo } \\
\text { tratan bien? }\end{array}$ & Calidad estructura: valores. \\
\hline $\begin{array}{l}\text { ¿Le alcanza el tiempo que dura la consulta? ¿Necesita más tiempo con el } \\
\text { profesional? }\end{array}$ & Calidad estructura: tiempo de atención. \\
\hline ¿Habría que agregar otros profesionales? ¿Cuáles? & Calidad estructura: oferta de prestaciones. \\
\hline $\begin{array}{l}\text { ¿Entiende cuando el médico le da las indicaciones o tratamiento? ¿Se las } \\
\text { escribe? ¿Se entiende la letra? ¿Le explica bien? }\end{array}$ & $\begin{array}{l}\text { Calidad proceso: claridad en las } \\
\text { indicaciones médicas. }\end{array}$ \\
\hline ¿Le entregan medicación o métodos anticonceptivos? & $\begin{array}{l}\text { Calidad proceso: entrega de medicamentos } \\
\text { o métodos anticonceptivos. }\end{array}$ \\
\hline $\begin{array}{l}\text { ¿Le han dado turnos programados o lo han citado a través de la } \\
\text { promotora de salud? }\end{array}$ & Calidad proceso: seguimiento del paciente. \\
\hline $\begin{array}{l}\text { ¿Ha participado de alguna actividad que organizó el centro de salud? } \\
\text { ¿Hacen campañas de prevención? ¿Lo han invitado? }\end{array}$ & Calidad proceso: actividades de prevención. \\
\hline $\begin{array}{l}\text { Si se formara una comisión barrial para colaborar con la salita, ¿le } \\
\text { interesaría? }\end{array}$ & Calidad proceso: participación social. \\
\hline $\begin{array}{l}\text { ¿Siente que el centro de salud resuelve sus problemas de salud? } \\
\text { ¿Encuentra respuesta cuando consulta? }\end{array}$ & $\begin{array}{l}\text { Calidad resultados: resolución motivo de } \\
\text { consulta. }\end{array}$ \\
\hline $\begin{array}{l}\text { ¿Mejoró su salud desde que se atiende acá? ¿Es necesario este CAPS } \\
\text { para la salud del barrio? }\end{array}$ & $\begin{array}{l}\text { Calidad resultados: mejoría del estado de } \\
\text { salud. }\end{array}$ \\
\hline ¿Siente que el centro de salud cumple con sus expectativas? ¿Qué le & Calidad resultados: satisfacción usuario \\
\hline
\end{tabular}




\section{Variables de la entrevista cerrada al usuario externo:}

\begin{tabular}{|c|c|}
\hline PREGUNTA & VARIABLE INVESTIGADA \\
\hline Edad, género, ocupación, escolaridad y estado civil & Variables sociodemográficas \\
\hline Qué opinión tiene de este centro de Salud & Calidad resultados: satisfacción \\
\hline $\begin{array}{l}\text { Las calles y veredas para llegar al centro de salud están en } \\
\text { buenas condiciones }\end{array}$ & Calidad estructura: accesibilidad geográfica \\
\hline Le parece cómoda la sala de espera & Calidad estructura edificio \\
\hline Qué opinión tiene sobre el estado del edificio & Calidad estructura: edificio \\
\hline Cómo definiría la limpieza & Calidad estructura: limpieza \\
\hline Es fácil sacar un turno & Calidad estructura: accesibilidad administrativa \\
\hline Cuando necesita atenderse con el médico consigue turno & Calidad estructura: accesibilidad administrativa \\
\hline Cuando necesita atenderse con otro profesional consigue turno & Calidad estructura: accesibilidad administrativa \\
\hline $\begin{array}{l}\text { Cuando necesita un control o atención de parte de la enfermera, } \\
\text { lo obtiene }\end{array}$ & Calidad estructura: accesibilidad administrativa \\
\hline El Personal es amable & Calidad estructura: valores \\
\hline $\begin{array}{l}\text { Está conforme con la atención que le brinda el médico u otro } \\
\text { profesional }\end{array}$ & Calidad-resultado: satisfacción \\
\hline $\begin{array}{l}\text { Le parece suficiente el tiempo de atención del médico y otros } \\
\text { profesionales }\end{array}$ & Calidad estructura: tiempo de atención \\
\hline $\begin{array}{l}\text { Le resulta fácil entender las indicaciones del médico, de otro } \\
\text { profesional o de la enfermera }\end{array}$ & $\begin{array}{l}\text { Calidad proceso: claridad en las indicaciones } \\
\text { médicas }\end{array}$ \\
\hline $\begin{array}{l}\text { El centro de salud puede resolver sus problemas de salud, sus } \\
\text { consultas o controles }\end{array}$ & Calidad resultados: resolución motivo de consulta. \\
\hline $\begin{array}{l}\text { Su estado de salud ha mejorado gracias a la atención que le } \\
\text { brinda el centro de salud }\end{array}$ & Calidad resultados: mejoría de la salud \\
\hline
\end{tabular}




\begin{tabular}{|l|l|}
\hline Volvería a atenderse en este centro de salud & Calidad resultados: satisfacción \\
\hline $\begin{array}{l}\text { Lo recomendaría a sus familiares y amigos- calidad resultados: } \\
\text { satisfacción }\end{array}$ & Calidad resultados: satisfacción \\
\hline $\begin{array}{l}\text { Consigue en el centro de salud los medicamentos o métodos } \\
\text { anticonceptivos que necesita }\end{array}$ & Calidad proceso: entrega de medicamentos \\
\hline
\end{tabular}

\section{Variables de la entrevista cerrada al Usuario Interno}

\begin{tabular}{|c|c|}
\hline PREGUNTA & VARIABLE A INVESTIGAR \\
\hline $\begin{array}{l}\text { Edad, género, escolaridad, puesto de trabajo, antigüedad, carga } \\
\text { horaria. }\end{array}$ & Variables sociodemográficas \\
\hline ¿Conoce Ud. los Objetivos y Metas del Centro de Salud? & Calidad estructura: sistema de gestión \\
\hline $\begin{array}{l}\text { ¿Qué opina del estado en que se encuentran las calles y veredas } \\
\text { de acceso al centro de salud? }\end{array}$ & Calidad estructura: accesibilidad geográfica. \\
\hline ¿Le parece bien cómo se dan los turnos? & Calidad estructura: accesibilidad administrativa. \\
\hline $\begin{array}{l}\text { ¿Cómo califica el estado del edificio, la iluminación, la } \\
\text { ventilación y la calefacción? }\end{array}$ & Calidad estructura: edificio \\
\hline ¿Qué opina de la limpieza? & Calidad estructura: limpieza. \\
\hline $\begin{array}{l}\text { ¿Siente que el personal es amable y respetuoso con las } \\
\text { personas que consultan? }\end{array}$ & Calidad estructura: valores \\
\hline $\begin{array}{l}\text { De acuerdo al trabajo que Ud. desempeña, el instrumental de } \\
\text { que dispone es: a) Adecuado b) Inadecuado }\end{array}$ & Calidad estructura: instrumental médico. \\
\hline $\begin{array}{l}\text { ¿Le parece suficiente el tiempo de atención que puede dedicar } \\
\text { al paciente? }\end{array}$ & Calidad estructura: tiempo de atención. \\
\hline $\begin{array}{l}\text { ¿Reconoce Ud. la existencia de conflictos, o problemas en el } \\
\text { Centro de Salud? }\end{array}$ & Calidad estructura: resolución de conflictos. \\
\hline $\begin{array}{l}\text { ¿Está Ud. conforme con la forma de resolver los conflictos o } \\
\text { problemas? }\end{array}$ & Calidad estructura: resolución de conflictos. \\
\hline $\begin{array}{l}\text { ¿Puede participar en el análisis de los diferentes problemas del } \\
\text { Centro de Salud y buscar soluciones en forma conjunta con los } \\
\text { demás trabajadores? }\end{array}$ & Calidad estructura: sistema de gestión. \\
\hline $\begin{array}{l}\text { ¿Considera Ud. que la labor que realiza, es reconocida por sus } \\
\text { superiores? }\end{array}$ & Calidad estructura: sistema de gestión. \\
\hline $\begin{array}{l}\text { ¿Cómo considera usted su trabajo? a) Importante b) Sin } \\
\text { importancia }\end{array}$ & Calidad resultados: satisfacción. \\
\hline $\begin{array}{l}\text { ¿Considera Ud. que en el Centro de Salud existen sistemas de } \\
\text { incentivo a la labor que se realiza? }\end{array}$ & Calidad estructura: sistema de gestión. \\
\hline ¿Conoce Ud. los sistemas de información existentes en el Centro & Calidad estructura: sistema de información. \\
\hline
\end{tabular}




\begin{tabular}{|l|l|}
\hline de Salud? & \\
\hline ¿Se realizan actividades de prevención? & Calidad procesos: actividades de prevención. \\
\hline ¿Se trabaja en forma interdisciplinaria? & Calidad procesos: trabajo interdisciplinario. \\
\hline ¿Se trabaja en red? & Calidad procesos: trabajo en red. \\
\hline ¿Se realiza seguimiento del paciente? & Calidad procesos: seguimiento del paciente. \\
\hline $\begin{array}{l}\text { ¿Considera que con su trabajo ha colaborado para mejorar la } \\
\text { salud de la comunidad? }\end{array}$ & Calidad resultados: mejoría de la salud. \\
\hline $\begin{array}{l}\text { ¿Considera que el centro de salud resuelve la mayoría de las } \\
\text { consultas? }\end{array}$ & Calidad resultados: resolución motivo de consulta \\
\hline $\begin{array}{l}\text { ¿Usted, se atendería o se ha atendido en este centro? ¿Lo ha } \\
\text { recomendado a familiares y amigos? }\end{array}$ & Calidad resultados: satisfacción U I \\
\hline \begin{tabular}{l} 
¿Se siente satisfecho por tu trabajo en este centro de salud? \\
\hline
\end{tabular} & Calidad resultados: satisfacción U I \\
\hline
\end{tabular}

\section{4- Muestra}

Entrevistas cerradas a los Usuarios Externos: se realizó técnica de muestreo no probabilístico y consecutivo, previa información al entrevistado sobre la naturaleza del estudio. El tamaño de la muestra para este trabajo se calculó sobre un universo de consultas registradas durante el año 2017, con un total de 9906 consultas anuales. Para un nivel de confianza del 90\% la muestra de entrevistas cerradas necesarias fue de 265 . (gráfico $\mathrm{N}^{\circ} 2$ )

Entrevistas abiertas a los Usuarios Externos: se realizaron por saturación hasta que una unidad más no generó mayor información.

Entrevistas cerradas a los Usuarios Internos: se incluyó a la totalidad de usuarios internos (todos los trabajadores del CAPS).

Grupos Focales: se invitó a todos los trabajadores del Centro de Salud. 


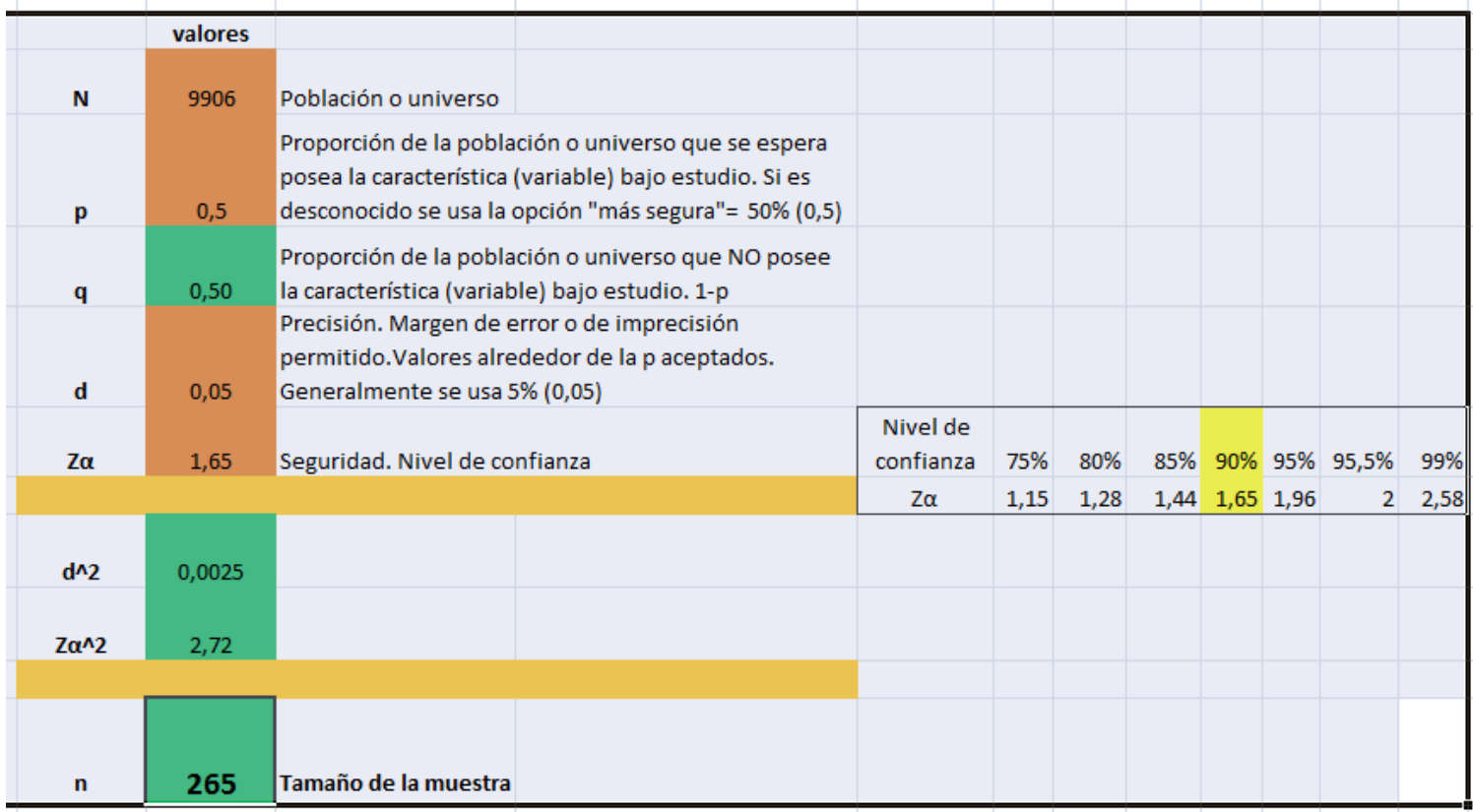

Gráfico $\mathrm{N}^{\circ} 2$

\section{5-Criterios de inclusión}

Personas mayores de 18 años de ambos sexos que se habían atendido previamente en el centro de salud y que aceptaron colaborar con este estudio y todos los trabajadores del CAPS que quisieron participar.

\section{6-Criterios de exclusión}

Se excluyeron como usuarios externos a las personas que no fueron atendidas previamente en el centro de salud. Se excluyeron como usuarios internos al personal de reemplazo temporario.

\section{7-Instrumentos de recolección de datos}

En base a las respuestas obtenidas de una guía de cotejo se elaboraron los cuestionarios para las entrevistas abiertas y cerradas a los usuarios externos, con apoyo de la bibliografía consultada para redactar el marco teórico.

A- Entrevistas Abiertas a los Usuarios Externos: las entrevistas fueron efectuadas por una persona que no trabaja en el CAPS y que fue entrenada previamente, para evitar sesgos en las respuestas de los usuarios externos. Fueron realizadas en la sala de espera, en forma individual, con preguntas abiertas sobre la calidad de atención del centro de salud. A los que aceptaron colaborar, se les informó sobre el objetivo de la encuesta y que era anónima.

B- B- Entrevistas Cerradas a los Usuarios Externos: mientras aguardaban ser atendidos en la sala de espera del centro de salud, se les preguntó a los usuarios externos si querían colaborar con un estudio de calidad para mejorar la atención del centro de salud. A los que aceptaron se les entregó el cuestionario para que completaran en forma individual y anónima tras una breve explicación informativa.

C- C- Grupos Focales: Se realizó un grupo focal con los usuarios internos del CAPS para enriquecer el debate y los resultados. Fueron invitados todos los trabajadores a la 
reunión, pero acudió sólo el $60 \%$ de los mismos. Los participantes expresaron sus opiniones sobre las diferentes dimensiones de la calidad de la atención (estructura, procesos y resultados) del CAPS y manifestaron su grado de satisfacción con el trabajo. Teniendo en cuenta las opiniones expresadas en el grupo focal y con apoyo del marco teórico, se elaboró el cuestionario para una entrevista cerrada al usuario interno.

D- D- Entrevistas cerradas a los Usuarios Internos: las completaron en forma individual y anónima el $100 \%$ de los trabajadores del CAPS. Todos aceptaron realizarlas con el propósito de mejorar la calidad de atención y su propia satisfacción con el trabajo.

\section{8- Elaboración de la Base de Datos}

Se diseñó una hoja de cálculo Excel para cargar las respuestas de cada entrevistado.

\section{9- Consideraciones Éticas}

Las entrevistas fueron realizadas a personas mayores de 18 años que aceptaron colaborar, luego de una explicación informativa sobre los objetivos de este estudio.

\subsection{0- Plan de Análisis}

Los datos obtenidos de las entrevistas cerradas a los usuarios internos y externos y de la entrevista abierta a los usuarios externos fueron volcados en una hoja de cálculo Excel y se procedió a establecer el porcentaje, promedio, etc. de las respuestas.

\section{6-RESULTADOS}

\section{1- Diagnóstico situacional de Bragado}

El equipo de Salud del CAPS está compuesto por: dos enfermeras, un médico clínico, una pediatra, una ginecóloga, una obstétrica, una fonoaudióloga, un psicólogo, una trabajadora social, una psicopedagoga, una promotora de salud, dos mucamas y dos administrativas. Aunque ambos usuarios solicitaron en las entrevistas, otros especialistas como odontólogo y maestra de Estimulación Temprana, no se han incorporado nuevos profesionales hasta la fecha. Se implementan en el CAPS programas del Ministerio de Salud de la Nación y de la Provincia como Programa Remediar, Programa de Inmunizaciones, Programa de Médicos Comunitarios, Plan Sumar, etc. En los últimos meses todos los programas han disminuido la provisión de insumos (medicamentos, preservativos, vacunas, etc.). La atención se realiza por demanda espontánea y algunos turnos son programados por medio de la promotora de salud. La mayoría de los profesionales tienen una carga horaria de 6 horas por semana distribuidas generalmente en dos horas por día tres veces por semana. Las administrativas y enfermeras cumplen 6 horas por día en turnos rotativos. Las mucamas pertenecen a una cooperativa. La financiación se realiza en forma conjunta entre nación y provincia que proveen los insumos correspondientes a los programas y el municipio que absorbe el resto de los gastos (sueldos, insumos, mantenimiento, luz, gas, etc.). El CAPS no cuenta con computadora ni con internet, por lo cual las planillas de estadísticas que se completan, se 
envían en un sobre al Centro de Estadísticas que se encuentra en el hospital. No existe devolución de datos estadísticos.

El centro de salud está situado en un barrio de calles de tierra. En los últimos meses, por el reclamo de la gente, el municipio hizo el cordón cuneta y mayor mantenimiento de las calles de acceso, pero no de las veredas, que continúan en malas condiciones. También se amplió la sala de espera, por pedido de los trabajadores y se mejoró con una puerta de emergencia y un aire acondicionado frío calor. El resto del edificio continúa sin refacciones.

\section{2- Análisis de las variables de la entrevista cerrada al usuario interno}

Se realizaron 15 entrevistas cerradas a los trabajadores del centro de salud en forma anónima. Todos aceptaron colaborar con este estudio.

\subsection{1-Análisis variables sociodemográficas de los entrevistados}

La edad mínima de los encuestados fue de 22 años y la máxima de 64 años siendo el $87 \%$ del personal femenino y sólo el $13 \%$ masculino. El $73 \%$ completó estudios terciarios o universitarios y trabaja como profesional del centro de salud. El resto de los trabajadores no es profesional, de los cuales la mitad completó la escuela primaria y la mitad la secundaria. Con respecto a la antigüedad laboral, la mitad de los trabajadores refirió entre 6 y 10 años y $26 \%$ más de 10 años. Sobre las horas semanales que realizan en el CAPS, el $40 \%$ de los usuarios internos cumple más de 10 horas, el $30 \%$ hasta 6 horas y $26 \%$ más de 30 horas semanales.

\begin{tabular}{|l|l|l|}
\hline Género & Femenino 86,6\% & Masculino 13,4\% \\
\hline \multirow{4}{*}{ Edad } & 22 a 64 años & Mediana 49 \\
\hline \multirow{5}{*}{ Escolaridad } & Primaria completa & $13,3 \%$ \\
\cline { 2 - 3 } & Primaria incompleta & 0 \\
\cline { 2 - 3 } & Secundaria completa & $13,3 \%$ \\
\cline { 2 - 3 } & Secundaria incompleta & 0 \\
\cline { 2 - 3 } & Terciario /universitario completo & $73,3 \%$ \\
\cline { 2 - 3 } & Terciario incompleto & 0 \\
\hline \multirow{5}{*}{ Puesto de trabajo } & No profesional & $26,7 \%$ \\
\cline { 2 - 3 } & Profesional & $73,3 \%$ \\
\hline \multirow{5}{*}{ Horas semanales de trabajo } & Menor a 1 año & $6,6 \%$ \\
\cline { 2 - 3 } & De 1 a 5 años & $13,3 \%$ \\
\cline { 2 - 3 } & De 6 a 10 años & $53,3 \%$ \\
\cline { 2 - 3 } & Mayor a 10 años & $26,6 \%$ \\
\hline & Hasta 6 horas & $33,3 \%$ \\
\cline { 2 - 3 } & Más de 10 horas & $26,6 \%$ \\
\cline { 2 - 3 } & Más de 30 horas & \\
\hline
\end{tabular}




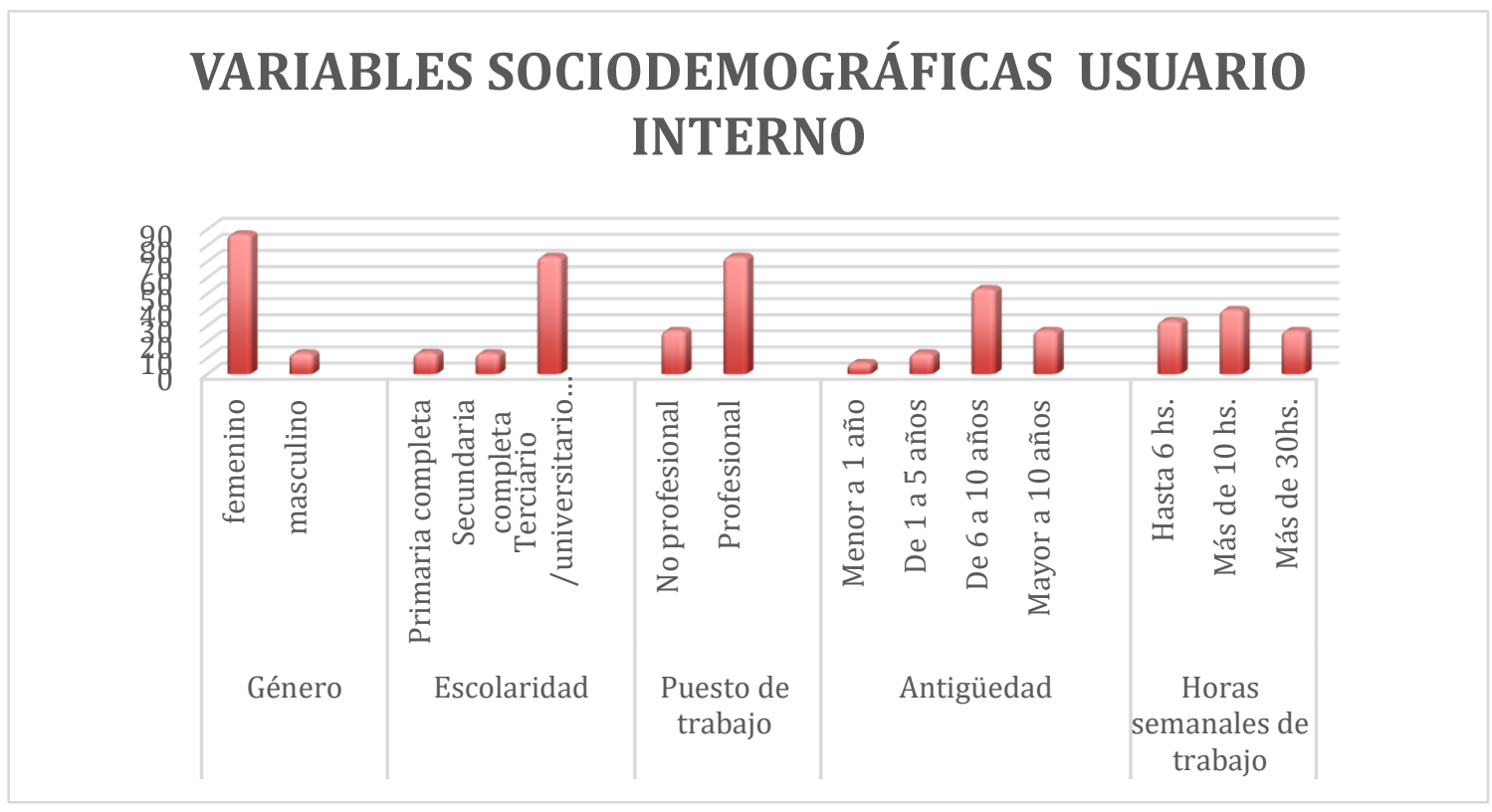

Gráfico $N^{\circ} 3$

\subsection{2-Análisis variables de estructura, proceso y resultado}

Todos los usuarios internos contestaron que conocen los objetivos que debe cumplir el CAPS para satisfacer las necesidades de salud de la población. Del estado de las calles y veredas de acceso opinaron que es regular y malo y del edificio la mayoría dijo lo mismo. Casi el $87 \%$ estuvo de acuerdo con la manera de otorgar los turnos. Sobre la limpieza $60 \%$ refirió que es buena y $40 \%$ que es mala. Todos contestaron que son amables con los usuarios externos. Más del $70 \%$ respondió que el tiempo de atención es suficiente y el $80 \%$ expresó que cuenta con el instrumental que necesita para desarrollar su trabajo. El $60 \%$ aceptó que existen conflictos entre los trabajadores y más de la mitad estuvo desconforme con la manera de resolver dichos conflictos. Cuando se les preguntó si han participado en el análisis de los problemas que van surgiendo en el CAPS y en la propuesta de soluciones, dos tercios respondió que sí y un tercio que no. Sobre las actividades de prevención sólo un entrevistado contestó que se realizan. Se sintió reconocido por sus superiores el $67 \%$ del personal y expresó que su trabajo es importante el $100 \%$. Todos declararon que no existen incentivos al buen desempeño. La mitad confirmó desconocer el sistema de información que tiene el centro de salud. El $87 \%$ del personal aseguró que el CAPS resuelve los problemas de salud de las personas que consultan y el $100 \%$ respondió que mejoró la salud del barrio y por lo tanto lo recomiendan. Más de la mitad afirmó que se realiza trabajo interdisciplinario y el $40 \%$ que se lleva a cabo trabajo en red con otros sectores como educación, desarrollo social, etc. Sobre el seguimiento de los pacientes la mayoría definió que es bueno y sólo el $20 \%$ opinó que es regular. Al preguntarles si se sentían satisfechos con su trabajo en este centro de salud, el 80\% refirió que sí.

\begin{tabular}{|c|c|c|}
\hline \multirow{2}{*}{ Objetivos del CAPS } & $\mathrm{Si}$ & $100 \%$ \\
\hline \multirow{3}{*}{ Estado de calles y veredas } & No & 0 \\
\cline { 2 - 3 } & Muy bueno & 0 \\
\cline { 2 - 3 } & Bueno & $40 \%$ \\
\cline { 2 - 3 } & Regular & $53,3 \%$ \\
\cline { 2 - 3 } & Malo & $13,3 \%$ \\
\hline \multirow{2}{*}{ Estado edificio } & Bueno & $66,6 \%$ \\
\cline { 2 - 3 } & Regular & $20 \%$ \\
\cline { 2 - 3 } & Malo & $13,3 \%$ \\
\hline
\end{tabular}




\begin{tabular}{|c|c|c|}
\hline & De acuerdo & $86,7 \%$ \\
\hline \multirow[t]{4}{*}{ Limpieza } & Muy buena & $6,6 \%$ \\
\hline & Buena & $53,3 \%$ \\
\hline & Regular & $40 \%$ \\
\hline & Mala & 0 \\
\hline Amabilidad & $\mathrm{Si}$ & $100 \%$ \\
\hline \multirow[t]{2}{*}{ Tiempo de atención } & Suficiente & $73,3 \%$ \\
\hline & Insuficiente & $26,6 \%$ \\
\hline \multirow[t]{2}{*}{ Instrumental } & Adecuado & $80 \%$ \\
\hline & Inadecuado & $20 \%$ \\
\hline \multirow[t]{2}{*}{ Conflictos } & Existen & $60 \%$ \\
\hline & No existen & $40 \%$ \\
\hline \multirow[t]{3}{*}{ Resolución de conflictos } & Conforme & $53,3 \%$ \\
\hline & Desconforme & $40 \%$ \\
\hline & No contesta & $6,6 \%$ \\
\hline \multirow[t]{2}{*}{ Análisis problemas } & $\mathrm{Si}$ & $66,7 \%$ \\
\hline & No & $33,3 \%$ \\
\hline \multirow[t]{3}{*}{ Actividades de prevención } & $\mathrm{Si}$ & $6,6 \%$ \\
\hline & No & $86,6 \%$ \\
\hline & No contesta & $6,6 \%$ \\
\hline \multirow[t]{2}{*}{ Reconocimiento } & $\mathrm{Si}$ & $66,7 \%$ \\
\hline & No & $33,3 \%$ \\
\hline \multirow{2}{*}{$\begin{array}{l}\text { Importante su trabajo } \\
\text { Dan Incentivos }\end{array}$} & Si & $100 \%$ \\
\hline & No & $100 \%$ \\
\hline \multirow[t]{2}{*}{ Sistema de información } & Si & $53,3 \%$ \\
\hline & No & $46,7 \%$ \\
\hline \multirow[t]{2}{*}{ Resolución problema de salud } & Si & $86,6 \% \%$ \\
\hline & No & $13,3 \%$ \\
\hline Mejora salud barrio & Si & $100 \%$ \\
\hline Recomendaría el CAPS & $\mathrm{Si}$ & $100 \%$ \\
\hline \multirow[t]{3}{*}{ Interdisciplina } & Si & $53,3 \%$ \\
\hline & No & $26,6 \%$ \\
\hline & No contesta & $20 \%$ \\
\hline \multirow[t]{3}{*}{ Trabajo en red } & $\mathrm{Si}$ & $40 \%$ \\
\hline & No & $40 \%$ \\
\hline & No contesta & $20 \%$ \\
\hline \multirow[t]{5}{*}{ Seguimiento del paciente } & Muy bueno & $26,6 \%$ \\
\hline & Bueno & $40 \%$ \\
\hline & Regular & $20 \%$ \\
\hline & Malo & 0 \\
\hline & No contesta & $13,3 \%$ \\
\hline \multirow[t]{3}{*}{ Satisfacción } & $\mathrm{Si}$ & $80 \%$ \\
\hline & No & $13,3 \%$ \\
\hline & No contesta & $6,6 \%$ \\
\hline
\end{tabular}




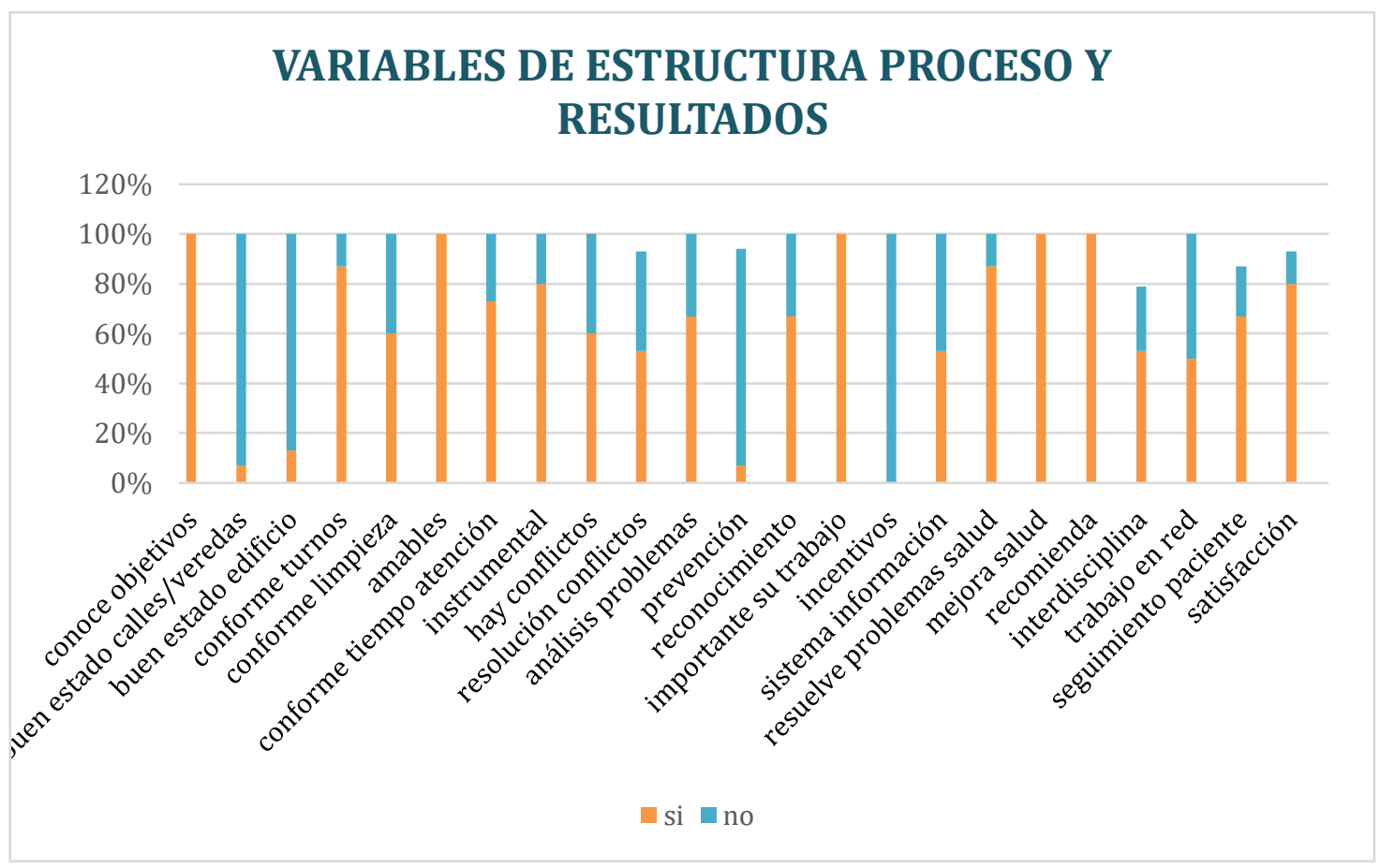

Gráfico $N^{\circ} 4$

\subsection{3-Análisis de las respuestas según la edad de los entrevistados}

No hubo diferencias significativas en las respuestas sobre los objetivos del CAPS, el estado de las calles y veredas y el otorgamiento de turnos en cuanto a la edad de los entrevistados. Sobre el estado edilicio del centro la mayoría dijo que es regular y malo pero un $28 \%$ de los mayores de 49 años contestó que es bueno. El $75 \%$ de los menores de 49 años calificó la limpieza como buena y sólo coincidieron con ellos el $43 \%$ de los mayores, en cambio, el $57 \%$ restante la definió como regular. Sin importar la edad todos opinaron que el personal es amable. Con respecto al tiempo de atención el $63 \%$ de los menores de 49 años y el $87 \%$ de los mayores respondió que es suficiente. Sin presentar diferencias según la edad, la mayoría dijo tener el instrumental necesario para realizar su trabajo. El 75\% de los menores de 49 años reconoció conflictos entre el personal, pero de los mayores de 49 años sólo el $43 \%$. Al preguntarles si estaban de acuerdo con la forma en que se resuelven los conflictos, el $75 \%$ de los menores de 49 años opinó que no y el 100\% de los mayores que sí. Sobre la participación en el análisis y resolución de los problemas del CAPS y el reconocimiento por parte de los superiores, la mitad de los menores de 49 años y el $87 \%$ de los mayores contestó que sí. Sobre las actividades de prevención, la mayoría de ambos grupos aseguró que no se realizan. El $100 \%$ de ambas categorías afirmó que su trabajo es importante y que no existen incentivos por buen desempeño para los trabajadores. Dijo que conoce el sistema de información del Centro de salud, tan sólo el 37\% de los menores de 49 años. Pero de los mayores de 49 años, el $72 \%$, casi el doble que el grupo anterior. No hubo diferencias en ambas categorías con respecto a que la atención del centro de salud mejora la salud de la gente y resuelve los problemas de salud de la comunidad. Por todo eso, la mayoría, lo recomienda. El $63 \%$ de los menores y el $43 \%$ de los mayores de 49 años respondieron que se trabaja en forma interdisciplinaria. En cuanto al trabajo en red, lo afirmaron el $63 \%$ de los menores y sólo el $14 \%$ de los mayores de 49 años. Gran parte de todos los usuarios, refirieron que el seguimiento de los pacientes es bueno o muy bueno y apenas el $25 \%$ y $14 \%$ respectivamente lo calificaron como regular. La satisfacción fue alta en ambas categorías, con $75 \%$ en los menores de 49 años y $87 \%$ en los mayores. 


\begin{tabular}{|c|c|c|c|}
\hline & & $<0=$ de 49 años & $>$ de 49 años \\
\hline \multirow[t]{2}{*}{ Objetivos } & $\mathrm{Si}$ & $100 \%$ & $100 \%$ \\
\hline & No & 0 & 0 \\
\hline \multirow[t]{4}{*}{ Estado de calles y veredas } & Muy bueno & 0 & $14,3 \%$ \\
\hline & Bueno & 0 & 0 \\
\hline & Regular & $25 \%$ & $57,2 \%$ \\
\hline & Malo & $75 \%$ & $28,5 \%$ \\
\hline \multirow[t]{2}{*}{ Obtener turno } & Fácil & $87,5 \%$ & $87,5 \%$ \\
\hline & Difícil & $12,5 \%$ & $12,5 \%$ \\
\hline \multirow[t]{3}{*}{ Estado de edificio } & Bueno & 0 & $28,5 \%$ \\
\hline & Regular & $87,5 \%$ & $43 \%$ \\
\hline & Malo & $12,5 \%$ & $28,5 \%$ \\
\hline \multirow[t]{4}{*}{ Limpieza } & Muy Buena & 0 & $14,3 \%$ \\
\hline & Buena & $75 \%$ & $28,5 \%$ \\
\hline & Regular & $25 \%$ & $57,2 \%$ \\
\hline & Mala & 0 & 0 \\
\hline Amabilidad & $\mathrm{Si}$ & $100 \%$ & $100 \%$ \\
\hline \multirow[t]{2}{*}{ Tiempo de atención } & Suficiente & $62,5 \%$ & $87,5 \%$ \\
\hline & Insuficiente & $37,5 \%$ & $12,5 \%$ \\
\hline \multirow[t]{2}{*}{ Tiene instrumental } & $\mathrm{Si}$ & $75 \%$ & $87,5 \%$ \\
\hline & No & $25 \%$ & $12,5 \%$ \\
\hline \multirow[t]{2}{*}{ Existen conflictos } & $\mathrm{Si}$ & $75 \%$ & $43 \%$ \\
\hline & No & $25 \%$ & $57 \%$ \\
\hline \multirow[t]{3}{*}{ Resolución de conflictos } & Si & $12,5 \%$ & $100 \%$ \\
\hline & No & $75 \%$ & 0 \\
\hline & No sabe & $12,5 \%$ & \\
\hline \multirow[t]{2}{*}{ Análisis de problemas } & Si & $50 \%$ & $87,5 \%$ \\
\hline & No & $50 \%$ & $12,5 \%$ \\
\hline \multirow[t]{3}{*}{ Actividades de prevención } & $\mathrm{Si}$ & 0 & $14,2 \%$ \\
\hline & No & $100 \%$ & $71,5 \%$ \\
\hline & No contesta & & $14,2 \%$ \\
\hline \multirow[t]{2}{*}{ Siente reconocimiento } & $\mathrm{Si}$ & $50 \%$ & $87,5 \%$ \\
\hline & No & $50 \%$ & $12,5 \%$ \\
\hline \multirow[t]{2}{*}{ Importancia de su trabajo } & Si & $100 \%$ & $100 \%$ \\
\hline & No & 0 & 0 \\
\hline Recibe incentivo & No & $100 \%$ & $100 \%$ \\
\hline \multirow[t]{2}{*}{ Sistema de información } & Si & $37,5 \%$ & $71,5 \%$ \\
\hline & No & $62,5 \%$ & $28,5 \%$ \\
\hline Mejora salud del barrio & Si & $100 \%$ & $100 \%$ \\
\hline \multirow{2}{*}{$\begin{array}{l}\text { Resuelve problemas de } \\
\text { salud }\end{array}$} & Si & $87,5 \%$ & $87,5 \%$ \\
\hline & No & $12,5 \%$ & $12,5 \%$ \\
\hline Recomendaría al CAPS & $\mathrm{Si}$ & $100 \%$ & $100 \%$ \\
\hline \multirow[t]{3}{*}{ Interdisciplina } & Si & $62,5 \%$ & $43 \%$ \\
\hline & No & $37,5 \%$ & $14 \%$ \\
\hline & No contesta & & $43 \%$ \\
\hline \multirow[t]{3}{*}{ Trabajo en red } & Si & $62,5 \%$ & $14 \%$ \\
\hline & No & $37,5 \%$ & $43 \%$ \\
\hline & No contesta & & $43 \%$ \\
\hline \multirow[t]{4}{*}{ Seguimiento del paciente } & Muy bueno & $37,5 \%$ & $14,2 \%$ \\
\hline & Bueno & $37,5 \%$ & $43 \%$ \\
\hline & Regular & $25 \%$ & $14,2 \%$ \\
\hline & Malo & 0 & 0 \\
\hline
\end{tabular}




\begin{tabular}{|l|l|l|l|}
\hline & No contesta & & $28,5 \%$ \\
\hline \multirow{3}{*}{ Satisfacción } & $\mathrm{Si}$ & $75 \%$ & $87,5 \%$ \\
\cline { 2 - 4 } & No & $25 \%$ & 0 \\
\cline { 2 - 4 } & No contesta & & $12,5 \%$ \\
\hline
\end{tabular}

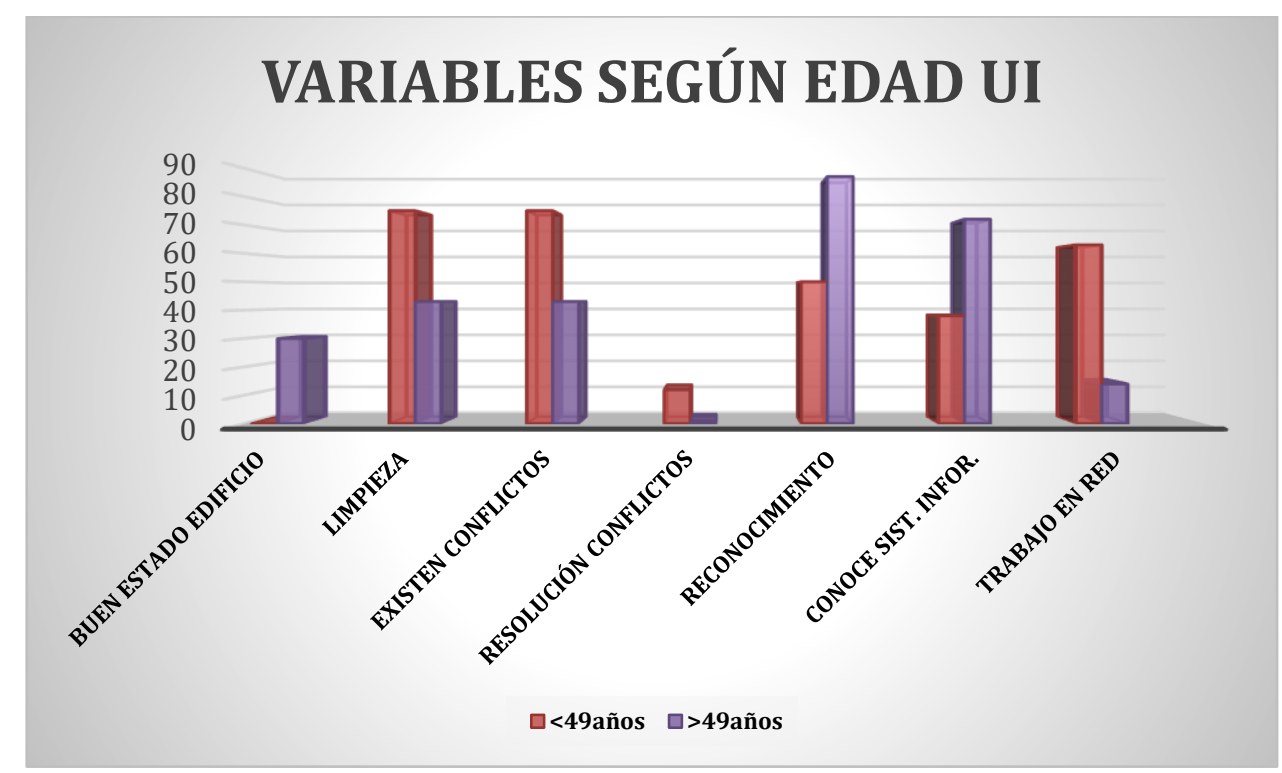

Gráfico $\mathbf{N}^{\circ} 5$

\subsection{4- Análisis de las respuestas según el género de los entrevistados}

Cuando se analizaron las respuestas teniendo en cuenta el género de los usuarios internos, no se encontraron diferencias significativas sobre el conocimiento de los objetivos del CAPS, la accesibilidad geográfica y administrativa. Cuando respondieron sobre el estado del edificio, el $100 \%$ de los hombres y el $70 \%$ de las mujeres, lo calificaron como regular y un $23 \%$ de estas últimas como malo. Las mujeres le dieron mejor puntuación a la limpieza y tan sólo el 38\% la definió como regular. De los hombres la mitad respondió que es buena y la mitad que es regular. Sin diferencias por género, todos los entrevistados opinaron que son amables. Sobre el tiempo de atención el $100 \%$ de los hombres y el $69 \%$ de las mujeres contestaron que es suficiente. El $85 \%$ de las trabajadoras y sólo la mitad de los trabajadores aseguraron que cuentan con el instrumental necesario para su labor. La mitad de los hombres admitieron que existen conflictos entre los usuarios internos y también la mitad estuvieron conformes con la resolución de los mismos. En cambio, de las mujeres, el $62 \%$ aceptó la existencia de conflictos y sólo el $38 \%$ no estuvo de acuerdo con su resolución. Cuando se les preguntó si participaban en la toma de decisiones, analizando y resolviendo los problemas que fueran surgiendo, se observó que las mujeres refirieron mayor participación, $69 \%$ contra sólo el $50 \%$ de los hombres. La mayoría de ambos grupos dijo que no se realizan actividades de prevención. En cuanto al reconocimiento por parte de las autoridades, las mujeres se sintieron más reconocidas que los hombres, $70 \%$ versus $50 \%$. Coincidieron ambos en las respuestas sobre la importancia de su trabajo y la carencia de incentivos. El sistema de información fue desconocido por el $38 \%$ de las mujeres y el $100 \%$ de los hombres. Respondieron que el CAPS resuelve los problemas de salud de las personas que consultan, el $100 \%$ de las mujeres y la mitad de los hombres. Ambas categorías contestaron que sienten que su trabajo ha mejorado el estado de salud de la comunidad que atiende y por lo tanto recomiendan el centro de salud. El total de los hombres afirmó que se hace trabajo interdisciplinario, pero sólo la mitad que se trabaja en red. En cambio, de las mujeres, apenas el $46 \%$ aseguró trabajar interdisciplinariamente y el $38 \%$ en red. 
Calificaron al seguimiento de los pacientes como muy bueno y bueno el $100 \%$ de los hombres y más del $60 \%$ de las mujeres. Se sintieron satisfechos todos los trabajadores y el $77 \%$ de las trabajadoras.

\begin{tabular}{|c|c|c|c|}
\hline & & Femenino & Masculino \\
\hline \multirow[t]{2}{*}{ Objetivos } & $\mathrm{Si}$ & $100 \%$ & $100 \%$ \\
\hline & No & 0 & 0 \\
\hline \multirow{4}{*}{$\begin{array}{l}\text { Estado de calles y } \\
\text { veredas }\end{array}$} & Muy bueno & $7,6 \%$ & 0 \\
\hline & Bueno & 0 & 0 \\
\hline & Regular & $38,4 \%$ & $50 \%$ \\
\hline & Malo & $54 \%$ & $50 \%$ \\
\hline \multirow[t]{2}{*}{ Obtener turno } & Fácil & $84,6 \%$ & $100 \%$ \\
\hline & Difícil & $15,4 \%$ & 0 \\
\hline \multirow[t]{3}{*}{ Estado edificio } & Bueno & $7,6 \%$ & 0 \\
\hline & Regular & $69,2 \%$ & $100 \%$ \\
\hline & Malo & $23 \%$ & 0 \\
\hline \multirow[t]{4}{*}{ Limpieza } & Muy Buena & $7,6 \%$ & 0 \\
\hline & Buena & $54 \%$ & $50 \%$ \\
\hline & Regular & $38,4 \%$ & $50 \%$ \\
\hline & Mala & 0 & 0 \\
\hline Amabilidad & $\mathrm{Si}$ & $100 \%$ & $100 \%$ \\
\hline \multirow[t]{2}{*}{ Tiempo de atención } & Suficiente & $69,2 \%$ & $100 \%$ \\
\hline & Insuficiente & $30,8 \%$ & 0 \\
\hline \multirow[t]{2}{*}{ Tiene Instrumental } & $\mathrm{Si}$ & $84,6 \%$ & $50 \%$ \\
\hline & No & $15,4 \%$ & $50 \%$ \\
\hline \multirow[t]{2}{*}{ Existen Conflictos } & $\mathrm{Si}$ & $61,5 \%$ & $50 \%$ \\
\hline & No & $38,5 \%$ & $50 \%$ \\
\hline \multirow[t]{3}{*}{ Resolución de conflictos } & $\mathrm{Si}$ & $53,8 \%$ & $50 \%$ \\
\hline & No & $38,4 \%$ & $50 \%$ \\
\hline & No sabe & $7,6 \%$ & \\
\hline \multirow[t]{2}{*}{ Análisis de problemas } & $\mathrm{Si}$ & $69 \%$ & $50 \%$ \\
\hline & No & $31 \%$ & $50 \%$ \\
\hline \multirow{3}{*}{$\begin{array}{l}\text { Actividades de } \\
\text { prevención }\end{array}$} & $\mathrm{Si}$ & 7,6 & 0 \\
\hline & No & $84,8 \%$ & $100 \%$ \\
\hline & No contesta & 7,6 & $14,2 \%$ \\
\hline \multirow[t]{2}{*}{ Siente Reconocimiento } & $\mathrm{Si}$ & $69,2 \%$ & $50 \%$ \\
\hline & No & $30,8 \%$ & $50 \%$ \\
\hline \multirow[t]{2}{*}{ Importancia de su trabajo } & $\mathrm{Si}$ & $100 \%$ & $100 \%$ \\
\hline & No & 0 & 0 \\
\hline Recibe Incentivo & No & $100 \%$ & $100 \%$ \\
\hline \multirow[t]{2}{*}{ Sistema de Información } & $\mathrm{Si}$ & $61,5 \%$ & 0 \\
\hline & No & $38,5 \%$ & $100 \%$ \\
\hline Mejora salud barrio & $\mathrm{Si}$ & $100 \%$ & $100 \%$ \\
\hline \multirow{2}{*}{$\begin{array}{l}\text { Resuelve problemas de } \\
\text { salud }\end{array}$} & $\mathrm{Si}$ & $92,4 \%$ & $50 \%$ \\
\hline & No & $7,6 \%$ & $50 \%$ \\
\hline Recomendaría el CAPS & $\mathrm{Si}$ & $100 \%$ & $100 \%$ \\
\hline \multirow[t]{3}{*}{ Interdisciplina } & $\mathrm{Si}$ & $46 \%$ & $100 \%$ \\
\hline & No & $31 \%$ & 0 \\
\hline & No contesta & $23 \%$ & 0 \\
\hline \multirow[t]{3}{*}{ Trabajo en red } & $\mathrm{Si}$ & $38,4 \%$ & $50 \%$ \\
\hline & No & $46 \%$ & 0 \\
\hline & No contesta & $15,4 \%$ & $50 \%$ \\
\hline \multirow[t]{4}{*}{ Seguimiento del paciente } & Muy bueno & $23 \%$ & $50 \%$ \\
\hline & Bueno & $38,4 \%$ & $50 \%$ \\
\hline & Regular & $23 \%$ & 0 \\
\hline & Malo & 0 & 0 \\
\hline
\end{tabular}




\begin{tabular}{|l|l|l|l|}
\hline & No contesta & $15,4 \%$ & \\
\hline \multirow{3}{*}{ Satisfacción } & $\mathrm{Si}$ & $77 \%$ & $100 \%$ \\
\cline { 2 - 4 } & No & $15,4 \%$ & 0 \\
\cline { 2 - 4 } & No contesta & $7,6 \%$ & \\
\hline
\end{tabular}

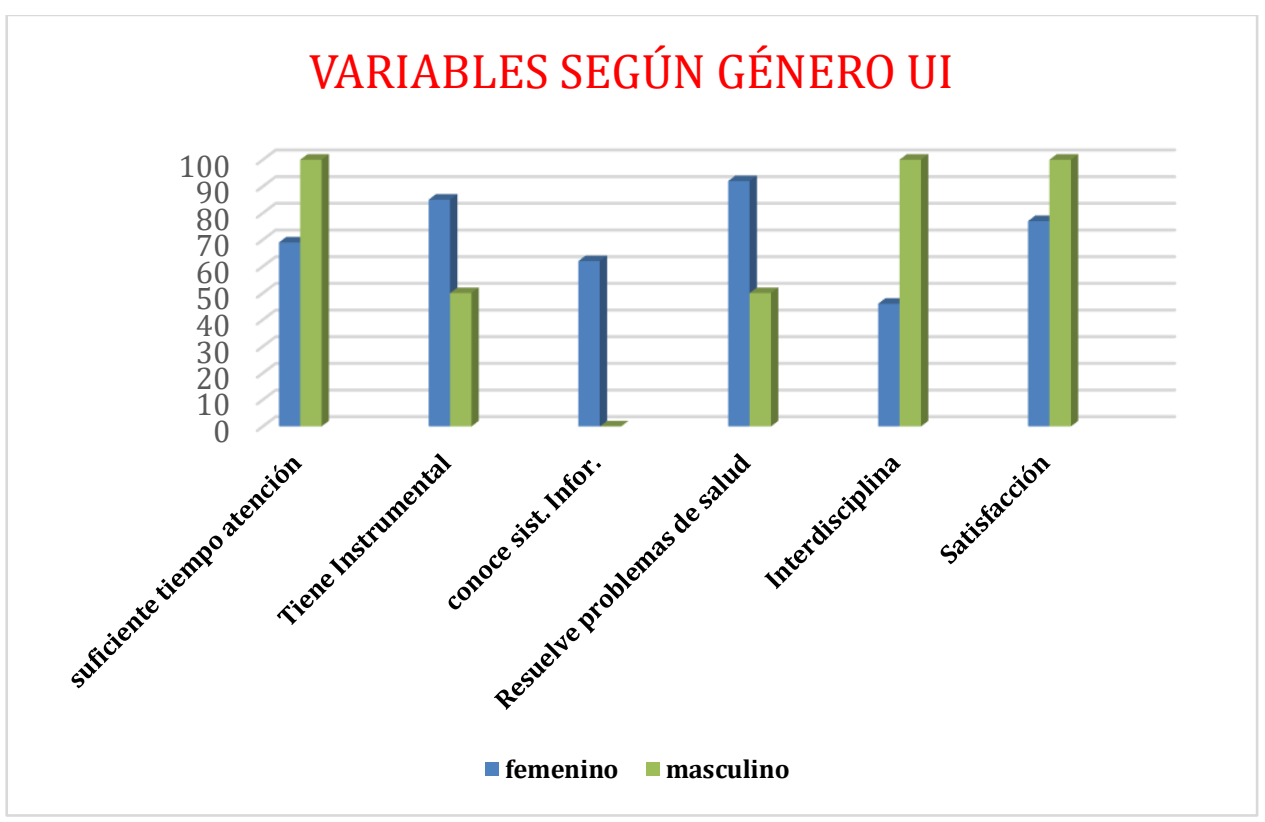

Gráfico $N^{\circ} 6$

\subsection{5-Análisis de las respuestas según la escolaridad de los entrevistados.}

Todos los encuestados coincidieron en que conocen los objetivos del CAPS sin presentar diferencias según la escolaridad. De los usuarios internos que cursaron $1^{\circ}$ y $3^{\circ}$ completos la mitad calificaron el estado de calles y veredas, como regular y la otra mitad como malo, en cambio, solamente como malo el $100 \%$ de los que cursaron $2^{\circ}$ completo. La obtención de turnos fue fácil para la mayoría de los que completaron estudios $2^{\circ}$ y $3^{\circ}$ y sólo para el $50 \%$ de los que completaron la escuela primaria. Todos los usuarios con nivel $1^{\circ}$ completo vieron regular el estado de calles y veredas. Los de $2^{\circ}$ completo se dividieron mitad y mitad entre regular y malo. El 64\%, la mayoría de los que completaron estudios superiores, definieron el estado de calles y veredas como regular. Sobre la limpieza el $100 \%$ de los que completaron la escuela primaria la definió como buena. En cambio, de los que completaron la educación $2^{\circ}$ y $3^{\circ}$, la mitad opinaron que es buena y la otra mitad que es regular. También se vieron diferencias en las respuestas sobre el tiempo de atención. El $50 \%$ de los que cursaron $1^{\circ}$ completo, el $100 \%$ de los que completaron la escuela $2^{\circ}$ y el $64 \%$ de los de educación universitaria contestaron que el tiempo de atención es suficiente. Gran parte de los que completaron instrucción $2^{\circ}$ y superior, refirieron que cuentan con el instrumental necesario para su desempeño, sin embargo, sólo el $50 \%$ de los que completaron la $1^{\circ}$ coincidieron en la respuesta. Admitieron que existen conflictos el $100 \%$ de los usuarios con nivel secundario completo y el $64 \%$ de los trabajadores con título universitario. Pero el total de los que cursaron sólo nivel primario completo, los niega. Con respecto a la resolución de los conflictos, estuvieron de acuerdo el $100 \%$ de los que hicieron escuela primaria únicamente y el $55 \%$ de los que cursaron estudios superiores. En cambio, no estuvieron de acuerdo todos los usuarios con secundario completo. El $100 \%$ de los entrevistados que completaron la escuela primaria participaron en la toma de decisiones en el centro de salud, pero sólo lo 
hicieron el $50 \%$ de los que completaron estudios $2^{\circ}$ y $64 \%$ de los profesionales. Sintieron reconocimiento todos los trabajadores con educación $1^{\circ}$ completa, la mitad de los empleados con $2^{\circ}$ completa y el $64 \%$ de los que cursaron estudios universitarios. Contestaron que no conocen el sistema de información del centro de salud todos los que completaron la escuela primaria, el $50 \%$ de los que terminaron la escuela secundaria y el $36 \%$ de los que cursaron estudios superiores. Refirieron que se realizan actividades de prevención, la mitad de los que completaron la primaria y $91 \%$ de los universitarios, sin embargo, el grupo con educación $2^{\circ}$ completa aseguró que no se hacen. También se observaron diferencias en las respuestas sobre el seguimiento de los pacientes. Los usuarios con $1^{\circ}$ completo opinaron que es muy bueno y bueno. Los empleados con $2^{\circ}$ completo se dividieron mitad y mitad entre bueno y regular y los profesionales en su mayoría contestaron que es muy bueno y bueno. Afirmaron mayor satisfacción los encuestados con educación $1^{\circ}$ y superior, pero sólo la mitad de los que completaron la educación $2^{\circ}$.

\begin{tabular}{|c|c|c|c|c|c|c|c|}
\hline & & $1^{\circ}$ completa & $1^{\circ}$ incompleta & $2^{\circ}$ completa & $2^{\circ}$ incompleta & $3^{\circ}$ completa & $3^{\circ}$ incompleta \\
\hline \multirow[t]{2}{*}{ Objetivos } & $\mathrm{Si}$ & $100 \%$ & & $100 \%$ & & $100 \%$ & \\
\hline & No & 0 & & 0 & & 0 & \\
\hline \multirow[t]{4}{*}{ Calles y veredas } & Muy bueno & 0 & & 0 & & $9 \%$ & \\
\hline & Bueno & 0 & & 0 & & 0 & \\
\hline & Regular & $50 \%$ & & 0 & & $45,5 \%$ & \\
\hline & Malo & $50 \%$ & & $100 \%$ & & $45,5 \%$ & \\
\hline \multirow[t]{2}{*}{ Obtener turno } & Fácil & $50 \%$ & & $100 \%$ & & $91 \%$ & \\
\hline & Difícil & $50 \%$ & & 0 & & $9 \%$ & \\
\hline \multirow{3}{*}{$\begin{array}{l}\text { Estado del } \\
\text { edificio }\end{array}$} & Bueno & 0 & & 0 & & $18 \%$ & \\
\hline & Regular & $100 \%$ & & $50 \%$ & & $64 \%$ & \\
\hline & Malo & 0 & & $50 \%$ & & $18 \%$ & \\
\hline \multirow[t]{4}{*}{ Limpieza } & Muy Buena & 0 & & 0 & & $9 \%$ & \\
\hline & Buena & $100 \%$ & & $50 \%$ & & $45,5 \%$ & \\
\hline & Regular & 0 & & $50 \%$ & & $45,5 \%$ & \\
\hline & Mala & 0 & & 0 & & 0 & \\
\hline Amabilidad & $\mathrm{Si}$ & $100 \%$ & & $100 \%$ & & $100 \%$ & \\
\hline \multirow{2}{*}{$\begin{array}{l}\text { Tiempo de } \\
\text { atención }\end{array}$} & Suficiente & $50 \%$ & & $100 \%$ & & $63,6 \%$ & \\
\hline & Insuficiente & $50 \%$ & & 0 & & $36,4 \%$ & \\
\hline \multirow{2}{*}{$\begin{array}{l}\text { Tiene } \\
\text { Instrumental }\end{array}$} & $\mathrm{Si}$ & $50 \%$ & & $100 \%$ & & $82 \%$ & \\
\hline & No & $50 \%$ & & 0 & & $18 \%$ & \\
\hline \multirow{2}{*}{$\begin{array}{l}\text { Existen } \\
\text { Conflictos }\end{array}$} & $\mathrm{Si}$ & 0 & & $100 \%$ & & $63,6 \%$ & \\
\hline & No & $100 \%$ & & 0 & & $36,4 \%$ & \\
\hline \multirow{3}{*}{$\begin{array}{l}\text { Resolución } \\
\text { conflictos }\end{array}$} & $\mathrm{Si}$ & $100 \%$ & & 0 & & $54,5 \%$ & \\
\hline & No & 0 & & $100 \%$ & & $36,5 \%$ & \\
\hline & No sabe & 0 & & & & $9 \%$ & \\
\hline \multirow{2}{*}{$\begin{array}{l}\text { Análisis } \\
\text { problemas }\end{array}$} & $\mathrm{Si}$ & $100 \%$ & & $50 \%$ & & $63,6 \%$ & \\
\hline & No & 0 & & $50 \%$ & & $36,4 \%$ & \\
\hline \multirow{2}{*}{$\begin{array}{l}\text { Siente } \\
\text { Reconocimiento }\end{array}$} & $\mathrm{Si}$ & $100 \%$ & & $50 \%$ & & $63,3 \%$ & \\
\hline & No & 0 & & $50 \%$ & & $36,4 \%$ & \\
\hline \multirow{2}{*}{$\begin{array}{l}\text { Importancia de } \\
\text { su trabajo }\end{array}$} & $\mathrm{Si}$ & $100 \%$ & & $100 \%$ & & $100 \%$ & \\
\hline & No & 0 & & 0 & & 0 & \\
\hline $\begin{array}{l}\text { Recibe } \\
\text { Incentivo }\end{array}$ & No & $100 \%$ & & $100 \%$ & & $100 \%$ & \\
\hline \multirow{2}{*}{$\begin{array}{l}\text { Sistema de } \\
\text { información }\end{array}$} & $\mathrm{Si}$ & 0 & & $50 \%$ & & $63,6 \%$ & \\
\hline & No & $100 \%$ & & $50 \%$ & & $36,4 \%$ & \\
\hline $\begin{array}{l}\text { Mejora salud } \\
\text { barrio }\end{array}$ & $\mathrm{Si}$ & $100 \%$ & & $100 \%$ & & $100 \%$ & \\
\hline \multirow{2}{*}{$\begin{array}{l}\text { Resuelve } \\
\text { problemas De } \\
\text { salud }\end{array}$} & $\mathrm{Si}$ & $100 \%$ & & $100 \%$ & & $82 \%$ & \\
\hline & No & 0 & & 0 & & $18 \%$ & \\
\hline $\begin{array}{l}\text { Recomendaría } \\
\text { CAPS }\end{array}$ & $\mathrm{Si}$ & $100 \%$ & & $100 \%$ & & $100 \%$ & \\
\hline
\end{tabular}




\begin{tabular}{|c|c|c|c|c|}
\hline \multirow{2}{*}{$\begin{array}{l}\text { Actividades de } \\
\text { prevención }\end{array}$} & Si & $50 \%$ & 0 & $91 \%$ \\
\hline & No & $50 \%$ & $100 \%$ & $9 \%$ \\
\hline \multirow[t]{3}{*}{ Interdisciplina } & $\mathrm{Si}$ & $50 \%$ & $50 \%$ & $54,5 \%$ \\
\hline & No & 0 & $50 \%$ & $27,5 \%$ \\
\hline & $\mathrm{NC}$ & $50 \%$ & & $18 \%$ \\
\hline \multirow[t]{3}{*}{ Trabajo en red } & Si & $50 \%$ & $50 \%$ & $36,4 \%$ \\
\hline & No & 0 & $50 \%$ & $45,5 \%$ \\
\hline & $\mathrm{NC}$ & $50 \%$ & & $18 \%$ \\
\hline \multirow{5}{*}{$\begin{array}{l}\text { Seguimiento del } \\
\text { Paciente }\end{array}$} & Muy bueno & $50 \%$ & 0 & $27,3 \%$ \\
\hline & Bueno & $50 \%$ & $50 \%$ & $36,3 \%$ \\
\hline & Regular & 0 & $50 \%$ & $18,2 \%$ \\
\hline & Malo & 0 & 0 & 0 \\
\hline & NC & & & $18,2 \%$ \\
\hline \multirow[t]{3}{*}{ Satisfacción } & $\mathrm{Si}$ & $100 \%$ & $50 \%$ & $82 \%$ \\
\hline & No & 0 & $50 \%$ & $9 \%$ \\
\hline & $\mathrm{NC}$ & & & $9 \%$ \\
\hline
\end{tabular}

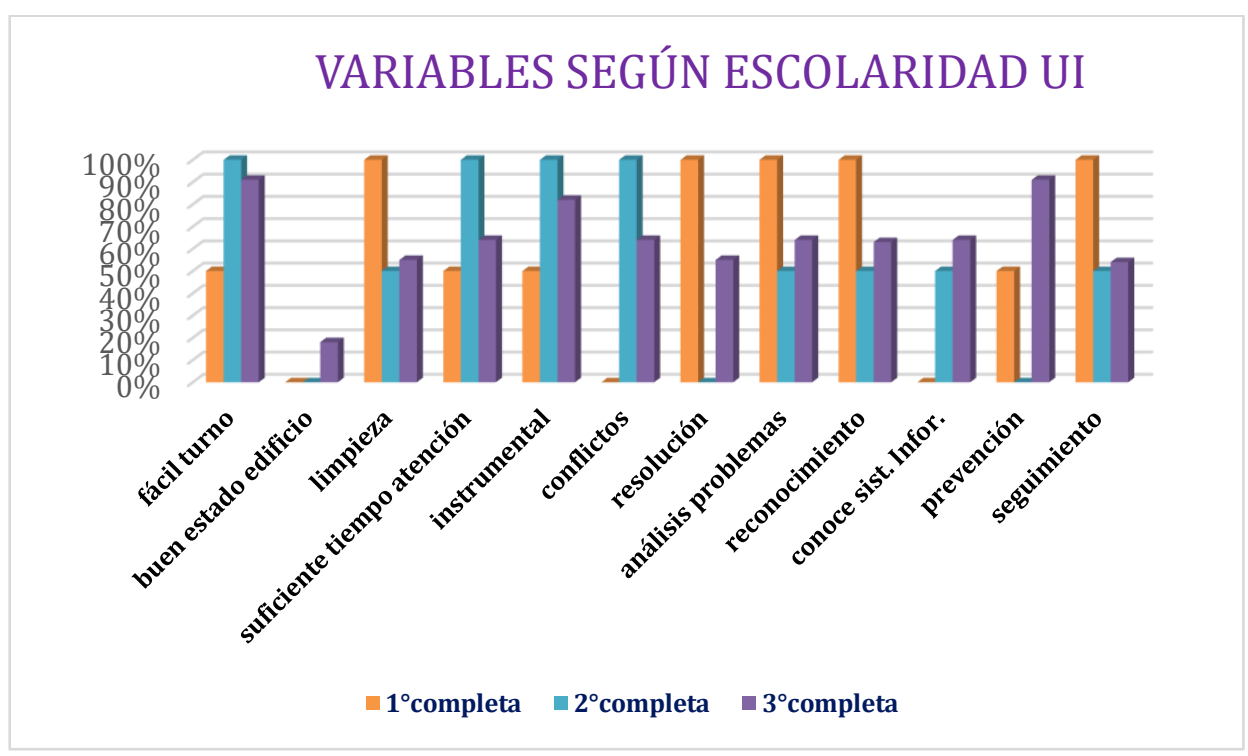

Gráfico $N^{\circ} 7$

\subsection{6 -Análisis de las respuestas según el puesto de trabajo de los entrevistados}

Al analizar las encuestas según el puesto de trabajo, se observaron diferencias en las respuestas sobre el estado de las calles y veredas. El 75\% de los no profesionales opinaron que el estado es malo. La mitad de los profesionales lo definieron como regular y la otra mitad como malo. No hubo diferencias significativas en las preguntas sobre los objetivos que debe cumplir el CAPS, la adjudicación de turnos y el estado del edificio. Los profesionales calificaron la limpieza $55 \%$ como buena y $45 \%$ como regular. El $75 \%$ de los no profesionales como buena y sólo el $25 \%$ como regular. Ambos grupos contestaron igual sobre amabilidad del personal y tiempo de atención. Declararon conflictos entre los trabajadores el $50 \%$ de los no profesionales y $91 \%$ de los profesionales. Estuvo de acuerdo con la resolución de los mismos el $75 \%$ de los primeros y el $54 \%$ de los últimos. En cuanto a si se realizaban actividades de prevención afirmaron que sí el $75 \%$ de los no profesionales y el $91 \%$ de los profesionales. Sintieron reconocimiento el $75 \%$ de los no profesionales y sólo el $64 \%$ de los profesionales. Dijo desconocer el sistema de información la mitad de los no profesionales, y apenas el $36 \%$ de los profesionales. No hubo diferencias en las respuestas 
sobre percepción de mejoría en la salud del barrio, resolución de los problemas de salud, recomendación del CAPS y trabajo interdisciplinario. La mayoría de los trabajadores no profesionales contestaron que se realiza trabajo intersectorial en red, en cambio, coincidieron con ellos tan sólo el $36 \%$ de los profesionales. Se definieron satisfechos el $75 \%$ de los no profesionales y el $82 \%$ de los profesionales, o sea la mayoría de ambos.

\begin{tabular}{|c|c|c|c|}
\hline & & No profesionales & Profesionales \\
\hline \multirow[t]{2}{*}{ Objetivos } & $\mathrm{Si}$ & $100 \%$ & $100 \%$ \\
\hline & No & 0 & 0 \\
\hline \multirow{4}{*}{$\begin{array}{l}\text { Estado de calles y } \\
\text { veredas }\end{array}$} & Muy bueno & 0 & $9 \%$ \\
\hline & Bueno & 0 & 0 \\
\hline & Regular & $25 \%$ & $45,5 \%$ \\
\hline & Malo & $75 \%$ & $45,5 \%$ \\
\hline \multirow[t]{2}{*}{ Obtener turno } & Fácil & $75 \%$ & $91 \%$ \\
\hline & Difícil & $25 \%$ & $9 \%$ \\
\hline \multirow[t]{3}{*}{ Estado del edificio } & Bueno & 0 & $18 \%$ \\
\hline & Regular & $75 \%$ & $64 \%$ \\
\hline & Malo & $25 \%$ & $18 \%$ \\
\hline \multirow[t]{4}{*}{ Limpieza } & Muy Buena & 0 & $9 \%$ \\
\hline & Buena & $75 \%$ & $45,5 \%$ \\
\hline & Regular & $25 \%$ & $45,5 \%$ \\
\hline & Mala & 0 & 0 \\
\hline Amabilidad & $\mathrm{Si}$ & $100 \%$ & $100 \%$ \\
\hline \multirow[t]{2}{*}{ Tiempo de atención } & Suficiente & $75 \%$ & $73 \%$ \\
\hline & Insuficiente & $25 \%$ & $27 \%$ \\
\hline \multirow[t]{2}{*}{ Tiene Instrumental } & $\mathrm{Si}$ & $75 \%$ & $82 \%$ \\
\hline & No & $25 \%$ & $18 \%$ \\
\hline \multirow[t]{2}{*}{ Existen Conflictos } & $\mathrm{Si}$ & $50 \%$ & $91 \%$ \\
\hline & No & $50 \%$ & $9 \%$ \\
\hline \multirow{3}{*}{$\begin{array}{l}\text { Resolución de } \\
\text { conflictos }\end{array}$} & $\mathrm{Si}$ & $75 \%$ & $54,5 \%$ \\
\hline & No & $25 \%$ & $36,5 \%$ \\
\hline & No sabe & & $9 \%$ \\
\hline \multirow{2}{*}{$\begin{array}{l}\text { Análisis de } \\
\text { problemas }\end{array}$} & $\mathrm{Si}$ & $75 \%$ & $63,5 \%$ \\
\hline & No & $25 \%$ & $36,5 \%$ \\
\hline \multirow{3}{*}{$\begin{array}{l}\text { Actividades de } \\
\text { prevención }\end{array}$} & $\mathrm{Si}$ & 0 & $9 \%$ \\
\hline & No & $75 \%$ & $91 \%$ \\
\hline & No contesta & $25 \%$ & \\
\hline \multirow{2}{*}{$\begin{array}{l}\text { Siente } \\
\text { Reconocimiento }\end{array}$} & $\mathrm{Si}$ & $75 \%$ & $63,5 \%$ \\
\hline & No & $25 \%$ & $36,5 \%$ \\
\hline \multirow{2}{*}{$\begin{array}{l}\text { Importancia de su } \\
\text { trabajo }\end{array}$} & $\mathrm{Si}$ & $100 \%$ & $100 \%$ \\
\hline & No & & \\
\hline Recibe Incentivo & No & $100 \%$ & $100 \%$ \\
\hline \multirow{2}{*}{$\begin{array}{l}\text { Sistema de } \\
\text { Información }\end{array}$} & $\mathrm{Si}$ & $50 \%$ & $63,5 \%$ \\
\hline & No & $50 \%$ & $36,5 \%$ \\
\hline Mejora salud barrio & $\mathrm{Si}$ & $100 \%$ & $100 \%$ \\
\hline \multirow{2}{*}{$\begin{array}{l}\text { Resuelve problemas } \\
\text { salud }\end{array}$} & $\mathrm{Si}$ & $100 \%$ & $82 \%$ \\
\hline & No & 0 & $18 \%$ \\
\hline Recomendaría & $\mathrm{Si}$ & $100 \%$ & $100 \%$ \\
\hline \multirow[t]{3}{*}{ Interdisciplina } & $\mathrm{Si}$ & $50 \%$ & $54,5 \%$ \\
\hline & No & $25 \%$ & $27,5 \%$ \\
\hline & No contesta & $25 \%$ & $18 \%$ \\
\hline \multirow[t]{3}{*}{ Trabajo en red } & $\mathrm{Si}$ & $50 \%$ & $36,5 \%$ \\
\hline & No & $25 \%$ & $45,5 \%$ \\
\hline & No contesta & $25 \%$ & $18 \%$ \\
\hline \multirow{3}{*}{$\begin{array}{l}\text { Seguimiento del } \\
\text { paciente }\end{array}$} & Muy bueno & $25 \%$ & $27,5 \%$ \\
\hline & Bueno & $50 \%$ & $36,5 \%$ \\
\hline & Regular & $25 \%$ & $18 \%$ \\
\hline
\end{tabular}




\begin{tabular}{|l|l|l|l|}
\hline \multirow{2}{*}{} & Malo & 0 & 0 \\
\cline { 2 - 4 } & No contesta & & $18 \%$ \\
\hline \multirow{2}{*}{ Satisfacción } & Si & $75 \%$ & $82 \%$ \\
\cline { 2 - 4 } & No & $25 \%$ & $9 \%$ \\
\cline { 2 - 4 } & No contesta & & $9 \%$ \\
\hline
\end{tabular}

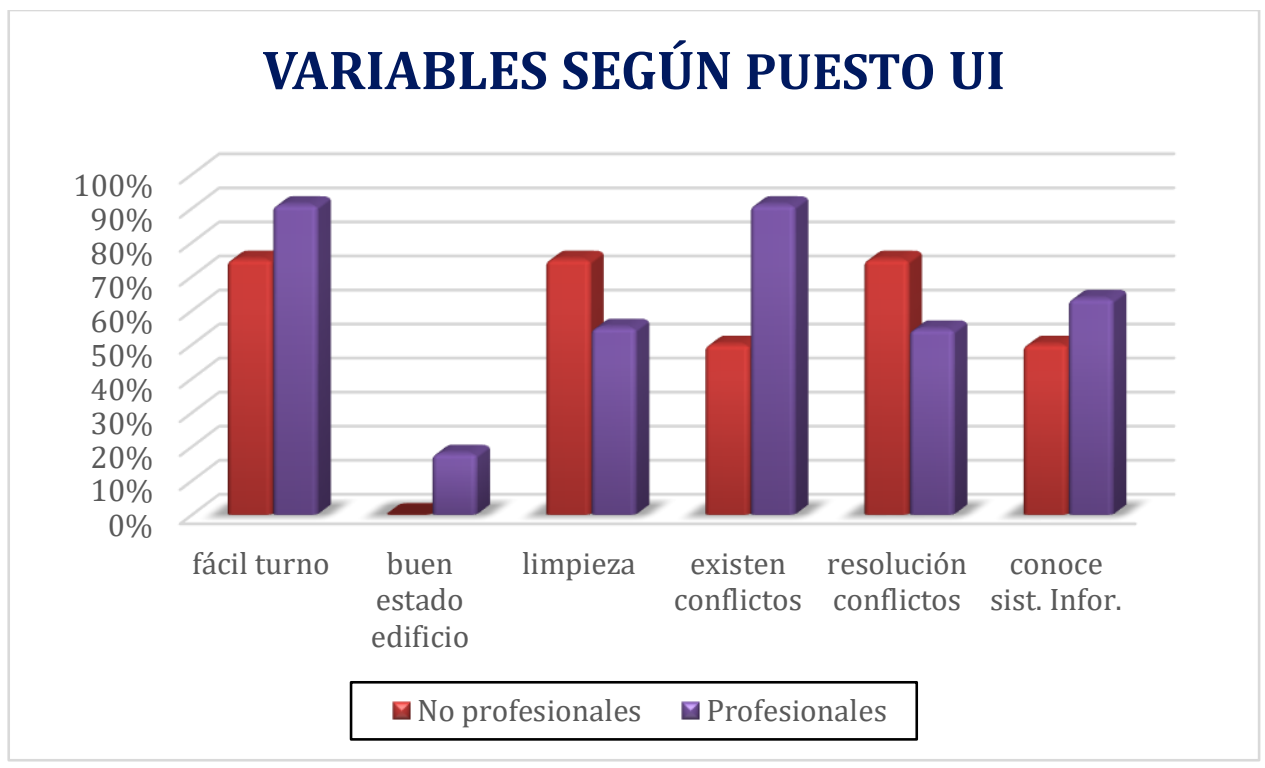

Gráfico $\mathbf{N}^{\circ} 8$

\subsection{7- Análisis de las respuestas según la antigüedad de los entrevistados}

Todos los usuarios internos respondieron que conocen los objetivos del centro de salud. Los que trabajan en el CAPS hace menos de un año opinaron que el estado de calles y veredas es malo, igual que la mitad de los que tienen más de 10 años de antigüedad. Los que están hace 1 a 5 años lo calificaron como regular y se dividieron entre regular y malo, los que están empleados hace 6 a 10 años. Todos los entrevistados aseguraron que es fácil sacar un turno, excepto el $50 \%$ de los que trabajan hace 6 a 10 años que contestaron que es difícil. Cuando respondieron por el estado del edificio, los que tienen menos de 1 año trabajando dijeron que es bueno, los que están hace 1 a 5 años se dividieron mitad y mitad entre bueno y regular, los que trabajan hace 6 a 10 años y más de 10 años opinaron que el estado edilicio es regular y malo. Los empleados con menos de 1 año de antigüedad calificaron regular la limpieza, los de 1 a 5 años se dividieron 50\% y 50\% entre buena y regular, los de 6 a 10 años en su mayoría expresaron que es buena y el 75\% de los más antiguos la evaluaron como regular. La mayoría de los entrevistados respondieron que el tiempo de atención es suficiente. En cambio, el $37 \%$ de los que trabajan hace 6 a 10 años y el 25\% de los de más de 10 años opinaron que es insuficiente. Afirmaron que cuentan con el instrumental para su labor el $100 \%$ de los que tienen menor y mayor antigüedad en el CAPS, el $50 \%$ de los que trabajan hace 1 a 5 años y el $75 \%$ del grupo de 6 a 10 años. Admitieron conflictos entre el personal todos los que tienen menor y mayor tiempo trabajando. Los negaron todos los que trabajan hace 1 a 5 años y la mitad de los de 6 a 10 años. Estuvieron de acuerdo con la resolución de los mismos, el 100\% de los que están empleados hace 1 a 5 años y el $50 \%$ de los más antiguos, en cambio, no estuvieron de acuerdo los que tienen menos de 1 año en el CAPS. Participaron en el análisis de los problemas del centro de salud el $100 \%$ de los que tienen menos de 6 años de antigüedad, el 50\% de los que trabajan hace 6 a 10 años y 75\% 
de los usuarios con más de 10 años. Sintieron reconocimiento el $100 \%$ de los usuarios internos con menos de 6 años en el CAPS, 50\% de los que están hace 6 a 10 años y 75\% de los más antiguos. Respondieron que conocen el sistema de información del centro de salud la totalidad de los empleados más nuevos y más antiguos, el 38\% de los que trabajan hace 6 a 10 años y ninguno de los que están hace 1 a 5 años. Todos los entrevistados opinaron que el centro de salud mejoró la salud del barrio y lo recomendaron. Con respecto a la resolución de los problemas de salud también todos contestaron afirmativamente, excepto el $50 \%$ de los que hace 1 a 5 años que trabaja en el CAPS. Aseguraron que existe trabajo interdisciplinario el $50 \%$ de los que están empleados hace 1 a 10 años y el $75 \%$ de los mayores de 10 años de antigüedad, en cambio el 100\% de los más nuevos contestaron que no. Sobre el trabajo intersectorial, los usuarios internos con menos de 1 año respondieron que no se hace, los de 1 a 5 años no contestaron y el 50\% de los empleados de 6 a 10 años y más de 10 años estimaron que se trabaja en red. En cuanto al seguimiento de los pacientes, en general, opinaron que es bueno, salvo por el $50 \%$ de los más antiguos que lo calificaron como regular. Refirieron satisfacción el $100 \%$ de los trabajadores con 1 a 5 años de antigüedad, el $88 \%$ de los usuarios con 6 a 10 años y el $75 \%$ de los de más de 10 años. No estuvieron satisfechos todos los que trabajan hace menos de 1 año.

\begin{tabular}{|c|c|c|c|c|c|}
\hline & & $<1$ año & 1-5 años & 6-10años & >10años \\
\hline \multirow[t]{2}{*}{ Objetivos } & $\mathrm{Si}$ & $100 \%$ & $100 \%$ & $100 \%$ & $100 \%$ \\
\hline & No & 0 & 0 & 0 & \\
\hline \multirow[t]{4}{*}{ Calles y veredas } & Muy bueno & 0 & 0 & 0 & $25 \%$ \\
\hline & Bueno & 0 & 0 & 0 & 0 \\
\hline & Regular & 0 & $100 \%$ & $37,5 \%$ & $25 \%$ \\
\hline & Malo & $100 \%$ & 0 & $62,5 \%$ & $50 \%$ \\
\hline \multirow[t]{2}{*}{ Obtener turno } & Fácil & $100 \%$ & $100 \%$ & $50 \%$ & $100 \%$ \\
\hline & Difícil & 0 & 0 & $50 \%$ & 0 \\
\hline \multirow[t]{3}{*}{ Estado del edificio } & Bueno & 0 & $50 \%$ & $12,5 \%$ & 0 \\
\hline & Regular & $100 \%$ & $50 \%$ & $62,5 \%$ & $75 \%$ \\
\hline & Malo & 0 & 0 & $25 \%$ & $25 \%$ \\
\hline \multirow[t]{4}{*}{ Limpieza } & Muy Buena & 0 & 0 & $12,5 \%$ & 0 \\
\hline & Buena & 0 & $50 \%$ & $75 \%$ & $25 \%$ \\
\hline & Regular & $100 \%$ & $50 \%$ & $12,5 \%$ & $75 \%$ \\
\hline & Mala & 0 & 0 & 0 & 0 \\
\hline Amabilidad & $\mathrm{Si}$ & $100 \%$ & $100 \%$ & $100 \%$ & $100 \%$ \\
\hline \multirow[t]{2}{*}{ Tiempo de atención } & Suficiente & $100 \%$ & $100 \%$ & $62,5 \%$ & $75 \%$ \\
\hline & Insuficiente & 0 & 0 & $37,5 \%$ & $25 \%$ \\
\hline \multirow[t]{2}{*}{ Tiene Instrumental } & $\mathrm{Si}$ & $100 \%$ & $50 \%$ & $75 \%$ & $100 \%$ \\
\hline & No & 0 & $50 \%$ & $25 \%$ & 0 \\
\hline \multirow[t]{2}{*}{ Existen Conflictos } & $\mathrm{Si}$ & $100 \%$ & 0 & $50 \%$ & $100 \%$ \\
\hline & No & 0 & $100 \%$ & $50 \%$ & 0 \\
\hline \multirow{3}{*}{$\begin{array}{l}\text { Resolución de } \\
\text { conflictos }\end{array}$} & $\mathrm{Si}$ & 0 & $100 \%$ & $50 \%$ & $50 \%$ \\
\hline & No & $100 \%$ & 0 & $37,5 \%$ & $50 \%$ \\
\hline & No sabe & & & $12,5 \%$ & \\
\hline \multirow{2}{*}{$\begin{array}{l}\text { Análisis de } \\
\text { problemas }\end{array}$} & $\mathrm{Si}$ & $100 \%$ & $100 \%$ & $50 \%$ & $75 \%$ \\
\hline & No & 0 & 0 & $50 \%$ & $25 \%$ \\
\hline \multirow{2}{*}{$\begin{array}{l}\text { Siente } \\
\text { Reconocimiento }\end{array}$} & $\mathrm{Si}$ & $100 \%$ & $100 \%$ & $50 \%$ & $75 \%$ \\
\hline & No & 0 & 0 & $50 \%$ & $25 \%$ \\
\hline \multirow{2}{*}{$\begin{array}{l}\text { Importancia de su } \\
\text { trabajo }\end{array}$} & $\mathrm{Si}$ & $100 \%$ & $100 \%$ & $100 \%$ & $100 \%$ \\
\hline & No & & & & \\
\hline Recibe Incentivo & No & $100 \%$ & $100 \%$ & $100 \%$ & $100 \%$ \\
\hline \multirow{2}{*}{$\begin{array}{l}\text { Sistema de } \\
\text { información }\end{array}$} & $\mathrm{Si}$ & $100 \%$ & 0 & $37,5 \%$ & $100 \%$ \\
\hline & No & 0 & $100 \%$ & $62,5 \%$ & 0 \\
\hline
\end{tabular}




\begin{tabular}{|c|c|c|c|c|c|}
\hline Mejora salud barrio & $\mathrm{Si}$ & $100 \%$ & $100 \%$ & $100 \%$ & $100 \%$ \\
\hline \multirow{2}{*}{$\begin{array}{l}\text { Resuelve } \\
\text { problemas salud }\end{array}$} & $\mathrm{Si}$ & $100 \%$ & $50 \%$ & $87,5 \%$ & $100 \%$ \\
\hline & No & 0 & $50 \%$ & $12,5 \%$ & 0 \\
\hline Recomendaría & $\mathrm{Si}$ & $100 \%$ & $100 \%$ & $100 \%$ & $100 \%$ \\
\hline \multirow{3}{*}{$\begin{array}{l}\text { Actividades De } \\
\text { prevención }\end{array}$} & SI & 0 & 0 & 0 & $25 \%$ \\
\hline & NO & $100 \%$ & $50 \%$ & $100 \%$ & $75 \%$ \\
\hline & $\mathrm{NC}$ & & $50 \%$ & & \\
\hline \multirow[t]{3}{*}{ Interdisciplina } & $\mathrm{Si}$ & 0 & $50 \%$ & $50 \%$ & $75 \%$ \\
\hline & No & $100 \%$ & $0 \%$ & $37,5 \%$ & 0 \\
\hline & $\mathrm{NC}$ & & $50 \%$ & $12,5 \%$ & $25 \%$ \\
\hline \multirow[t]{3}{*}{ Trabajo en red } & $\mathrm{Si}$ & 0 & 0 & $50 \%$ & $50 \%$ \\
\hline & No & $100 \%$ & 0 & $37,5 \%$ & $50 \%$ \\
\hline & $\mathrm{NC}$ & & $100 \%$ & $12,5 \%$ & \\
\hline \multirow{5}{*}{$\begin{array}{l}\text { Seguimiento del } \\
\text { Paciente }\end{array}$} & Muy bueno & 0 & $50 \%$ & $25 \%$ & $25 \%$ \\
\hline & Bueno & $100 \%$ & $50 \%$ & $37,5 \%$ & $25 \%$ \\
\hline & Regular & 0 & 0 & $12,5 \%$ & $50 \%$ \\
\hline & Malo & 0 & 0 & 0 & 0 \\
\hline & NC & & & $25 \%$ & \\
\hline \multirow[t]{3}{*}{ Satisfacción } & $\mathrm{Si}$ & 0 & $100 \%$ & $87,5 \%$ & $75 \%$ \\
\hline & No & $100 \%$ & 0 & 0 & $25 \%$ \\
\hline & $\mathrm{NC}$ & & & $12,5 \%$ & \\
\hline
\end{tabular}

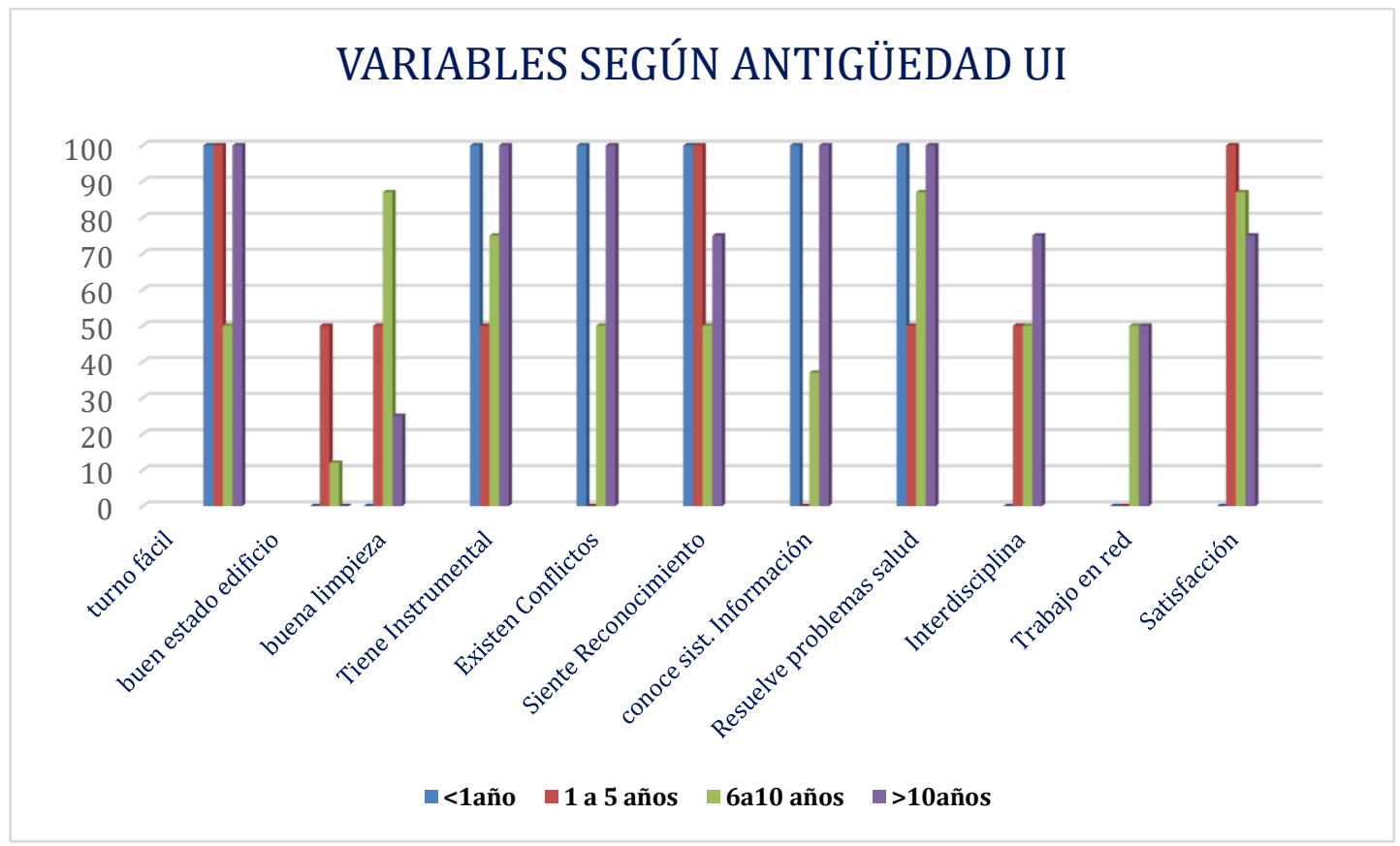

Gráfico $\mathbf{N}^{\circ} 9$

\subsection{8- Análisis de las respuestas según las horas de trabajo de los entrevistados}

Del análisis de las respuestas según las horas de trabajo por semana, se obtuvo que sólo el $25 \%$ de los que trabajan más de 30 horas semanales evaluó el estado de las calles y veredas como buena, el resto de los entrevistados lo calificaron como regular y malo. La mayoría de los tres grupos opinó que es fácil conseguir turno y que el estado del edificio es regular o malo. Sobre la limpieza únicamente los que trabajan entre 10 a 30 horas dijeron que es muy buena y buena. Los demás se dividieron entre buena y regular. Todos contestaron que el personal es amable y de las tres categorías un alto porcentaje afirmó que el tiempo de atención es suficiente. De los que asisten entre 10 y 30 horas un tercio respondió que no 
cuenta con el instrumental suficiente para su labor. Todos aceptaron que tienen conflictos, pero con mayor porcentaje (75\%) los que trabajan más horas que, a su vez, estuvieron en un $100 \%$ conformes con la resolución de los mismos. En cuanto a la participación en el análisis y la resolución de problemas, los que cumplen entre 10 y 30 horas refirieron en su mayoría que no participan, al contrario de los otros grupos. Sólo el $25 \%$ de los usuarios que concurren más de 30 horas respondieron que realizan actividades de prevención. El $67 \%$ de los que trabajan entre 10 a 30 horas no se sintió reconocido, el resto, en general sí. Un alto porcentaje de los entrevistados contestó que conoce el sistema de información, excepto, los empleados entre 10 y 30 horas que aseguraron desconocerlo en un 67\%. Los encuestados con menos de 6 horas fueron los únicos que en un $80 \%$ afirmaron que se atiende en forma interdisciplinaria, los demás grupos en su mayoría respondieron que no. Sobre si se realiza trabajo intersectorial, la mitad aproximadamente de las dos primeras categorías opinaron que sí, en cambio la que tiene más carga horaria refirió, en gran parte, que no. La mayoría de los usuarios respondió que el seguimiento de los pacientes es bueno. Se observó un alto porcentaje de satisfacción, siendo el menor, con $60 \%$ solamente, para los trabajadores que cumplen 6 horas semanales.

\begin{tabular}{|c|c|c|c|c|}
\hline & & Hasta 6hs & 10 a 30hs & $>30 \mathrm{hs}$ \\
\hline \multirow[t]{2}{*}{ Objetivos } & $\mathrm{Si}$ & $100 \%$ & $100 \%$ & $100 \%$ \\
\hline & No & 0 & 0 & 0 \\
\hline \multirow[t]{4}{*}{ Estado de calles y veredas } & Muy bueno & 0 & 0 & $25 \%$ \\
\hline & Bueno & 0 & 0 & 0 \\
\hline & Regular & $40 \%$ & $50 \%$ & $25 \%$ \\
\hline & Malo & $60 \%$ & $50 \%$ & $50 \%$ \\
\hline \multirow[t]{2}{*}{ Obtener turno } & Fácil & $80 \%$ & $100 \%$ & $75 \%$ \\
\hline & Difícil & $20 \%$ & 0 & $25 \%$ \\
\hline \multirow[t]{3}{*}{ Estado edificio } & Bueno & $20 \%$ & $16,6 \%$ & 0 \\
\hline & Regular & $80 \%$ & $66,6 \%$ & $50 \%$ \\
\hline & Malo & 0 & $16,6 \%$ & $50 \%$ \\
\hline \multirow[t]{4}{*}{ Limpieza } & Muy Buena & 0 & $16,6 \%$ & 0 \\
\hline & Buena & $40 \%$ & $83,3 \%$ & $25 \%$ \\
\hline & Regular & $60 \%$ & 0 & $75 \%$ \\
\hline & Mala & 0 & 0 & 0 \\
\hline Amabilidad & $\mathrm{Si}$ & $100 \%$ & $100 \%$ & $100 \%$ \\
\hline \multirow[t]{2}{*}{ Tiempo de atención } & Suficiente & $60 \%$ & $83,3 \%$ & $75 \%$ \\
\hline & Insuficiente & $40 \%$ & $16,6 \%$ & $25 \%$ \\
\hline \multirow[t]{2}{*}{ Tiene Instrumental } & $\mathrm{Si}$ & $100 \%$ & $66,6 \%$ & $75 \%$ \\
\hline & No & 0 & $33,4 \%$ & $25 \%$ \\
\hline \multirow[t]{2}{*}{ Existen Conflictos } & $\mathrm{Si}$ & $60 \%$ & $50 \%$ & $75 \%$ \\
\hline & No & $40 \%$ & $50 \%$ & $25 \%$ \\
\hline \multirow[t]{3}{*}{ Resolución de conflictos } & $\mathrm{Si}$ & $40 \%$ & $33,3 \%$ & $100 \%$ \\
\hline & No & $60 \%$ & $50 \%$ & 0 \\
\hline & No sabe & & $16,6 \%$ & \\
\hline \multirow[t]{2}{*}{ Análisis de problemas } & $\mathrm{Si}$ & $80 \%$ & $33,4 \%$ & $100 \%$ \\
\hline & No & $20 \%$ & $66,6 \%$ & 0 \\
\hline \multirow[t]{3}{*}{ Actividades de prevención } & $\mathrm{Si}$ & 0 & 0 & $25 \%$ \\
\hline & No & $100 \%$ & $100 \%$ & $50 \%$ \\
\hline & No contesta & & & $25 \%$ \\
\hline \multirow[t]{2}{*}{ Siente Reconocimiento } & $\mathrm{Si}$ & $80 \%$ & $33,4 \%$ & $100 \%$ \\
\hline & No & $20 \%$ & $66,6 \%$ & 0 \\
\hline Importancia trabajo & $\mathrm{Si}$ & $100 \%$ & $100 \%$ & $100 \%$ \\
\hline Recibe incentivo & No & $100 \%$ & $100 \%$ & $100 \%$ \\
\hline \multirow[t]{2}{*}{ Sistema de Información } & $\mathrm{Si}$ & $60 \%$ & $33,4 \%$ & $75 \%$ \\
\hline & No & $40 \%$ & $66,6 \%$ & $25 \%$ \\
\hline
\end{tabular}




\begin{tabular}{|c|c|c|c|c|}
\hline Mejora salud del barrio & $\mathrm{Si}$ & $100 \%$ & $100 \%$ & $100 \%$ \\
\hline \multirow[t]{2}{*}{ Resuelve problemas de salud } & $\mathrm{Si}$ & $80 \%$ & $83,3 \%$ & $100 \%$ \\
\hline & No & $20 \%$ & $16,6 \%$ & 0 \\
\hline Recomendaría CAPS & $\mathrm{Si}$ & $100 \%$ & $100 \%$ & $100 \%$ \\
\hline \multirow[t]{3}{*}{ Interdisciplina } & $\mathrm{Si}$ & $80 \%$ & $50 \%$ & $25 \%$ \\
\hline & No & $20 \%$ & $33,4 \%$ & $25 \%$ \\
\hline & No contesta & & $16,6 \%$ & $50 \%$ \\
\hline \multirow[t]{3}{*}{ Trabajo en red } & $\mathrm{Si}$ & $40 \%$ & $50 \%$ & $25 \%$ \\
\hline & No & $40 \%$ & $33,4 \%$ & $50 \%$ \\
\hline & No contesta & $20 \%$ & 16,65 & $25 \%$ \\
\hline \multirow[t]{5}{*}{ Seguimiento del paciente } & Muy bueno & $60 \%$ & $16,6 \%$ & 0 \\
\hline & Bueno & $20 \%$ & $50 \%$ & $50 \%$ \\
\hline & Regular & $20 \%$ & $16,6 \%$ & $25 \%$ \\
\hline & malo & 0 & 0 & 0 \\
\hline & No contesta & & $16,6 \%$ & $25 \%$ \\
\hline \multirow[t]{3}{*}{ Satisfacción } & $\mathrm{Si}$ & $60 \%$ & $83,3 \%$ & $100 \%$ \\
\hline & No & $40 \%$ & 0 & 0 \\
\hline & No contesta & & $16,6 \%$ & \\
\hline
\end{tabular}

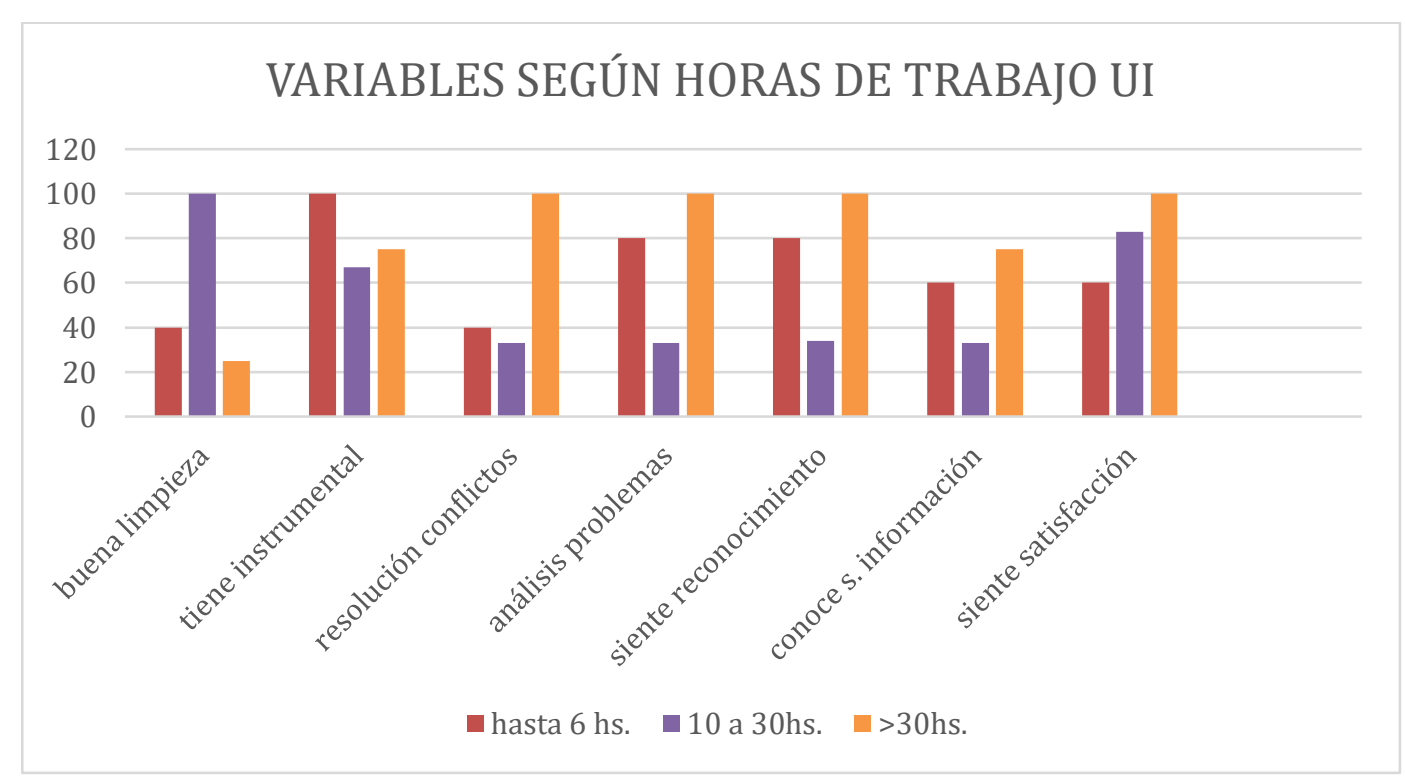

Gráfico N¹0

\section{3-Análisis de las variables de la entrevista cerrada usuario externo}

Se realizaron 265 entrevistas cerradas en forma anónima en la sala de espera del CAPS a las personas mayores de edad que aceptaron colaborar con este estudio.

\subsection{1-Análisis variables sociodemográficas de los entrevistados}

El $74 \%$ de los entrevistados fue de género femenino y las edades abarcaron entre 18 y 72 años. En cuanto a la ocupación la mitad respondió que era ama de casa, $22 \%$ que eran empleados y los demás, en pequeño número, contestaron que eran jubilados, desempleados, estudiantes, personas con oficios, que hacen changas y comerciantes. Si analizamos la escolaridad, el mayor porcentaje correspondió a secundaria incompleta, seguido de primaria completa y luego secundaria completa. $65 \%$ de los encuestados 
contestaron que eran solteros, $25 \%$ casados y un pequeña cantidad, que eran viudos y divorciados.

\begin{tabular}{|c|c|c|}
\hline Género & Femenino $73,9 \%$ & Masculino $26,1 \%$ \\
\hline \multirow[t]{2}{*}{ Edad } & 18 a 72 años & Mediana 42 \\
\hline & no contesta & $3,3 \%$ \\
\hline \multirow[t]{10}{*}{ Ocupación } & Ama de casa & $45,6 \%$ \\
\hline & Empleados & $22,6 \%$ \\
\hline & Jubilados & $6 \%$ \\
\hline & Desempleados & $7,5 \%$ \\
\hline & Estudiantes & $3 \%$ \\
\hline & Oficio & $6,4 \%$ \\
\hline & Comerciantes & $1,9 \%$ \\
\hline & Changa & $1,1 \%$ \\
\hline & Profesionales & $2,2 \%$ \\
\hline & No contesta & $3 \%$ \\
\hline \multirow[t]{7}{*}{ Escolaridad } & Primaria completa & $24,1 \%$ \\
\hline & Primaria incompleta & $7,1 \%$ \\
\hline & Secundaria completa & $18,4 \%$ \\
\hline & Secundaria incompleta & $32 \%$ \\
\hline & Terciario completo & $5,2 \%$ \\
\hline & Terciario incompleto & $4,5 \%$ \\
\hline & No contesta & $3,3 \%$ \\
\hline \multirow[t]{5}{*}{ Estado civil } & Soltero & $65,6 \%$ \\
\hline & Casado & $25,2 \%$ \\
\hline & Viudo & $1,1 \%$ \\
\hline & Divorciado & $7,1 \%$ \\
\hline & No contesta & $0,7 \%$ \\
\hline
\end{tabular}

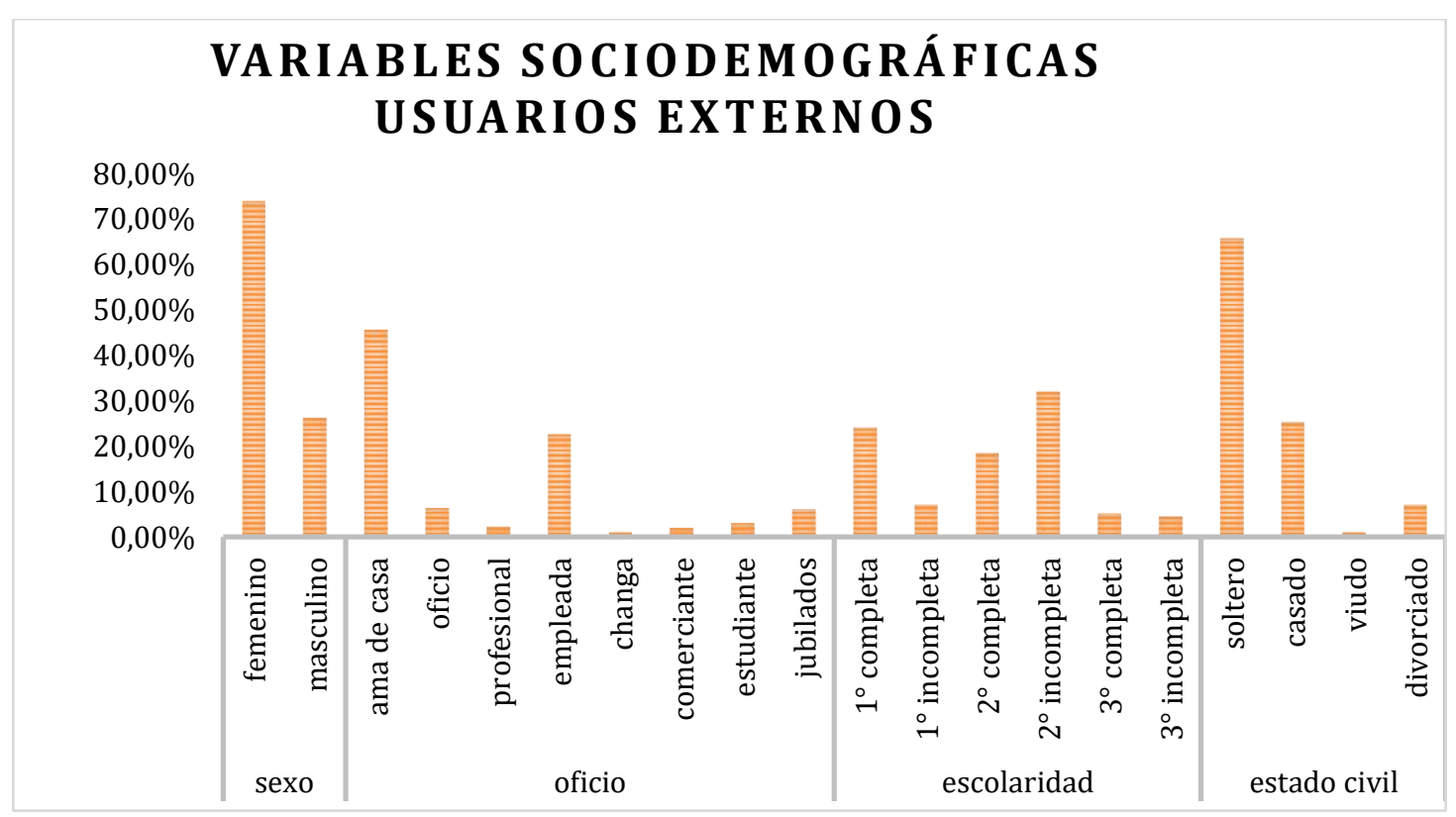

Gráfico N¹1

\subsection{2-Análisis variables de estructura, proceso y resultado}

Los encuestados calificaron al CAPS como muy bueno y bueno. La mitad contestó que el estado de calles y veredas de acceso es bueno y la mitad que no. La mayoría de los usuarios 
externos opinó que la sala de espera es cómoda, que el edificio está en buenas condiciones y que la limpieza es muy buena y buena. Casi el $80 \%$ de los entrevistados dijeron que es fácil sacar un turno y que siempre o casi siempre que lo solicitaron para el médico u otro profesional, lo consiguieron. Aumentó, casi al $100 \%$, cuando requirieron la atención de la enfermera. Más del $95 \%$ de los encuestados contestaron que el personal es amable, que están conformes con la atención, que es suficiente el tiempo de atención y que entienden las indicaciones del profesional. Más del $90 \%$ de los entrevistados opinaron que el CAPS resuelve los problemas de salud de la población y que ha mejorado su propio estado de salud, siempre o casi siempre. Casi el $100 \%$ de los usuarios externos afirmaron que volverían a atenderse en el centro de salud y que lo recomiendan. Sólo el $10 \%$ dijo que consigue a veces los medicamentos, el resto siempre o casi siempre.

\begin{tabular}{|c|c|c|}
\hline \multirow[t]{5}{*}{ Califica al CAPS } & Muy Bueno & $65,2 \%$ \\
\hline & Bueno & $32,4 \%$ \\
\hline & Regular & $0,4 \%$ \\
\hline & Malo & $0,4 \%$ \\
\hline & No contesta & $1,9 \%$ \\
\hline \multirow[t]{3}{*}{ Buen estado de Calles y vereda } & SI & $51,6 \%$ \\
\hline & NO & $45 \%$ \\
\hline & No contesta & $3,4 \%$ \\
\hline \multirow[t]{3}{*}{ Sala de espera Cómoda } & $\mathrm{SI}$ & $88 \%$ \\
\hline & NO & $8 \%$ \\
\hline & No contesta & $4 \%$ \\
\hline \multirow[t]{5}{*}{ Estado del edificio } & $\mathrm{MB}$ & $28,3 \%$ \\
\hline & B & $55,8 \%$ \\
\hline & $\mathrm{R}$ & $13,2 \%$ \\
\hline & $\mathrm{M}$ & $1,9 \%$ \\
\hline & No contesta & $0,7 \%$ \\
\hline \multirow[t]{5}{*}{ Limpieza } & Muy buena & $49 \%$ \\
\hline & Buena & $46 \%$ \\
\hline & Regular & $3,7 \%$ \\
\hline & Mala & 0 \\
\hline & No contesta & $1,1 \%$ \\
\hline \multirow[t]{3}{*}{ Conseguir Turno } & Fácil & $78,3 \%$ \\
\hline & Difícil & $20,7 \%$ \\
\hline & No contesta & $1 \%$ \\
\hline \multirow[t]{5}{*}{ Turno Médico Consigue } & Siempre & $57 \%$ \\
\hline & Casi siempre & $19,6 \%$ \\
\hline & A veces & $22,6 \%$ \\
\hline & Nunca & $0,4 \%$ \\
\hline & No contesta & $0,4 \%$ \\
\hline \multirow[t]{5}{*}{ Turno profesional Consigue } & Siempre & $49,4 \%$ \\
\hline & Casi siempre & $22,6 \%$ \\
\hline & A veces & $21,8 \%$ \\
\hline & Nunca & $0,7 \%$ \\
\hline & No contesta & $5,2 \%$ \\
\hline \multirow[t]{5}{*}{ Turno enfermera Consigue } & Siempre & $92,4 \%$ \\
\hline & Casi siempre & $4,5 \%$ \\
\hline & A veces & $0,7 \%$ \\
\hline & Nunca & $0,4 \%$ \\
\hline & No contesta & $2 \%$ \\
\hline \multirow[t]{3}{*}{ Personal amable } & $\mathrm{Si}$ & $96 \%$ \\
\hline & No & $0,7 \%$ \\
\hline & No contesta & $3,4 \%$ \\
\hline \multirow[t]{3}{*}{ Conforme con la Atención } & $\mathrm{Si}$ & $98,4 \%$ \\
\hline & No & $0,4 \%$ \\
\hline & No contesta & $1,1 \%$ \\
\hline \multirow[t]{2}{*}{ Tiempo de atención } & Suficiente & $95,4 \%$ \\
\hline & Insuficiente & $4,1 \%$ \\
\hline
\end{tabular}




\begin{tabular}{|l|l|l|}
\hline \multirow{4}{*}{ Indicaciones claras } & No contesta & $0,4 \%$ \\
\hline \multirow{5}{*}{ Resolución problema de salud } & Si & $96,2 \%$ \\
\cline { 2 - 3 } & No & $2,7 \%$ \\
\cline { 2 - 3 } & No contesta & $1,1 \%$ \\
\cline { 2 - 3 } & Siempre & $76 \%$ \\
\cline { 2 - 3 } & Casi siempre & $17 \%$ \\
\cline { 2 - 3 } & A veces & $7 \%$ \\
\hline \multirow{5}{*}{ Mejora su salud } & Nunca & 0 \\
\cline { 2 - 3 } & Siempre & $82 \%$ \\
\cline { 2 - 3 } & Casi siempre & $12 \%$ \\
\cline { 2 - 3 } & A veces & $4 \%$ \\
\cline { 2 - 3 } & Nunca & $2 \%$ \\
\hline Volvería a atenderse & No contesta & $0,4 \%$ \\
\hline \multirow{5}{*}{ Recomendaría el CAPS } & Si & $99,6 \%$ \\
\cline { 2 - 3 } & No & $0,4 \%$ \\
\hline Consigue Medicamentos & Si & $97,3 \%$ \\
\cline { 2 - 3 } & No & $2 \%$ \\
\cline { 2 - 3 } & No contesta & $0,7 \%$ \\
\hline & Siempre & $74 \%$ \\
\cline { 2 - 3 } & Casi siempre & $15 \%$ \\
\cline { 2 - 3 } & A veces & $9,8 \%$ \\
\cline { 2 - 3 } & Nunca & $1,1 \%$ \\
\cline { 2 - 3 } & No contesta & $0,4 \%$ \\
\hline
\end{tabular}

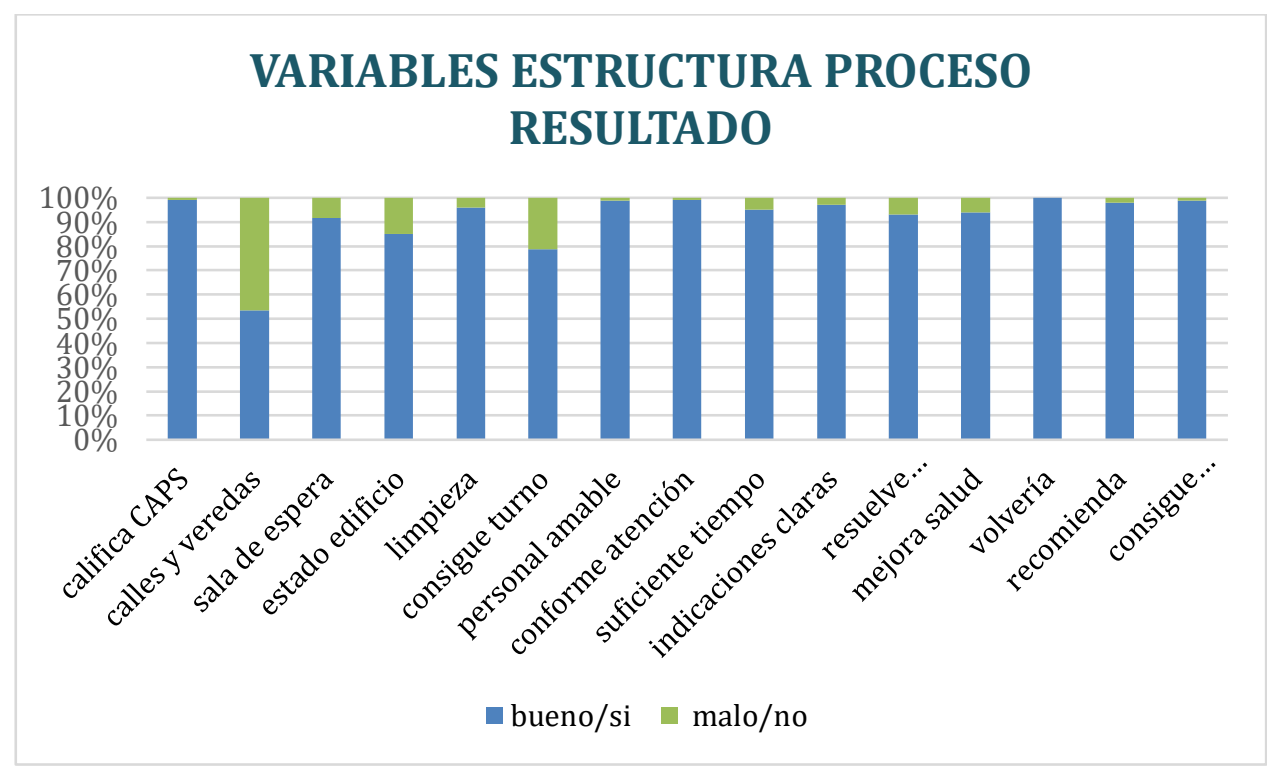

Gráfico N¹2

\subsection{3-Análisis de las respuestas según el género de los entrevistados}

Cuando se analizaron las respuestas según el género de los entrevistados no se observaron diferencias significativas. Existió coincidencia en la percepción de las variables de estructura, proceso y resultado en ambos grupos.

\begin{tabular}{|l|l|l|l|}
\hline & & FEMENINO & MASCULINO \\
\hline \multirow{3}{*}{ Califica al CAPS } & Muy Bueno & $68,7 \%$ & $58 \%$ \\
\cline { 2 - 4 } & Bueno & $30,8 \%$ & $39 \%$ \\
\cline { 2 - 4 } & Regular & $0 \%$ & $1 \%$ \\
\hline
\end{tabular}




\begin{tabular}{|c|c|c|c|}
\hline & Malo & $0,5 \%$ & $0 \%$ \\
\hline & no sabe & $0 \%$ & $2 \%$ \\
\hline \multirow{3}{*}{$\begin{array}{l}\text { Buen estado de calles y } \\
\text { veredas }\end{array}$} & $\mathrm{Si}$ & $45 \%$ & $49 \%$ \\
\hline & No & $53 \%$ & $49 \%$ \\
\hline & No sabe & $2 \%$ & $2 \%$ \\
\hline \multirow[t]{3}{*}{ Sala de espera cómoda } & $\mathrm{Si}$ & $90 \%$ & $89 \%$ \\
\hline & No & $6 \%$ & $10 \%$ \\
\hline & No sabe & $4 \%$ & $1 \%$ \\
\hline \multirow[t]{5}{*}{ Estado del edificio } & Muy bueno & $29 \%$ & $24 \%$ \\
\hline & Bueno & $59 \%$ & $49 \%$ \\
\hline & Regular & $11 \%$ & $20 \%$ \\
\hline & Malo & $0,5 \%$ & $6 \%$ \\
\hline & No sabe & $0,5 \%$ & $1 \%$ \\
\hline \multirow[t]{5}{*}{ Limpieza } & Muy Buena & $52 \%$ & $40 \%$ \\
\hline & Buena & $42 \%$ & $57 \%$ \\
\hline & Regular & $4 \%$ & $3 \%$ \\
\hline & Mala & $0 \%$ & $0 \%$ \\
\hline & No sabe & $2 \%$ & $0 \%$ \\
\hline \multirow[t]{3}{*}{ Conseguir turno } & Fácil & $79 \%$ & $82 \%$ \\
\hline & Difícil & $20 \%$ & $17 \%$ \\
\hline & No sabe & $1 \%$ & $1 \%$ \\
\hline \multirow{4}{*}{$\begin{array}{l}\text { Turno médico } \\
\text { consigue }\end{array}$} & Siempre & $54 \%$ & $64 \%$ \\
\hline & Casi siempre & $22 \%$ & $16 \%$ \\
\hline & A veces & $24 \%$ & $18,5 \%$ \\
\hline & Nunca & $0 \%$ & $1,5 \%$ \\
\hline \multirow{5}{*}{$\begin{array}{l}\text { Turno profesional } \\
\text { consigue }\end{array}$} & Siempre & $47 \%$ & $61 \%$ \\
\hline & Casi siempre & $26 \%$ & $17 \%$ \\
\hline & A veces & $22 \%$ & $22 \%$ \\
\hline & Nunca & $1 \%$ & $0 \%$ \\
\hline & No sabe & $4 \%$ & $3 \%$ \\
\hline \multirow{5}{*}{$\begin{array}{l}\text { Turno enfermera } \\
\text { consigue }\end{array}$} & Siempre & $94 \%$ & $93 \%$ \\
\hline & Casi siempre & $4 \%$ & $4 \%$ \\
\hline & A veces & $1 \%$ & $0 \%$ \\
\hline & Nunca & $0 \%$ & $1 \%$ \\
\hline & No sabe & $1 \%$ & $2 \%$ \\
\hline \multirow[t]{3}{*}{ Personal amable } & $\mathrm{Si}$ & $98 \%$ & $98 \%$ \\
\hline & No & $1 \%$ & $0 \%$ \\
\hline & No sabe & $1 \%$ & $2 \%$ \\
\hline \multirow{3}{*}{$\begin{array}{l}\text { Conforme con La } \\
\text { atención }\end{array}$} & $\mathrm{Si}$ & $99 \%$ & $98,5 \%$ \\
\hline & No & $0 \%$ & $1,5 \%$ \\
\hline & No sabe & $1 \%$ & $0 \%$ \\
\hline \multirow[t]{3}{*}{ Tiempo de atención } & Suficiente & $96 \%$ & $95 \%$ \\
\hline & Insuficiente & $4 \%$ & $4 \%$ \\
\hline & No sabe & $0 \%$ & $1 \%$ \\
\hline \multirow[t]{3}{*}{ Indicaciones claras } & $\mathrm{Si}$ & $98 \%$ & $93 \%$ \\
\hline & No & $1 \%$ & $7 \%$ \\
\hline & No sabe & $1 \%$ & 0 \\
\hline \multirow{4}{*}{$\begin{array}{l}\text { Resolución } \\
\text { Problemas de salud }\end{array}$} & Siempre & $76 \%$ & $77 \%$ \\
\hline & Casi siempre & $18 \%$ & $13 \%$ \\
\hline & A veces & $6 \%$ & $10 \%$ \\
\hline & Nunca & $0 \%$ & $0 \%$ \\
\hline \multirow[t]{5}{*}{ Mejora su salud } & Siempre & $82,5 \%$ & $80 \%$ \\
\hline & Casi siempre & $13 \%$ & $9 \%$ \\
\hline & A veces & $3,5 \%$ & $6 \%$ \\
\hline & Nunca & $1 \%$ & 0 \\
\hline & No sabe & 0 & $1 \%$ \\
\hline \multirow[t]{2}{*}{ Volvería a atenderse } & $\mathrm{Si}$ & $99,5 \%$ & $100 \%$ \\
\hline & No & $0,5 \%$ & $0 \%$ \\
\hline Recomendaría el & $\mathrm{Si}$ & $98 \%$ & $99 \%$ \\
\hline
\end{tabular}




\begin{tabular}{|l|l|l|l|}
\hline \multirow{3}{*}{ CAPS } & No & $1,5 \%$ & $0 \%$ \\
\cline { 2 - 4 } & No sabe & $0,50 \%$ & $1 \%$ \\
\hline \multirow{3}{*}{$\begin{array}{l}\text { Consigue } \\
\text { Medicamentos }\end{array}$} & Siempre & $77 \%$ & $68 \%$ \\
\cline { 2 - 4 } & Casi siempre & $14 \%$ & $16 \%$ \\
\cline { 2 - 4 } & A veces & $8 \%$ & $14 \%$ \\
\cline { 2 - 4 } & Nunca & $1 \%$ & $1 \%$ \\
\cline { 2 - 4 } & No sabe & 0 & $1 \%$ \\
\hline
\end{tabular}

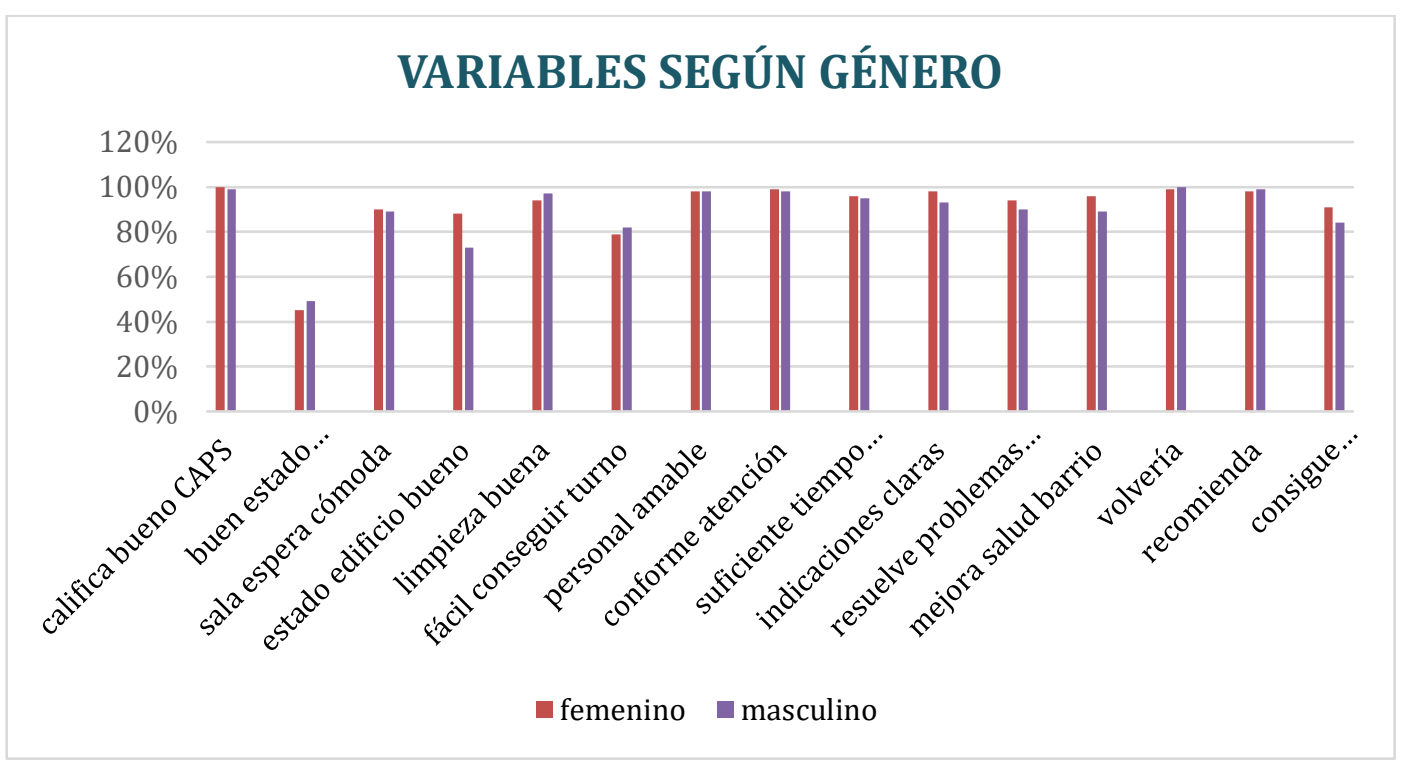

Gráfico N¹3

\subsection{4-Análisis de las respuestas según la edad de los entrevistados}

La comparación de las respuestas según la edad de los encuestados evidenció, que alrededor de la mitad de los menores de 42 años encontraron bueno el estado de las calles y veredas, mientras que la mayoría (69\%) de los mayores de esa edad lo hallaron malo. Ambos grupos definieron como bueno el estado del edificio, pero de los mayores de 42 años, un $29 \%$ lo evaluó como regular. Sobre la limpieza, casi todos los usuarios la calificaron como buena o muy buena. En cuanto a si el CAPS resuelve los problemas de salud, todos respondieron que siempre o casi siempre, pero un $17 \%$ de los mayores de 42 años opinó que a veces. Otra diferencia se observó en la entrega de medicamentos, la mayoría de los entrevistados afirmaron que siempre o casi siempre los consiguen, excepto para un $19 \%$ de los mayores de 42 años.

\begin{tabular}{|c|l|l|l|}
\hline \multirow{4}{*}{ Califica al CAPS } & & $<=42$ años & $>$ de 42 años \\
\cline { 2 - 4 } & Muy Bueno & $64 \%$ & $73 \%$ \\
\cline { 2 - 4 } & Bueno & $33 \%$ & $27 \%$ \\
\cline { 2 - 4 } & Regular & $0,5 \%$ & $0 \%$ \\
\cline { 2 - 4 } & Malo & $0,5 \%$ & $0 \%$ \\
\hline \multirow{2}{*}{$\begin{array}{l}\text { Buen estado de } \\
\text { calles y veredas }\end{array}$} & No sabe & $2 \%$ & $28 \%$ \\
\cline { 2 - 4 } & Si & $51 \%$ & $69 \%$ \\
\hline \multirow{2}{*}{$\begin{array}{l}\text { Sala de espera } \\
\text { Cómoda }\end{array}$} & No sabe & $47 \%$ & $3 \%$ \\
\cline { 2 - 4 } & Si & $91 \%$ & $8 \%$ \\
\hline & No & $6 \%$ & $5 \%$ \\
\hline \multirow{2}{*}{$\begin{array}{l}\text { Estado del } \\
\text { edificio }\end{array}$} & No sabe & $27 \%$ & $30 \%$ \\
\cline { 2 - 4 } & Buen bueno & $61,6 \%$ & $40 \%$ \\
\hline
\end{tabular}




\begin{tabular}{|c|c|c|c|}
\hline & Regular & $9 \%$ & $29 \%$ \\
\hline & Malo & $2 \%$ & $0 \%$ \\
\hline & No sabe & $0,4 \%$ & $1 \%$ \\
\hline \multirow[t]{5}{*}{ Limpieza } & Muy Buena & $51 \%$ & $42 \%$ \\
\hline & Buena & $45 \%$ & $48 \%$ \\
\hline & Regular & $2 \%$ & $10 \%$ \\
\hline & Mala & $0 \%$ & $0 \%$ \\
\hline & No sabe & $2 \%$ & $0 \%$ \\
\hline \multirow[t]{3}{*}{ Conseguir turno } & Fácil & $80 \%$ & $76 \%$ \\
\hline & Difícil & $19 \%$ & $24 \%$ \\
\hline & No sabe & $1 \%$ & $0 \%$ \\
\hline \multirow{5}{*}{$\begin{array}{l}\text { Turno médico } \\
\text { Consigue }\end{array}$} & Siempre & $50 \%$ & $78 \%$ \\
\hline & Casi siempre & $25 \%$ & $3,3 \%$ \\
\hline & A veces & $24 \%$ & $18,6 \%$ \\
\hline & Nunca & $0,5 \%$ & $0 \%$ \\
\hline & No sabe & $0.5 \%$ & $0 \%$ \\
\hline \multirow{5}{*}{$\begin{array}{l}\text { Turno } \\
\text { profesional } \\
\text { Consigue }\end{array}$} & Siempre & $45 \%$ & $72 \%$ \\
\hline & Casi siempre & $27 \%$ & $8 \%$ \\
\hline & A veces & $23 \%$ & $18 \%$ \\
\hline & Nunca & $1 \%$ & $0 \%$ \\
\hline & No sabe & $4 \%$ & $2 \%$ \\
\hline \multirow{5}{*}{$\begin{array}{l}\text { Turno } \\
\text { enfermera } \\
\text { Consigue }\end{array}$} & Siempre & $93 \%$ & $92 \%$ \\
\hline & Casi siempre & $5 \%$ & $5 \%$ \\
\hline & A veces & $0,5 \%$ & $2 \%$ \\
\hline & Nunca & $0,5 \%$ & $0 \%$ \\
\hline & No sabe & $1 \%$ & $1 \%$ \\
\hline \multirow[t]{3}{*}{ Personal Amable } & Si & $98 \%$ & $100 \%$ \\
\hline & No & $1 \%$ & $0 \%$ \\
\hline & No sabe & $1 \%$ & $0 \%$ \\
\hline \multirow{3}{*}{$\begin{array}{l}\text { Conforme con } \\
\text { La atención }\end{array}$} & $\mathrm{Si}$ & $99,5 \%$ & $98 \%$ \\
\hline & No & $0 \%$ & $1 \%$ \\
\hline & No sabe & $0,5 \%$ & $1 \%$ \\
\hline \multirow{3}{*}{$\begin{array}{l}\text { Tiempo de } \\
\text { Atención }\end{array}$} & Suficiente & $96,6 \%$ & $92 \%$ \\
\hline & Insuficiente & $3,4 \%$ & $7 \%$ \\
\hline & No sabe & $0 \%$ & $1 \%$ \\
\hline \multirow{3}{*}{$\begin{array}{l}\text { Indicaciones } \\
\text { claras }\end{array}$} & $\mathrm{Si}$ & $96 \%$ & $98,3 \%$ \\
\hline & No & $3 \%$ & $1,7 \%$ \\
\hline & No sabe & $1 \%$ & $0 \%$ \\
\hline \multirow{4}{*}{$\begin{array}{l}\text { Resolución } \\
\text { Problemas de } \\
\text { Salud }\end{array}$} & Siempre & $77,6 \%$ & $71 \%$ \\
\hline & Casi siempre & $18,4 \%$ & $12 \%$ \\
\hline & A veces & $4 \%$ & $17 \%$ \\
\hline & Nunca & $0 \%$ & $0 \%$ \\
\hline \multirow[t]{5}{*}{ Mejora su Salud } & Siempre & $81 \%$ & $85 \%$ \\
\hline & Casi siempre & $14 \%$ & $5 \%$ \\
\hline & A veces & $3 \%$ & $7 \%$ \\
\hline & Nunca & $1,6 \%$ & $3 \%$ \\
\hline & No sabe & $0,4 \%$ & $0 \%$ \\
\hline \multirow{2}{*}{$\begin{array}{l}\text { Volvería a } \\
\text { atenderse }\end{array}$} & $\mathrm{Si}$ & $99,5 \%$ & $100 \%$ \\
\hline & No & $0,5 \%$ & $0 \%$ \\
\hline \multirow[t]{3}{*}{ Recomendaría } & $\mathrm{Si}$ & $98 \%$ & $96 \%$ \\
\hline & No & $1,5 \%$ & $3 \%$ \\
\hline & No sabe & $0,5 \%$ & $1 \%$ \\
\hline \multirow{5}{*}{$\begin{array}{l}\text { Consigue } \\
\text { Medicamentos }\end{array}$} & Siempre & $76,6 \%$ & $65 \%$ \\
\hline & Casi siempre & $15,5 \%$ & $12 \%$ \\
\hline & A veces & $7,2 \%$ & $19 \%$ \\
\hline & Nunca & $0,5 \%$ & $3 \%$ \\
\hline & No sabe & $0 \%$ & $1 \%$ \\
\hline
\end{tabular}




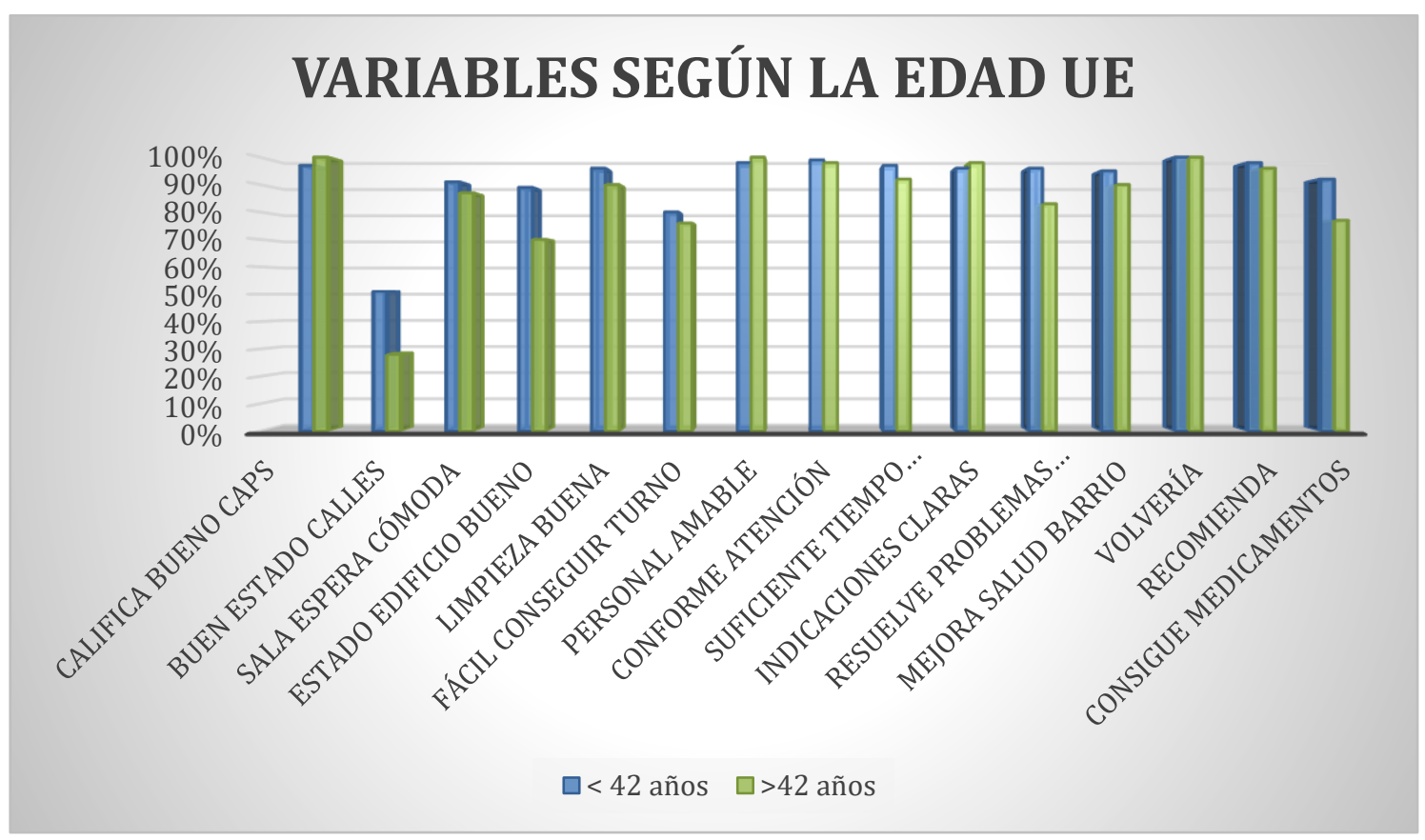

Gráfico $N^{\circ} 14$

\subsection{5-Análisis de las respuestas según la ocupación de los entrevistados}

En el análisis de las respuestas según la ocupación, se encontró que, en general, los entrevistados calificaron al CAPS como bueno o muy bueno, excepto el $12 \%$ de los jubilados que lo consideró como regular. Sobre el estado de las calles y veredas refirieron que es malo, la mayoría de los profesionales, empleados, jubilados y desempleados, que es bueno gran parte de los usuarios que realizan changas y los comerciantes y la mitad aproximadamente de las amas de casa, estudiantes y personas con un oficio. Sólo el $40 \%$ de los profesionales dijo que la sala de espera no es cómoda, para los demás encuestados lo es. En general, los entrevistados estimaron el estado del edificio como bueno, pero el $60 \%$ de los comerciantes, $25 \%$ de los estudiantes, $38 \%$ de los jubilados y $15 \%$ de los desempleados lo evaluaron como regular. Conseguir turno fue difícil para el $33 \%$ de los que realizan changas, $23 \%$ de los empleados, $27 \%$ de los que tienen un oficio y $23 \%$ de las amas de casa. Contestaron que a veces consiguen turno con el médico el $30 \%$ de las amas de casa, y los que tienen un oficio, el $20 \%$ de los empleados, $12,5 \%$ de los estudiantes y $15 \%$ de los desempleados. El resto de los usuarios respondió siempre o casi siempre. Se encontró similares porcentajes en las respuestas de los turnos para otro profesional. En cambio, cuando solicitaron atención de la enfermera, todos respondieron siempre y casi siempre, salvo el $12 \%$ de los estudiantes. El tiempo de atención fue suficiente para la mayoría de los entrevistados, excepto para el $12,5 \%$ de los estudiantes. Las indicaciones no fueron claras para el $33 \%$ de los que trabajan de changas. El CAPS resolvió los problemas de salud de la población siempre y casi siempre para casi todos los encuestados, menos para el $19 \%$ de los jubilados y $12,5 \%$ de los estudiantes. Respondieron que consiguieron siempre o casi siempre los medicamentos la mayoría de los usuarios externos, excepto el $10 \%$ de las amas de casa, $12 \%$ de personas con oficio, $24 \%$ de los estudiantes, $12 \%$ de los jubilados y $10 \%$ de los desempleados.

\begin{tabular}{|l|l|l|l|l|l|l|l|l|l|l|}
\hline & & $\begin{array}{l}\text { ama } \\
\text { casa }\end{array}$ & oficio & $\begin{array}{l}\text { profesion } \\
\text { al }\end{array}$ & $\begin{array}{l}\text { emplea } \\
\text { do }\end{array}$ & changa & $\begin{array}{l}\text { comercia } \\
\text { nte }\end{array}$ & $\begin{array}{l}\text { estudia } \\
\text { nte }\end{array}$ & $\begin{array}{l}\text { Jubilad } \\
\text { o }\end{array}$ & $\begin{array}{l}\text { desem } \\
\text { pleado }\end{array}$ \\
\hline Califica & Muy B & $59 \%$ & $63 \%$ & $65 \%$ & $80 \%$ & $74 \%$ & $67 \%$ & $40 \%$ & $38 \%$ & $56 \%$ \\
\hline
\end{tabular}




\begin{tabular}{|c|c|c|c|c|c|c|c|c|c|c|}
\hline \multirow[t]{4}{*}{ CAPS } & Bueno & $40 \%$ & $28 \%$ & $30 \%$ & $20 \%$ & $25 \%$ & $33 \%$ & $60 \%$ & $50 \%$ & $44 \%$ \\
\hline & Regular & $1 \%$ & $0 \%$ & $0 \%$ & $0 \%$ & $0 \%$ & $0 \%$ & $0 \%$ & $12 \%$ & $0 \%$ \\
\hline & Malo & $0 \%$ & $4 \%$ & $5 \%$ & $0 \%$ & $0 \%$ & $0 \%$ & $0 \%$ & $0 \%$ & $0 \%$ \\
\hline & No sabe & $0 \%$ & $5 \%$ & $0 \%$ & $0 \%$ & $1 \%$ & $0 \%$ & $0 \%$ & $0 \%$ & $0 \%$ \\
\hline \multirow{3}{*}{$\begin{array}{l}\text { Estado de } \\
\text { Calles }\end{array}$} & $\mathrm{SI}$ & $49 \%$ & $47 \%$ & $20 \%$ & $40 \%$ & $67 \%$ & $60 \%$ & $50 \%$ & $24 \%$ & $39 \%$ \\
\hline & No & $48 \%$ & $53 \%$ & $80 \%$ & $60 \%$ & $33 \%$ & $40 \%$ & $50 \%$ & $70 \%$ & $51 \%$ \\
\hline & No sabe & $3 \%$ & $0 \%$ & $0 \%$ & $0 \%$ & $0 \%$ & $0 \%$ & $0 \%$ & $6 \%$ & $10 \%$ \\
\hline \multirow{3}{*}{$\begin{array}{l}\text { Sala espera } \\
\text { cómoda }\end{array}$} & SI & $90 \%$ & $88 \%$ & $60 \%$ & $86 \%$ & $100 \%$ & $100 \%$ & $100 \%$ & $83 \%$ & $100 \%$ \\
\hline & NO & $5 \%$ & $12 \%$ & $40 \%$ & $11 \%$ & $0 \%$ & $0 \%$ & $0 \%$ & $5 \%$ & $0 \%$ \\
\hline & No sabe & $5 \%$ & $0 \%$ & $0 \%$ & $3 \%$ & $0 \%$ & $0 \%$ & $0 \%$ & $12 \%$ & $0 \%$ \\
\hline \multirow{5}{*}{$\begin{array}{l}\text { Estado del } \\
\text { edificio }\end{array}$} & Muy B & $28 \%$ & $17 \%$ & $20 \%$ & $38 \%$ & $67 \%$ & $40 \%$ & $25 \%$ & $12,5 \%$ & $20 \%$ \\
\hline & Bueno & $61 \%$ & $67 \%$ & $80 \%$ & $45 \%$ & $33 \%$ & $0 \%$ & $50 \%$ & $50 \%$ & $65 \%$ \\
\hline & Regular & $11 \%$ & $10 \%$ & $0 \%$ & $8 \%$ & $0 \%$ & $60 \%$ & $25 \%$ & $37,5 \%$ & $15 \%$ \\
\hline & Malo & $0 \%$ & $0 \%$ & $0 \%$ & $8 \%$ & $0 \%$ & $0 \%$ & $0 \%$ & $0 \%$ & $0 \%$ \\
\hline & No sabe & $0 \%$ & $6 \%$ & $0 \%$ & $1 \%$ & $0 \%$ & $0 \%$ & $0 \%$ & $0 \%$ & $0 \%$ \\
\hline \multirow[t]{5}{*}{ Limpieza } & Muy B & $50 \%$ & $47 \%$ & $37 \%$ & $51 \%$ & $67 \%$ & $20 \%$ & $50 \%$ & $44 \%$ & $50 \%$ \\
\hline & Buena & $45 \%$ & $53 \%$ & $38 \%$ & $44 \%$ & $33 \%$ & $80 \%$ & $50 \%$ & $44 \%$ & $45 \%$ \\
\hline & Regular & $2 \%$ & $0 \%$ & $0 \%$ & $5 \%$ & $0 \%$ & $0 \%$ & $0 \%$ & $12 \%$ & $5 \%$ \\
\hline & Mala & $0 \%$ & $0 \%$ & $0 \%$ & $0 \%$ & $0 \%$ & $0 \%$ & $0 \%$ & $0 \%$ & $0 \%$ \\
\hline & No sabe & $3 \%$ & $0 \%$ & $25 \%$ & $0 \%$ & $0 \%$ & $0 \%$ & $0 \%$ & $0 \%$ & $0 \%$ \\
\hline \multirow{3}{*}{$\begin{array}{l}\text { Conseguir } \\
\text { turno }\end{array}$} & Difícil & $23 \%$ & $27 \%$ & $0 \%$ & $23 \%$ & $33 \%$ & $0 \%$ & $12,5 \%$ & $12 \%$ & $10 \%$ \\
\hline & Fácil & $76 \%$ & $67 \%$ & $100 \%$ & $77 \%$ & $67 \%$ & $100 \%$ & 87,5 & $88 \%$ & $90 \%$ \\
\hline & No sabe & $1 \%$ & $6 \%$ & $0 \%$ & $0 \%$ & $0 \%$ & $0 \%$ & $0 \%$ & $0 \%$ & $0 \%$ \\
\hline \multirow{5}{*}{$\begin{array}{l}\text { Turno } \\
\text { médico } \\
\text { consigue }\end{array}$} & Siempre & $52 \%$ & $40 \%$ & $80 \%$ & $60 \%$ & $67 \%$ & $60 \%$ & 37,5 & $94 \%$ & $45 \%$ \\
\hline & Casi siempre & $17 \%$ & $30 \%$ & $20 \%$ & $20 \%$ & $33 \%$ & $40 \%$ & $37,5 \%$ & $0 \%$ & $40 \%$ \\
\hline & A veces & $30 \%$ & $30 \%$ & $0 \%$ & $20 \%$ & $0 \%$ & $0 \%$ & $12,5 \%$ & $6 \%$ & $15 \%$ \\
\hline & Nunca & $0 \%$ & $0 \%$ & $0 \%$ & $0 \%$ & $0 \%$ & $0 \%$ & $12,5 \%$ & $0 \%$ & $0 \%$ \\
\hline & No sabe & $1 \%$ & $0 \%$ & $0 \%$ & $0 \%$ & $0 \%$ & $0 \%$ & $0 \%$ & $0 \%$ & $0 \%$ \\
\hline \multirow{5}{*}{$\begin{array}{l}\text { Turno } \\
\text { Profesional } \\
\text { consigue }\end{array}$} & Siempre & $49 \%$ & $30 \%$ & $40 \%$ & $50 \%$ & $67 \%$ & $80 \%$ & $25 \%$ & $90 \%$ & $45 \%$ \\
\hline & Casi siempre & $19 \%$ & $35 \%$ & $60 \%$ & $19 \%$ & $33 \%$ & $20 \%$ & $50 \%$ & $0 \%$ & $35 \%$ \\
\hline & A veces & $24 \%$ & $35 \%$ & $0 \%$ & $25 \%$ & $0 \%$ & $0 \%$ & $25 \%$ & $4 \%$ & $15 \%$ \\
\hline & Nunca & $1 \%$ & $0 \%$ & $0 \%$ & $1 \%$ & $0 \%$ & $0 \%$ & $0 \%$ & $0 \%$ & $0 \%$ \\
\hline & No sabe & $7 \%$ & $0 \%$ & $0 \%$ & $5 \%$ & $0 \%$ & $0 \%$ & $0 \%$ & $6 \%$ & $5 \%$ \\
\hline \multirow{5}{*}{$\begin{array}{l}\text { Turno } \\
\text { Enfermera } \\
\text { Consigue }\end{array}$} & Siempre & $94 \%$ & $82 \%$ & $100 \%$ & $92 \%$ & $100 \%$ & $80 \%$ & $75 \%$ & $100 \%$ & $85 \%$ \\
\hline & Casi siempre & $5 \%$ & $12 \%$ & $0 \%$ & $0 \%$ & $0 \%$ & $20 \%$ & $12,5 \%$ & $0 \%$ & $15 \%$ \\
\hline & A veces & $1 \%$ & $6 \%$ & $0 \%$ & $0 \%$ & $0 \%$ & $0 \%$ & $0 \%$ & $0 \%$ & $0 \%$ \\
\hline & Nunca & $0 \%$ & $0 \%$ & $0 \%$ & $0 \%$ & $0 \%$ & $0 \%$ & $12,5 \%$ & $0 \%$ & $0 \%$ \\
\hline & No sabe & $0 \%$ & $0 \%$ & $0 \%$ & $8 \%$ & $0 \%$ & $0 \%$ & $0 \%$ & $0 \%$ & $0 \%$ \\
\hline \multirow{3}{*}{$\begin{array}{l}\text { Personal } \\
\text { Amable }\end{array}$} & $\mathrm{SI}$ & $97 \%$ & $94 \%$ & $100 \%$ & $100 \%$ & $67 \%$ & $100 \%$ & $100 \%$ & $100 \%$ & $100 \%$ \\
\hline & NO & $1 \%$ & $6,00 \%$ & $0 \%$ & $0 \%$ & $0 \%$ & $0 \%$ & $0,00 \%$ & $0,00 \%$ & $0 \%$ \\
\hline & No sabe & $2 \%$ & $0 \%$ & $0 \%$ & $0 \%$ & $33 \%$ & $0 \%$ & $0 \%$ & $0 \%$ & $0 \%$ \\
\hline & SI & $99 \%$ & $100 \%$ & $100 \%$ & $99 \%$ & $100 \%$ & $100 \%$ & $100 \%$ & $100 \%$ & $100 \%$ \\
\hline Con & NO & $0 \%$ & $0 \%$ & $0 \%$ & $0 \%$ & $0 \%$ & $0 \%$ & $0 \%$ & $0 \%$ & $0 \%$ \\
\hline & No sabe & $1 \%$ & $0 \%$ & $0 \%$ & $1 \%$ & $0 \%$ & $0 \%$ & $0 \%$ & $0 \%$ & $0 \%$ \\
\hline Tiempo de & Suficiente & $95 \%$ & $94 \%$ & $100 \%$ & $95 \%$ & $100 \%$ & $100 \%$ & $87,5 \%$ & $100 \%$ & $95 \%$ \\
\hline Atención & Insuficiente & $5 \%$ & $6 \%$ & $0 \%$ & $5 \%$ & $0 \%$ & $0 \%$ & $12,5 \%$ & $0 \%$ & $0 \%$ \\
\hline & No sabe & $0 \%$ & $0 \%$ & $0 \%$ & $0 \%$ & $0 \%$ & $0 \%$ & $0 \%$ & $0 \%$ & $5 \%$ \\
\hline Indicación & $\mathrm{SI}$ & $98 \%$ & $100 \%$ & $100 \%$ & $96 \%$ & $67 \%$ & $100 \%$ & $100 \%$ & $94 \%$ & $87 \%$ \\
\hline Clara & NO & $1 \%$ & $0 \%$ & $0 \%$ & $3 \%$ & $33 \%$ & $0 \%$ & $0 \%$ & $6 \%$ & $8 \%$ \\
\hline & No sabe & $1 \%$ & $0 \%$ & $0 \%$ & $1 \%$ & $0 \%$ & $0 \%$ & $0 \%$ & $0 \%$ & $5 \%$ \\
\hline Resolución & Siempre & $74 \%$ & $76 \%$ & $80 \%$ & $82 \%$ & $100 \%$ & $60 \%$ & $62,5 \%$ & $75 \%$ & $90 \%$ \\
\hline Problemas & Casi siempre & $18 \%$ & $18 \%$ & $20 \%$ & $15 \%$ & $0 \%$ & $40 \%$ & $25 \%$ & $6 \%$ & $5 \%$ \\
\hline Salud & A veces & $8 \%$ & $6 \%$ & $0 \%$ & $3 \%$ & $0 \%$ & $0 \%$ & $12,5 \%$ & $19 \%$ & $5 \%$ \\
\hline & Nunca & $0 \%$ & $0 \%$ & $0 \%$ & $0 \%$ & $0 \%$ & $0 \%$ & $0 \%$ & $0 \%$ & $0 \%$ \\
\hline Mejora su & Siempre & $82 \%$ & $88 \%$ & $100 \%$ & $90 \%$ & $67 \%$ & $100 \%$ & $62,5 \%$ & $75 \%$ & $60 \%$ \\
\hline Salud & Casi siempre & $12 \%$ & $6 \%$ & $0 \%$ & $7 \%$ & $0 \%$ & $0 \%$ & $25 \%$ & $12,5 \%$ & $40 \%$ \\
\hline & A veces & $5 \%$ & $0 \%$ & $0 \%$ & $3 \%$ & $0 \%$ & $0 \%$ & $12,5 \%$ & $12,5 \%$ & $0 \%$ \\
\hline & Nunca & $1 \%$ & $6 \%$ & $0 \%$ & $0 \%$ & $0 \%$ & $0 \%$ & $0 \%$ & $0 \%$ & $0 \%$ \\
\hline & No sabe & $0 \%$ & $0 \%$ & $0 \%$ & $0 \%$ & $33 \%$ & $0 \%$ & $0 \%$ & $0 \%$ & $0 \%$ \\
\hline Volvería al & SI & $100 \%$ & $94 \%$ & $100 \%$ & $100 \%$ & $100 \%$ & $100 \%$ & $100 \%$ & $100 \%$ & $100 \%$ \\
\hline CAPS & NO & $0 \%$ & $6 \%$ & $0 \%$ & $0 \%$ & $0 \%$ & $0 \%$ & $0 \%$ & $0 \%$ & $0 \%$ \\
\hline Recomend & $\mathrm{SI}$ & $96 \%$ & $94 \%$ & $100 \%$ & $100 \%$ & $100 \%$ & $100 \%$ & $100 \%$ & $100 \%$ & $95 \%$ \\
\hline aría CAPS & NO & $3 \%$ & $6 \%$ & $0 \%$ & $0 \%$ & $0 \%$ & $0 \%$ & $0 \%$ & $0 \%$ & $0 \%$ \\
\hline & No sabe & $1 \%$ & $0 \%$ & $0 \%$ & $0 \%$ & $0 \%$ & $0 \%$ & $0 \%$ & $0 \%$ & $5 \%$ \\
\hline Consigue & Siempre & $77 \%$ & $76 \%$ & $100 \%$ & $79 \%$ & $67 \%$ & $38 \%$ & $62,5 \%$ & $50 \%$ & $75 \%$ \\
\hline Medicame & Casi siempre & $13 \%$ & $12 \%$ & $0 \%$ & $15 \%$ & $33 \%$ & $37 \%$ & $25 \%$ & $25 \%$ & $15 \%$ \\
\hline ntos & A veces & $10 \%$ & $12 \%$ & $0 \%$ & $5 \%$ & $0 \%$ & $0 \%$ & $12,5 \%$ & $12,5 \%$ & $10 \%$ \\
\hline
\end{tabular}




\begin{tabular}{|l|l|l|l|l|l|l|l|l|l|l|}
\hline & Nunca & $0 \%$ & $0 \%$ & $0 \%$ & $1 \%$ & $0 \%$ & $0 \%$ & $0 \%$ & $12,5 \%$ & $0 \%$ \\
\cline { 2 - 9 } & No sabe & $0 \%$ & $0 \%$ & $0 \%$ & $0 \%$ & $0 \%$ & $25 \%$ & $0 \%$ & $0 \%$ \\
\hline
\end{tabular}

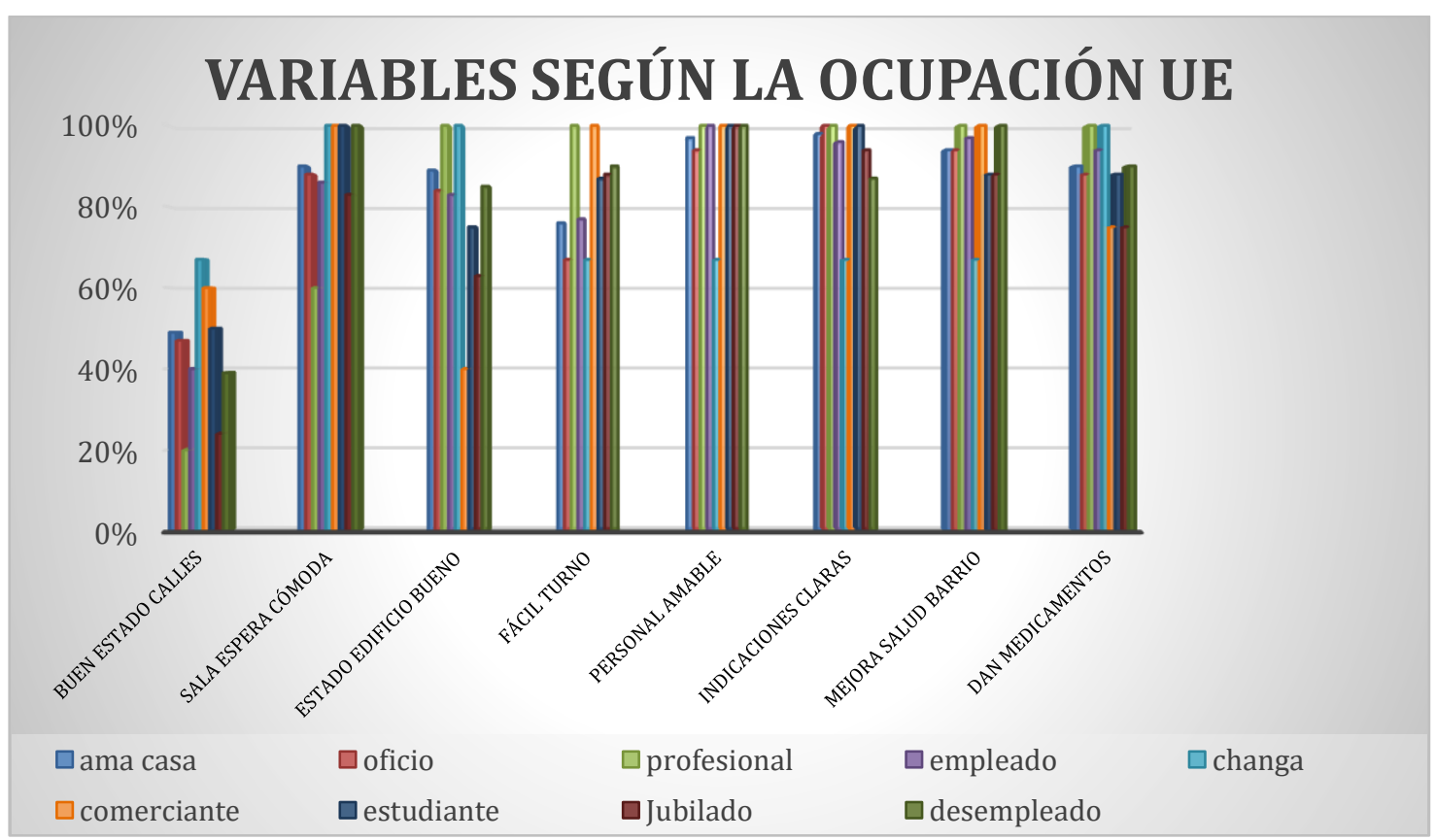

Gráfico $\mathbf{N}^{\circ} 15$

\subsection{6-Análisis de las respuestas según la escolaridad de los entrevistados}

La evaluación del estado de veredas y calles según la escolaridad de los usuarios externos arrojó que la mayor parte de los que refieren educación $1^{\circ}$ completa e incompleta y $2^{\circ}$ completa afirmaron que es malo, la mayoría de las personas con educación superior completa que es bueno y el resto mitad y mitad aproximadamente. Respondieron que la sala de espera es incómoda, $20 \%$ de los que completaron la escuela primaria, $12 \%$ de los que no terminaron la secundaria y $21 \%$ con $3^{\circ}$ incompleta. Sobre el estado del edificio, entre el 8 y el $21 \%$ de todos los grupos lo evaluaron como regular y el resto como bueno. La limpieza fue calificada, en general, como buena menos para el $15 \%$ de los que cursaron $1^{\circ}$ completa que la definieron como regular. Entre el 14 y el $28 \%$ de los entrevistados consiguieron turno para el médico a veces. Cuando el turno es para otro profesional respondieron a veces, el $25 \%$ que no terminó la escuela primaria, el $16 \%$ que no completó la secundaria, el $27 \%$ con $2^{\circ}$ completa y el $20 \%$ con estudios terciarios incompletos. De la categoría con estudios primarios completos, sólo el 16\% opinó que el CAPS resuelve a veces los problemas de salud de la comunidad y el $11 \%$ que a veces mejora su estado de salud. El resto de los usuarios externos contestaron que siempre o casi siempre a ambas preguntas. Con respecto a los medicamentos, casi todos los entrevistados respondieron que pudieron conseguirlos siempre o casi siempre, salvo el $16 \%$ de los que completaron estudios superiores, el $14 \%$ que no los completaron aún, y el $11 \%$ de los que no terminaron la primaria.

\begin{tabular}{|l|l|l|l|l|l|l|l|}
\hline & & $1^{\circ}$ & $1^{\circ}$ & $2^{\circ}$ & $2^{\circ}$ & $3^{\circ}$ & $3^{\circ}$ \\
& incompleta & completa & incompleta & completa & incompleta & \begin{tabular}{l} 
completa \\
\hline
\end{tabular}
\end{tabular}




\begin{tabular}{|c|c|c|c|c|c|c|c|}
\hline \multirow[t]{5}{*}{ Califica CAPS } & Muy Bueno & $65 \%$ & $68 \%$ & $71 \%$ & $58 \%$ & $86 \%$ & $62 \%$ \\
\hline & Bueno & $32 \%$ & $32 \%$ & $27 \%$ & $42 \%$ & $14 \%$ & $28 \%$ \\
\hline & Regular & $0 \%$ & $0 \%$ & $2 \%$ & $0 \%$ & $0 \%$ & $0 \%$ \\
\hline & Malo & $0 \%$ & $0 \%$ & $0 \%$ & $0 \%$ & $0 \%$ & $0 \%$ \\
\hline & No sabe & $3 \%$ & $0 \%$ & $0 \%$ & $0 \%$ & $0 \%$ & $10 \%$ \\
\hline \multirow{3}{*}{$\begin{array}{l}\text { Buen estado } \\
\text { Calles }\end{array}$} & $\mathrm{Si}$ & $39,00 \%$ & $32,00 \%$ & $51,00 \%$ & $40,00 \%$ & $50,00 \%$ & $76,00 \%$ \\
\hline & No & $55,00 \%$ & $68,00 \%$ & $47,00 \%$ & $59,00 \%$ & $43,00 \%$ & $24,00 \%$ \\
\hline & No sabe & $6 \%$ & $0 \%$ & $2 \%$ & $1 \%$ & $7 \%$ & $0 \%$ \\
\hline \multirow{3}{*}{$\begin{array}{l}\text { S. espera } \\
\text { Cómoda }\end{array}$} & $\mathrm{Si}$ & $91,00 \%$ & $75,00 \%$ & $87 \%$ & $95,00 \%$ & $79,00 \%$ & $86,00 \%$ \\
\hline & No & $2,00 \%$ & $20,00 \%$ & $12 \%$ & $5,00 \%$ & $21,00 \%$ & $2,00 \%$ \\
\hline & No sabe & $7 \%$ & $5 \%$ & $1 \%$ & $0 \%$ & $0 \%$ & $12 \%$ \\
\hline \multirow{5}{*}{$\begin{array}{l}\text { Estado del } \\
\text { Edificio }\end{array}$} & Muy bueno & $28,00 \%$ & $21,00 \%$ & $27,00 \%$ & $31,00 \%$ & $28,00 \%$ & $32,00 \%$ \\
\hline & Bueno & $54,00 \%$ & $58,00 \%$ & $57,00 \%$ & $56,00 \%$ & $57,00 \%$ & $52,00 \%$ \\
\hline & Regular & $15,00 \%$ & $21,00 \%$ & $8,00 \%$ & $12,00 \%$ & $15,00 \%$ & $16,00 \%$ \\
\hline & Malo & $0,00 \%$ & $0,00 \%$ & $8,00 \%$ & $1,00 \%$ & $0,00 \%$ & $0,00 \%$ \\
\hline & No sabe & $3 \%$ & $0 \%$ & $0 \%$ & $0 \%$ & $0 \%$ & $0 \%$ \\
\hline \multirow[t]{5}{*}{ Limpieza } & Muy Buena & $47,00 \%$ & $37,00 \%$ & $61,00 \%$ & $48,00 \%$ & $43,00 \%$ & $56,00 \%$ \\
\hline & Buena & $50,00 \%$ & $43,00 \%$ & $37,00 \%$ & $45,00 \%$ & $50,00 \%$ & $40,00 \%$ \\
\hline & Regular & $3,00 \%$ & $15,00 \%$ & $2,00 \%$ & $5,00 \%$ & $0,00 \%$ & $0,00 \%$ \\
\hline & Mala & $0,00 \%$ & $0,00 \%$ & $0,00 \%$ & $0,00 \%$ & $0,00 \%$ & $0,00 \%$ \\
\hline & No sabe & $0 \%$ & $5 \%$ & $0 \%$ & $2 \%$ & $7 \%$ & $4 \%$ \\
\hline \multirow{3}{*}{$\begin{array}{l}\text { Conseguir } \\
\text { Turno }\end{array}$} & difícil & $15,00 \%$ & $15,00 \%$ & $20,00 \%$ & $27,00 \%$ & $14,00 \%$ & $8,00 \%$ \\
\hline & fácil & $85,00 \%$ & $80,00 \%$ & $80,00 \%$ & $71,00 \%$ & $86,00 \%$ & $92,00 \%$ \\
\hline & No sabe & $0 \%$ & $5 \%$ & $0 \%$ & $2 \%$ & $0 \%$ & $0 \%$ \\
\hline \multirow{5}{*}{$\begin{array}{l}\text { Turno Médico } \\
\text { Consigue }\end{array}$} & Siempre & $63,00 \%$ & $74,00 \%$ & $63,00 \%$ & $43,00 \%$ & $79,00 \%$ & $48,00 \%$ \\
\hline & Casi siempre & $14,00 \%$ & $10,00 \%$ & $23,00 \%$ & $28,00 \%$ & $7,00 \%$ & $24,00 \%$ \\
\hline & A veces & $23,00 \%$ & $16,00 \%$ & $14,00 \%$ & $28,00 \%$ & $14,00 \%$ & $28,00 \%$ \\
\hline & Nunca & $0,00 \%$ & $0,00 \%$ & $0,00 \%$ & $0,00 \%$ & $0,00 \%$ & $0,00 \%$ \\
\hline & No sabe & $0 \%$ & $0 \%$ & $0 \%$ & $1 \%$ & $0 \%$ & $0 \%$ \\
\hline \multirow{5}{*}{$\begin{array}{l}\text { Turno } \\
\text { Profesional } \\
\text { consigue }\end{array}$} & Siempre & $54,00 \%$ & $80,00 \%$ & $50,00 \%$ & $39,00 \%$ & $44,00 \%$ & $62,00 \%$ \\
\hline & Casi siempre & $17,00 \%$ & $10,00 \%$ & $30,00 \%$ & $26,00 \%$ & $29,00 \%$ & $20,00 \%$ \\
\hline & A veces & $25,00 \%$ & $5,00 \%$ & $16,00 \%$ & $27,00 \%$ & $20,00 \%$ & $10,00 \%$ \\
\hline & nunca & $0,00 \%$ & $0,00 \%$ & $2,00 \%$ & $1,00 \%$ & $0,00 \%$ & $0,00 \%$ \\
\hline & No sabe & $4 \%$ & $5 \%$ & $2 \%$ & $7 \%$ & $7 \%$ & $8 \%$ \\
\hline \multirow{5}{*}{$\begin{array}{l}\text { Turno } \\
\text { Enfermera } \\
\text { consigue }\end{array}$} & Siempre & $95 \%$ & $90,00 \%$ & $96,00 \%$ & $90,00 \%$ & $86,00 \%$ & $96,00 \%$ \\
\hline & Casi siempre & $5,00 \%$ & $5,00 \%$ & $4,00 \%$ & $7,00 \%$ & $0,00 \%$ & $4,00 \%$ \\
\hline & A veces & $0,00 \%$ & $5,00 \%$ & $0,00 \%$ & $0,00 \%$ & $0,00 \%$ & $0,00 \%$ \\
\hline & Nunca & $0,00 \%$ & $0,00 \%$ & $0,00 \%$ & $0,00 \%$ & $0,00 \%$ & $0,00 \%$ \\
\hline & No sabe & $0 \%$ & $0 \%$ & $0 \%$ & $3 \%$ & $14 \%$ & $0 \%$ \\
\hline \multirow{3}{*}{$\begin{array}{l}\text { Personal } \\
\text { amable }\end{array}$} & $\mathrm{Si}$ & $97,00 \%$ & $100,00 \%$ & $97,00 \%$ & $99,00 \%$ & $100,00 \%$ & $96 \%$ \\
\hline & No & $0,00 \%$ & $0,00 \%$ & $1,00 \%$ & $1,00 \%$ & $0,00 \%$ & $0,00 \%$ \\
\hline & No sabe & $3 \%$ & $0 \%$ & $2 \%$ & $0 \%$ & $0 \%$ & $4 \%$ \\
\hline \multirow{3}{*}{$\begin{array}{l}\text { Conforme con } \\
\text { atención }\end{array}$} & $\mathrm{Si}$ & $97,00 \%$ & $100,00 \%$ & $100,00 \%$ & $100,00 \%$ & $100,00 \%$ & $92 \%$ \\
\hline & No & $2,00 \%$ & $0,00 \%$ & $0,00 \%$ & $0,00 \%$ & $0,00 \%$ & $0,00 \%$ \\
\hline & No sabe & $1 \%$ & $0 \%$ & $0 \%$ & $0 \%$ & $0 \%$ & $8 \%$ \\
\hline \multirow{3}{*}{$\begin{array}{l}\text { Tiempo de } \\
\text { atención }\end{array}$} & Suficiente & $93,00 \%$ & $95,00 \%$ & $100,00 \%$ & $94,00 \%$ & $100,00 \%$ & $100 \%$ \\
\hline & Insuficiente & $6,00 \%$ & $5,00 \%$ & $0,00 \%$ & $6,00 \%$ & $0,00 \%$ & $0,00 \%$ \\
\hline & No sabe & $1 \%$ & $0 \%$ & $0 \%$ & $0 \%$ & $0 \%$ & $0 \%$ \\
\hline \multirow{3}{*}{$\begin{array}{l}\text { Indicaciones } \\
\text { claras }\end{array}$} & $\mathrm{Si}$ & $97,00 \%$ & $95,00 \%$ & $98,00 \%$ & $94,00 \%$ & $100,00 \%$ & $100 \%$ \\
\hline & No & $3,00 \%$ & $0,00 \%$ & $2,00 \%$ & $4,00 \%$ & $0,00 \%$ & $0,00 \%$ \\
\hline & No sabe & $0 \%$ & $5 \%$ & $0 \%$ & $2 \%$ & $0 \%$ & $0 \%$ \\
\hline \multirow{4}{*}{$\begin{array}{l}\text { Resolución } \\
\text { Problemas de } \\
\text { salud }\end{array}$} & Siempre & $72,00 \%$ & $79,00 \%$ & $84,00 \%$ & $75,00 \%$ & $86,00 \%$ & $72,00 \%$ \\
\hline & Casi siempre & $19,00 \%$ & $5,00 \%$ & $14,00 \%$ & $18,00 \%$ & $14,00 \%$ & $28,00 \%$ \\
\hline & A veces & $9,00 \%$ & $16,00 \%$ & $2,00 \%$ & $7,00 \%$ & $0,00 \%$ & $0,00 \%$ \\
\hline & Nunca & $0,00 \%$ & $0,00 \%$ & $0,00 \%$ & $0,00 \%$ & $0,00 \%$ & $0,00 \%$ \\
\hline \multirow{5}{*}{$\begin{array}{l}\text { Mejora su } \\
\text { salud }\end{array}$} & Siempre & $80,00 \%$ & $84,00 \%$ & $92,00 \%$ & $77,00 \%$ & $93,00 \%$ & $84,00 \%$ \\
\hline & Casi siempre & $8,00 \%$ & $5,00 \%$ & $8,00 \%$ & $19,00 \%$ & $7,00 \%$ & $12,00 \%$ \\
\hline & A veces & $8,00 \%$ & $11,00 \%$ & $0,00 \%$ & $2,00 \%$ & $0,00 \%$ & $4,00 \%$ \\
\hline & Nunca & $3,00 \%$ & $0,00 \%$ & $0,00 \%$ & $2,00 \%$ & $0,00 \%$ & $0,00 \%$ \\
\hline & No sabe & $1 \%$ & $0 \%$ & $0 \%$ & $0 \%$ & $0 \%$ & $0 \%$ \\
\hline
\end{tabular}




\begin{tabular}{|c|c|c|c|c|c|c|c|}
\hline \multirow{2}{*}{$\begin{array}{l}\text { Volvería a } \\
\text { atenderse }\end{array}$} & $\mathrm{Si}$ & $100,00 \%$ & $100,00 \%$ & $98,00 \%$ & $100,00 \%$ & $100,00 \%$ & $100 \%$ \\
\hline & No & $0,00 \%$ & $0,00 \%$ & $2,00 \%$ & $0,00 \%$ & $0,00 \%$ & $0,00 \%$ \\
\hline \multirow{3}{*}{$\begin{array}{l}\text { recomendaría } \\
\text { CAPS }\end{array}$} & $\mathrm{Si}$ & $99,00 \%$ & $100,00 \%$ & $98,00 \%$ & $94,00 \%$ & $100,00 \%$ & $100 \%$ \\
\hline & No & $0,00 \%$ & $0,00 \%$ & $2,00 \%$ & $5,00 \%$ & $0,00 \%$ & $0,00 \%$ \\
\hline & No sabe & $1 \%$ & $0 \%$ & $0 \%$ & $1 \%$ & $0 \%$ & $0 \%$ \\
\hline \multirow{5}{*}{$\begin{array}{l}\text { Consigue } \\
\text { Medicamentos }\end{array}$} & Siempre & $74,00 \%$ & $74,00 \%$ & $82,00 \%$ & $72,00 \%$ & $79,00 \%$ & $68,00 \%$ \\
\hline & Casi siempre & $11,00 \%$ & $21,00 \%$ & $12,00 \%$ & $19,00 \%$ & $7,00 \%$ & $16,00 \%$ \\
\hline & A veces & $11,00 \%$ & $5,00 \%$ & $6,00 \%$ & $8,00 \%$ & $14,00 \%$ & $16,00 \%$ \\
\hline & Nunca & $3,00 \%$ & $0,00 \%$ & $0,00 \%$ & $1,00 \%$ & $0,00 \%$ & $0,00 \%$ \\
\hline & No sabe & $1 \%$ & $0 \%$ & $0 \%$ & $0 \%$ & $0 \%$ & $0 \%$ \\
\hline
\end{tabular}

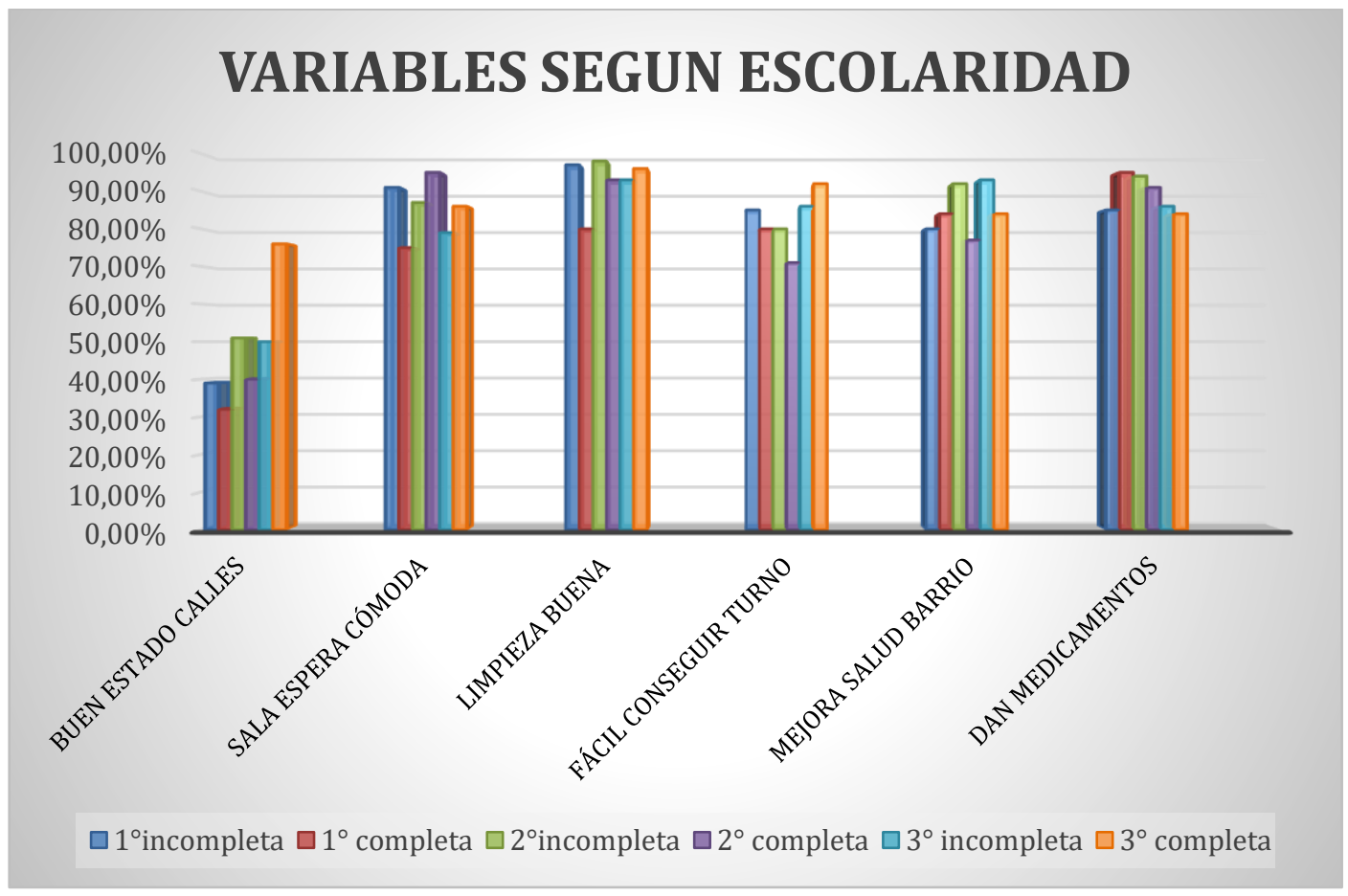

Gráfico $N^{\circ} 16$

\subsection{7-Análisis de las respuestas según el estado civil de los entrevistados}

Teniendo en cuenta el estado civil de los usuarios externos, las respuestas sobre el estado de las calles y veredas de solteros y viudos se dividieron mitad y mitad entre bueno y malo, en cambio, la mayoría de los casados y $80 \%$ de los divorciados contestaron que es malo. El $15 \%$ de los divorciados solamente dijo que la sala de espera es incómoda. La mayoría de los encuestados opinaron que el estado del edificio es bueno, salvo el $10 \%$ de los solteros, $18 \%$ de los casados, $33 \%$ de los viudos y $26 \%$ de los divorciados. Consiguieron turno para el médico siempre o casi siempre gran parte de los entrevistados, menos el $24 \%$ de los solteros y casados y el $16 \%$ de los divorciados que manifestaron a veces. Cuando el turno fue para otro profesional, sólo los viudos lo obtuvieron siempre o casi siempre, los otros grupos contestaron alrededor de un $20 \%$ a veces. Sobre la resolución de los problemas de salud, únicamente el $12 \%$ de los casados respondió a veces. En general, los usuarios externos, refirieron que les fueron entregados los medicamentos siempre o casi siempre, aunque el $6 \%$ de los solteros, el $13 \%$ de los casados, $33 \%$ de los viudos y $27 \%$ de los divorciados contestaron a veces. 


\begin{tabular}{|c|c|c|c|c|c|}
\hline & & Soltero & casado & Viudo & divorciado \\
\hline \multirow[t]{5}{*}{ Califica CAPS } & Muy Bueno & $66,00 \%$ & $55,00 \%$ & $33,00 \%$ & $84,00 \%$ \\
\hline & Bueno & $31,00 \%$ & $41,00 \%$ & $67,00 \%$ & $16,00 \%$ \\
\hline & Regular & $0.5 \%$ & $0 \%$ & $0 \%$ & $0 \%$ \\
\hline & Malo & $2 \%$ & $0 \%$ & $0 \%$ & $0 \%$ \\
\hline & No sabe & $0,5 \%$ & $4 \%$ & $0 \%$ & $0 \%$ \\
\hline \multirow{3}{*}{$\begin{array}{l}\text { Buen estado } \\
\text { calles }\end{array}$} & $\mathrm{Si}$ & $48,00 \%$ & $41,00 \%$ & $33,00 \%$ & $15,00 \%$ \\
\hline & No & $51,00 \%$ & $56,00 \%$ & $33,00 \%$ & $80,00 \%$ \\
\hline & No sabe & $1 \%$ & $3 \%$ & $33 \%$ & $5 \%$ \\
\hline \multirow{3}{*}{$\begin{array}{l}\text { Sala espera } \\
\text { cómoda }\end{array}$} & $\mathrm{Si}$ & $90,00 \%$ & $90,00 \%$ & $67,00 \%$ & $80,00 \%$ \\
\hline & No & $8,00 \%$ & $6,00 \%$ & $0,00 \%$ & $15,00 \%$ \\
\hline & No sabe & $2 \%$ & $4 \%$ & $33 \%$ & $5 \%$ \\
\hline \multirow{5}{*}{$\begin{array}{l}\text { Estado del } \\
\text { edificio }\end{array}$} & Muy bueno & $30,00 \%$ & $27 \%$ & $0,00 \%$ & $16,00 \%$ \\
\hline & Bueno & $58,00 \%$ & $51 \%$ & $67,00 \%$ & $58,00 \%$ \\
\hline & Regular & $10,00 \%$ & $18 \%$ & $33,00 \%$ & $26,00 \%$ \\
\hline & Malo & $2,00 \%$ & $1 \%$ & $0,00 \%$ & $0,00 \%$ \\
\hline & No sabe & $0 \%$ & $3 \%$ & $0 \%$ & $0 \%$ \\
\hline \multirow[t]{5}{*}{ Limpieza } & Muy Buena & $50,00 \%$ & $48,00 \%$ & $33,00 \%$ & $38,00 \%$ \\
\hline & Buena & $47,00 \%$ & $43,00 \%$ & $33,00 \%$ & $57,00 \%$ \\
\hline & Regular & $2,00 \%$ & $8,00 \%$ & $0,00 \%$ & $0,00 \%$ \\
\hline & Mala & $0,00 \%$ & $0,00 \%$ & $0,00 \%$ & $0,00 \%$ \\
\hline & No sabe & $1 \%$ & $1 \%$ & $33 \%$ & $5 \%$ \\
\hline \multirow[t]{3}{*}{ Conseguir turno } & Difícil & $18,00 \%$ & $24,00 \%$ & $33,00 \%$ & $26,00 \%$ \\
\hline & Fácil & $81,00 \%$ & $76,00 \%$ & $67,00 \%$ & $74,00 \%$ \\
\hline & No sabe & $1 \%$ & $0 \%$ & $0 \%$ & $0 \%$ \\
\hline \multirow{5}{*}{$\begin{array}{l}\text { Turno médico } \\
\text { consigue }\end{array}$} & Siempre & $52,0 \%$ & $61,00 \%$ & $67,00 \%$ & $74,00 \%$ \\
\hline & Casi siempre & $23,00 \%$ & $15,00 \%$ & $33,00 \%$ & $10,00 \%$ \\
\hline & A veces & $24,00 \%$ & $24,00 \%$ & $0,00 \%$ & $16,00 \%$ \\
\hline & Nunca & $0,50 \%$ & $0,00 \%$ & $0,00 \%$ & $0,00 \%$ \\
\hline & No sabe & $0,5 \%$ & $0 \%$ & $0 \%$ & $0 \%$ \\
\hline \multirow{5}{*}{$\begin{array}{l}\text { Turno } \\
\text { profesional } \\
\text { consigue }\end{array}$} & Siempre & $45,00 \%$ & $58,00 \%$ & $67,00 \%$ & $63,00 \%$ \\
\hline & Casi siempre & $28,00 \%$ & $16,00 \%$ & $0,00 \%$ & $1,00 \%$ \\
\hline & A veces & $24,00 \%$ & $20,00 \%$ & $0,00 \%$ & $20,00 \%$ \\
\hline & Nunca & $1,00 \%$ & $0,00 \%$ & $0,00 \%$ & $0,00 \%$ \\
\hline & No sabe & $2 \%$ & $6 \%$ & $33 \%$ & $16 \%$ \\
\hline \multirow{5}{*}{$\begin{array}{l}\text { Turno } \\
\text { enfermera } \\
\text { Consigue }\end{array}$} & Siempre & $93,00 \%$ & $92,00 \%$ & $100,00 \%$ & $100,00 \%$ \\
\hline & Casi siempre & $4,00 \%$ & $6,00 \%$ & $0,00 \%$ & $0,00 \%$ \\
\hline & A veces & $0,50 \%$ & $1,00 \%$ & $0,00 \%$ & $0,00 \%$ \\
\hline & Nunca & $0,50 \%$ & $0,00 \%$ & $0,00 \%$ & $0,00 \%$ \\
\hline & No sabe & $2 \%$ & $1 \%$ & $0 \%$ & $0 \%$ \\
\hline \multirow{3}{*}{$\begin{array}{l}\text { Personal } \\
\text { Amable }\end{array}$} & $\mathrm{Si}$ & $99,00 \%$ & $96,00 \%$ & $100,00 \%$ & $100,00 \%$ \\
\hline & No & $1,00 \%$ & $0,00 \%$ & $0,00 \%$ & $0,00 \%$ \\
\hline & No sabe & $0 \%$ & $4 \%$ & 05 & $0 \%$ \\
\hline \multirow{3}{*}{$\begin{array}{l}\text { Conforme con } \\
\text { la atención }\end{array}$} & $\mathrm{Si}$ & $99,00 \%$ & $97,00 \%$ & $100,00 \%$ & $100,00 \%$ \\
\hline & No & $1,00 \%$ & $0,00 \%$ & $0,00 \%$ & $0,00 \%$ \\
\hline & No sabe & $0 \%$ & $3 \%$ & $0 \%$ & $0 \%$ \\
\hline \multirow{3}{*}{$\begin{array}{l}\text { Tiempo de } \\
\text { Atención }\end{array}$} & Suficiente & $97,00 \%$ & $93,00 \%$ & $100,00 \%$ & $95,00 \%$ \\
\hline & Insuficiente & $3,00 \%$ & $6,00 \%$ & $0,00 \%$ & $5,00 \%$ \\
\hline & No sabe & $0 \%$ & $1 \%$ & $0 \%$ & $0 \%$ \\
\hline \multirow{3}{*}{$\begin{array}{l}\text { Indicaciones } \\
\text { claras }\end{array}$} & $\mathrm{Si}$ & $96,00 \%$ & $97,00 \%$ & $100,00 \%$ & $100,00 \%$ \\
\hline & No & $3,00 \%$ & $3,00 \%$ & $0,00 \%$ & $0,00 \%$ \\
\hline & No sabe & $1 \%$ & $0 \%$ & $0 \%$ & $0 \%$ \\
\hline \multirow{4}{*}{$\begin{array}{l}\text { Resolución } \\
\text { Problemas de } \\
\text { Salud }\end{array}$} & Siempre & $75,00 \%$ & $79,00 \%$ & $67,00 \%$ & $79,00 \%$ \\
\hline & Casi siempre & $20,00 \%$ & $9,00 \%$ & $33,00 \%$ & $16,00 \%$ \\
\hline & A veces & $5,00 \%$ & $12,00 \%$ & $0,00 \%$ & $5,00 \%$ \\
\hline & Nunca & $0,00 \%$ & $0,00 \%$ & $0,00 \%$ & $0,00 \%$ \\
\hline \multirow[t]{4}{*}{ Mejora su Salud } & Siempre & $83,00 \%$ & $81,00 \%$ & $67,00 \%$ & $79,00 \%$ \\
\hline & Casi siempre & $12,00 \%$ & $9,00 \%$ & $33,00 \%$ & $16,00 \%$ \\
\hline & A veces & $3,00 \%$ & $6,00 \%$ & $0,00 \%$ & $5,00 \%$ \\
\hline & Nunca & $2,00 \%$ & $3,00 \%$ & $0,00 \%$ & $0,00 \%$ \\
\hline
\end{tabular}




\begin{tabular}{|l|l|l|l|l|l|}
\hline & No sabe & $0 \%$ & $1 \%$ & $0 \%$ & $0 \%$ \\
\hline \multirow{2}{*}{$\begin{array}{l}\text { Volvería a } \\
\text { atenderse }\end{array}$} & $\mathrm{Si}$ & $99,50 \%$ & $100,00 \%$ & $100,00 \%$ & $100,00 \%$ \\
\cline { 2 - 6 } & $\mathrm{No}$ & $0,50 \%$ & $0,00 \%$ & $0,00 \%$ & $0,00 \%$ \\
\hline \multirow{3}{*}{$\begin{array}{l}\text { Recomendaría } \\
\text { CAPS }\end{array}$} & $\mathrm{Si}$ & $99,50 \%$ & $93,00 \%$ & $100,00 \%$ & $100,00 \%$ \\
\cline { 2 - 6 } & No & $0,50 \%$ & $6,00 \%$ & $0,00 \%$ & $0,00 \%$ \\
\cline { 2 - 6 } \begin{tabular}{l} 
Consigue \\
\cline { 2 - 6 }
\end{tabular} & No sabe & $0 \%$ & $1 \%$ & $0 \%$ & $0 \%$ \\
\cline { 2 - 6 } & Siempre & $78,00 \%$ & $67,00 \%$ & $33,00 \%$ & $58,00 \%$ \\
\cline { 2 - 6 } & Casi siempre & $15,00 \%$ & $17,00 \%$ & $33,00 \%$ & $27,00 \%$ \\
\cline { 2 - 6 } & A veces & $6,00 \%$ & $13,00 \%$ & $0,00 \%$ & $0,00 \%$ \\
\hline
\end{tabular}

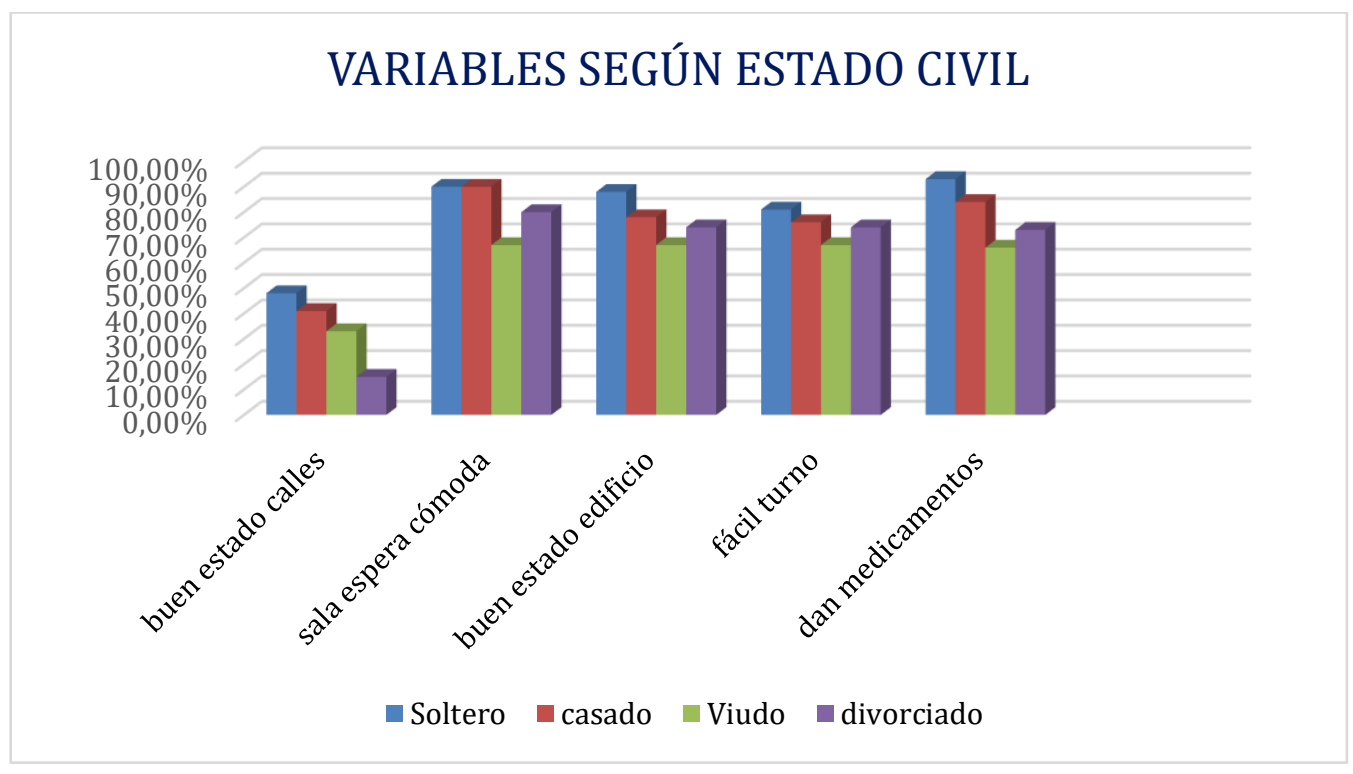

Gráfico N¹7

\section{4-Análisis de las variables de la entrevista abierta al usuario}

\section{externo}

Se realizaron 17 entrevistas abiertas en la Sala de espera del CAPS a personas que llegaban para solicitar un turno o para atenderse con la enfermera o con un profesional. Todos los usuarios que fueron entrevistadas expresaron su conformidad de colaborar con este estudio.

\subsection{1-Análisis variables sociodemográficas de los entrevistados}

De los encuestados el 70\% fueron mujeres y el 30\% hombres y el rango de edad abarcó desde 19 hasta 75 años con una mediana de 38 años. Casi la mitad de los entrevistados declararon que eran amas de casa, un quinto que eran empleados y un quinto jubilados. El resto se agrupó con apenas 5,9\% cada uno entre estudiantes, desempleados y personas con un oficio. La mayoría de los usuarios externos cursó primaria completa, aunque un $19 \%$ refirió primaria incompleta. Terminó la escuela secundaria, el $19 \%$ y no pudo completarla también el 19\%. Hubo sólo 1 entrevistada con terciario incompleto porque aún está estudiando. En cuanto al estado civil, la mitad de las personas contestaron que eran casadas y el $35 \%$ que eran solteras, aunque de éstas algunas se encontraban en uniones de hecho $\sin$ formalizar. El $12 \%$ respondió que era divorciado y el $6 \%$ que era viudo. 


\begin{tabular}{|l|l|l|}
\hline Sexo & Femenino 70\% & Masculino 30\% \\
\hline Edad & 19 a 75 años & Mediana 38 \\
\hline \multirow{5}{*}{ Ocupación } & Ama de casa & $47 \%$ \\
\cline { 2 - 3 } & Empleados & $17,6 \%$ \\
\cline { 2 - 3 } & Jubilados & $17,6 \%$ \\
\cline { 2 - 3 } & Desempleados & $5,9 \%$ \\
\cline { 2 - 3 } & Estudiante & $5,9 \%$ \\
\cline { 2 - 3 } & Oficio & $5,9 \%$ \\
\hline \multirow{5}{*}{ Escolaridad } & Primaria incompleta & $19 \%$ \\
\cline { 2 - 3 } & Primaria completa & $37 \%$ \\
\cline { 2 - 3 } & Secundaria incompleta & $19 \%$ \\
\cline { 2 - 3 } & Secundaria completa & $19 \%$ \\
\cline { 2 - 3 } & Terciario incompleto & $6 \%$ \\
\cline { 2 - 3 } & Terciario completo & 0 \\
\hline \multirow{5}{*}{ Estado civil } & Soltero & $35 \%$ \\
\cline { 2 - 3 } & Casado & $47 \%$ \\
\cline { 2 - 3 } & Viudo & $12 \%$ \\
\cline { 2 - 3 } & Divorciado & \\
\hline
\end{tabular}

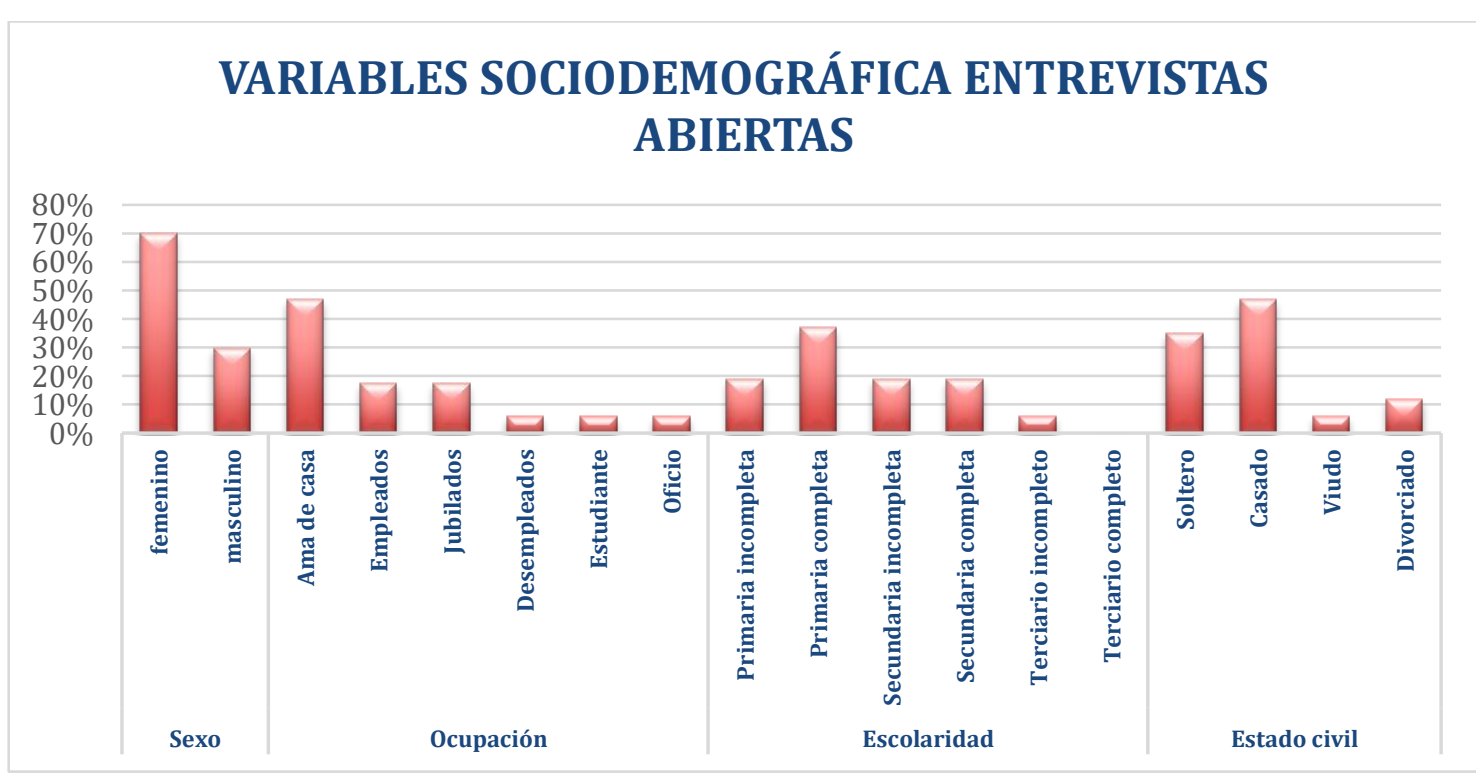

Gráfico N`18

\subsection{2-Análisis variables de estructura, proceso y resultado}

En su mayor parte, los entrevistados calificaron al Centro de Atención primaria de la salud como Bueno y Muy bueno. En cambio, la mayoría opinó que el estado de las calles y las veredas de acceso al CAPS era regular o malo. Al respecto, una mujer que concurrió al control prenatal relató "Prometieron hacer el asfalto en la calle de acceso al CAPS, que son sólo dos cuadras y están en muy mal estado, pero seguimos esperando" y un hombre explicó "no pasan nunca arreglando la calle y la tierra que trajeron para rellenar los pozos es mala." Durante la entrevista una señora mayor dijo "al menos rellenaron los pozos con tierra y se puede andar, pero si llega a llover es imposible pasar." Otra se quejó "Tiraron basura en la vereda y nadie la junta, antes estaban más limpias las veredas y cortaban el pasto. Ahora cuando llueve y la calle se llena de agua, cómo las veredas están abandonadas no tenes por donde pasar" 
Cuando se les preguntó si encontraban dificultad para conseguir turnos, el $60 \%$ respondió que era fácil y el $40 \%$ que era difícil. Un hombre que aguardaba ser atendido por el médico clínico refirió: "es facilísimo sacar turno, yo siempre consigo." En cambio, una mamá contó que debe levantarse muy temprano si quiere conseguir turno para el pediatra y agregó "el CAPS no tiene teléfono para hacer preguntas o sacar turno, tenes que venir hasta acá, sí o sí. A mí con los chicos me cuesta un montón"

Sobre el estado del edificio y la limpieza más del $80 \%$ de los encuestados los calificó como buenos. Sin embargo, una mujer relató "la limpieza es buena, pero a veces barren mientras estamos sentados en la sala de espera y levantan polvillo. Yo tuve que sacar a mi hijo afuera porque sufre de asma y le hace mal." Otro usuario comentó que "falta un cesto de basura en la sala de espera, la gente deja los papeles o bolsitas sobre las sillas."

Con respecto al edificio, aunque la mayoría lo evaluó en buen estado, algunos entrevistados refirieron que "las paredes están descascaradas y con humedad," "Las sillas de la sala de espera son incómodas," "Los consultorios tienen poco espacio." "Falta que lo pinten." "El edificio tiene una buena construcción, pero tiene sus años y le falta mantenimiento"

Todos los usuarios declararon que el personal es amable. Y muchos agregaron "siempre me ayudan." "Todos son muy buenos."

El 81\% de las personas entrevistadas afirmó que el tiempo de atención de los profesionales es suficiente, pero una usuaria se quejó porque algunos profesionales no respetan los horarios de atención. "Si nosotros tenemos que estar a horario cuando nos toca el turno y dejamos de hacer nuestras cosas, ellos también tienen que respetar el horario que tienen que atender." Otra pidió que el horario de atención fuera más prolongado "El médico tiene que estar más tiempo en la salita, y que cierre más tarde para no tener que ir hasta el hospital que queda lejos." Una señora comentó "La gente pregunta si hay un médico porque necesita atenderse y la mayor parte del tiempo sólo está la enfermera que te pregunta que te pasa y según lo que tengas te manda al hospital o te dice que vuelvas al otro día cuando viene el doctor."

El 71\% solicitó la incorporación de otras especialidades como odontología, cardiología y estimulación temprana. Un hombre refirió que necesita que atienda un odontólogo en el CAPS, "porque a veces no tengo dinero para pagar un remis hasta el hospital".

El 94\% encontró las indicaciones de los profesionales, claras. Una usuaria dijo "el doctor me anota todo." Otra contó, "si, me tienen mucha paciencia, por lo menos a mí me explican todo, tanto los doctores como las enfermeras."

Casi todos afirmaron que les entregaron la medicación cuando la requirieron. Sólo el 18\% dijo haber sido atendido con un turno programado y el $100 \%$ opinó que no se realizan actividades de prevención o por lo menos que desconoce si se realizan. "Si hacen yo no me enteré y vengo todas las semanas a la salita."

Cuando se les preguntó si les interesaría participar en la sociedad de fomento del barrio, el $68 \%$ respondió que sí, pero algunos aclararon que, aunque desean colaborar, no tienen tiempo. Todos los encuestados contestaron que el CAPS puede resolver los problemas de salud que presenta la población del barrio y que contribuye a mejorar el estado saludable de la misma. Un usuario comentó "A mí la salita me ayuda, me resuelve mucho. Mi hijo tuvo un accidente y se fracturó el peroné y la asistente social me consiguió las muletas. ¿De dónde iba a sacar yo las muletas? no puedo alquilarlas. Acá todos te ayudan mucho." El $88 \%$ de los encuestados dijo que el CAPS cubre sus expectativas. 


\begin{tabular}{|c|c|c|}
\hline \multirow[t]{4}{*}{ Califica CAPS } & Muy Bueno & $18 \%$ \\
\hline & Bueno & $82 \%$ \\
\hline & Regular & 0 \\
\hline & Malo & 0 \\
\hline \multirow[t]{4}{*}{ Estado de calles y veredas } & Muy bueno & 0 \\
\hline & Bueno & $18 \%$ \\
\hline & Regular & $12 \%$ \\
\hline & Malo & $70 \%$ \\
\hline \multirow[t]{2}{*}{ Obtener turno } & Fácil & $60 \%$ \\
\hline & Difícil & $40 \%$ \\
\hline \multirow[t]{4}{*}{ Estado edificio } & Muy bueno & $12 \%$ \\
\hline & Bueno & $70 \%$ \\
\hline & Regular & $12 \%$ \\
\hline & Malo & $6 \%$ \\
\hline \multirow[t]{3}{*}{ Limpieza } & Buena & $88 \%$ \\
\hline & Regular & $12 \%$ \\
\hline & Mala & 0 \\
\hline Amabilidad & $\mathrm{Si}$ & $100 \%$ \\
\hline \multirow[t]{2}{*}{ Tiempo de atención } & Suficiente & $81 \%$ \\
\hline & Insuficiente & $19 \%$ \\
\hline \multirow[t]{2}{*}{ Incorporar más profesionales } & $\mathrm{Si}$ & $73 \%$ \\
\hline & No & $27 \%$ \\
\hline \multirow[t]{2}{*}{ Indicaciones claras } & $\mathrm{Si}$ & $94 \%$ \\
\hline & No & $6 \%$ \\
\hline \multirow[t]{2}{*}{ Recibe medicación } & $\mathrm{Si}$ & $94 \%$ \\
\hline & No & $6 \%$ \\
\hline \multirow[t]{2}{*}{ Turno programado } & $\mathrm{Si}$ & $18 \%$ \\
\hline & No & $82 \%$ \\
\hline Actividades de prevención & No & $100 \%$ \\
\hline \multirow[t]{2}{*}{ Participación social } & $\mathrm{Si}$ & $68 \%$ \\
\hline & No & $32 \%$ \\
\hline Resolución problema de salud & $\mathrm{Si}$ & $100 \%$ \\
\hline Mejora salud barrio & $\mathrm{Si}$ & $100 \%$ \\
\hline \multirow[t]{2}{*}{ Cubre expectativas } & $\mathrm{Si}$ & $88 \%$ \\
\hline & No & $12 \%$ \\
\hline
\end{tabular}

\section{VARIABLES ENTREVISTA ABIERTA UE}

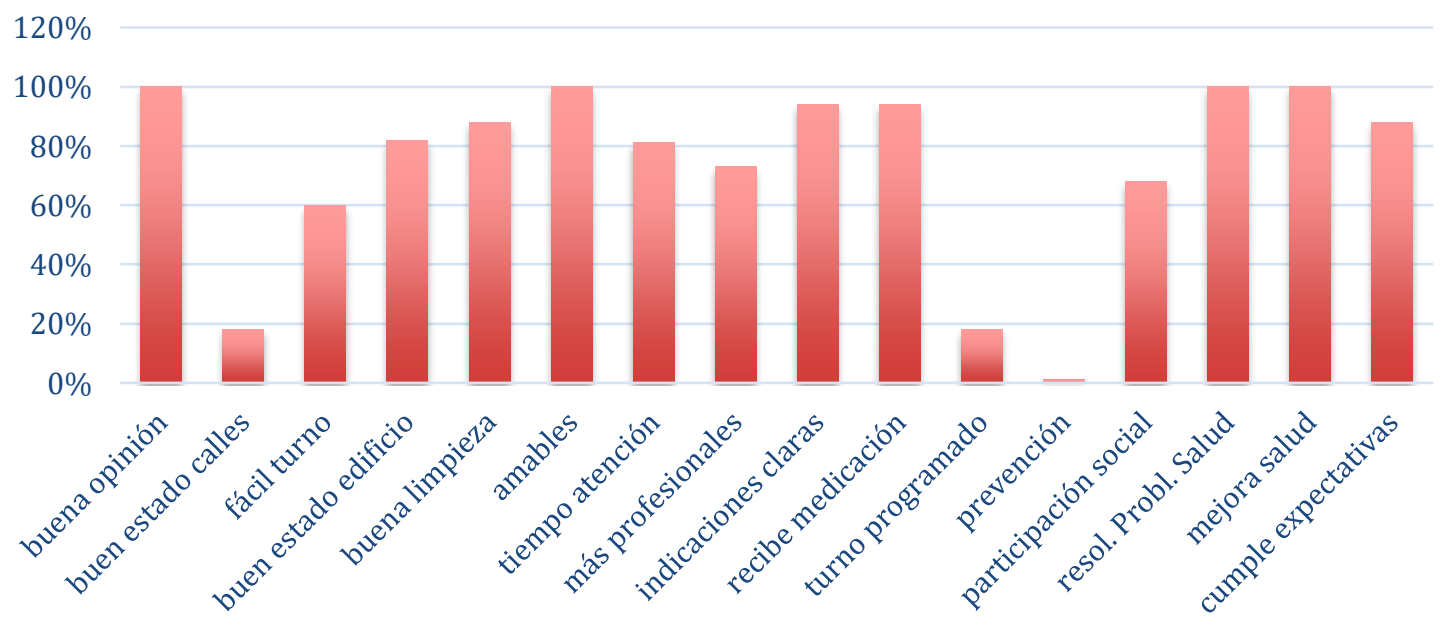




\subsubsection{Análisis de las respuestas según el género de los entrevistados}

No se hallaron diferencias significativas entre las respuestas de ambos géneros.

\subsection{4-Análisis de las respuestas según la edad de los entrevistados}

En cuanto a la edad de los entrevistados, la mayoría de las respuestas de los menores de 38 años y los mayores de esa edad, no presentaron diferencias significativas, excepto cuando se les preguntó si la oferta de especialidades del CAPS es suficiente. La mitad de los menores de 38 años contestaron que es suficiente, en cambio, todos los mayores de 38 años solicitaron otros profesionales como odontólogos, cardiólogos, etc. También al preguntarles si alguna vez fueron citados con un turno programado, todos los mayores de 38 años respondieron que no y $33 \%$ de los menores que sí.

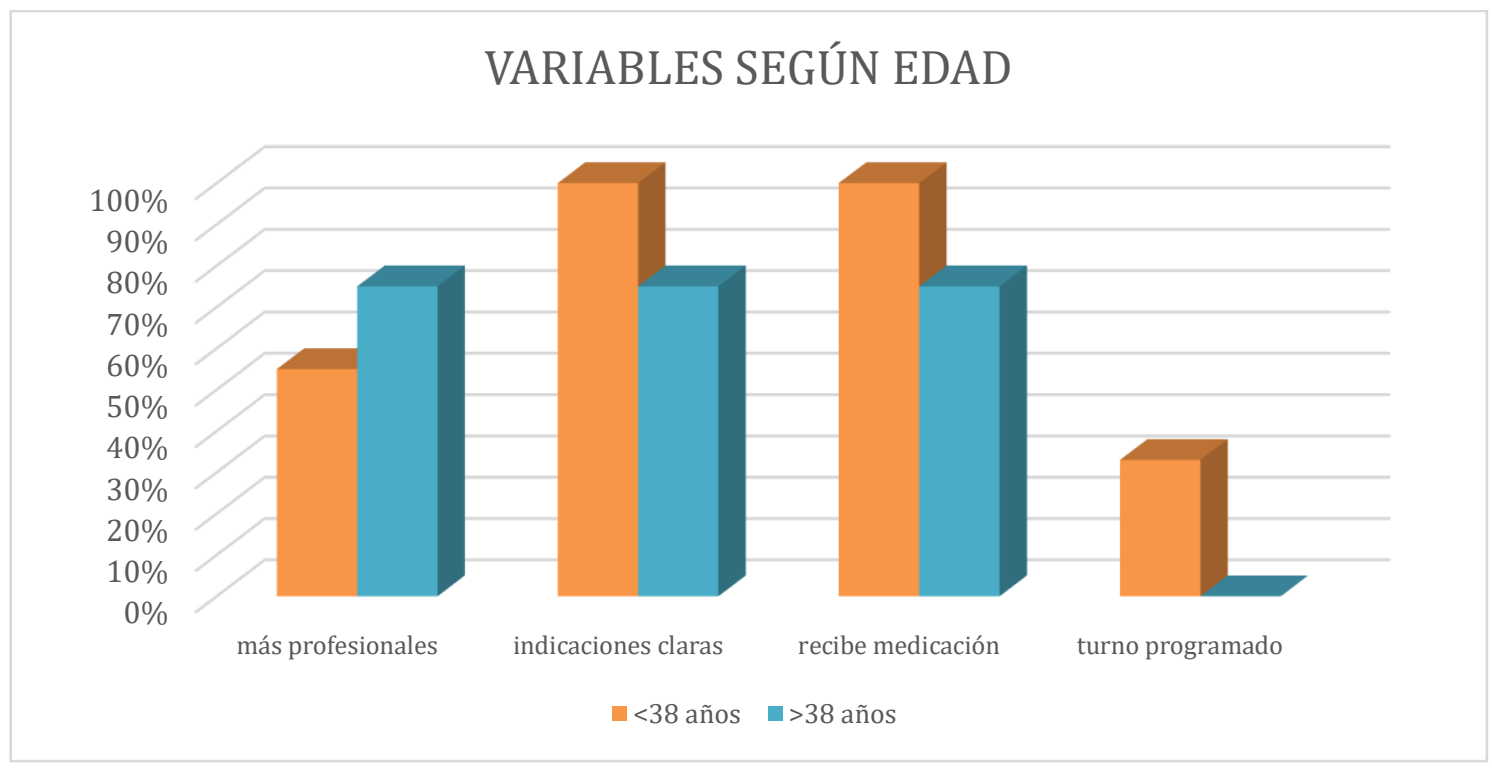

Gráfico $N^{\circ} 20$

\subsection{5-Análisis de las respuestas según la ocupación de los entrevistados}

Cuando se analizaron las respuestas según la ocupación de los usuarios no se encontraron diferencias en la calificación del CAPS, todos lo consideraron como muy bueno y bueno. Sobre el estado de las calles y veredas de acceso al CAPS, casi todos los entrevistados opinaron que era regular y malo, salvo los jubilados que lo describieron como bueno y muy bueno. Conseguir un turno fue fácil para los empleados, estudiantes, personas con oficio y para el $62,5 \%$ de las amas de casa. Pero para la mayoría de los jubilados, $67 \%$, fue difícil. El estado del edificio, en general, fue calificado por los encuestados como muy bueno y bueno, excepto por el $100 \%$ de los desempleados y el $33 \%$ de los empleados que lo describieron como regular. En cuanto a la limpieza todos los entrevistados afirmaron que era buena, salvo para el 33\% de los empleados que la juzgó como regular. Al preguntarles sobre el tiempo de atención de los profesionales, la mayoría de los usuarios externos respondió que era suficiente, pero el $25 \%$ de las amas de casa y el $34 \%$ de los empleados consideró que era insuficiente. Las amas de casa, los jubilados y las personas con oficio solicitaron la incorporación de más especialidades. En cambio, la mitad de los empleados y 
la totalidad de los estudiantes respondieron que no era necesario. Sólo el $25 \%$ de las amas de casa y el $34 \%$ de los empleados contestaron que recibieron un turno programado, el resto no. Cuando se les preguntó si les interesaría participar de la sociedad de fomento del barrio, afirmaron que sí, el $33 \%$ de los empleados, el $62 \%$ de las amas de casa y el $100 \%$ de las personas con oficio, los desempleados y los jubilados. Sobre las expectativas de los usuarios externos sobre el CAPS, únicamente no estuvieron satisfechas el $37,5 \%$ de las amas de casa.

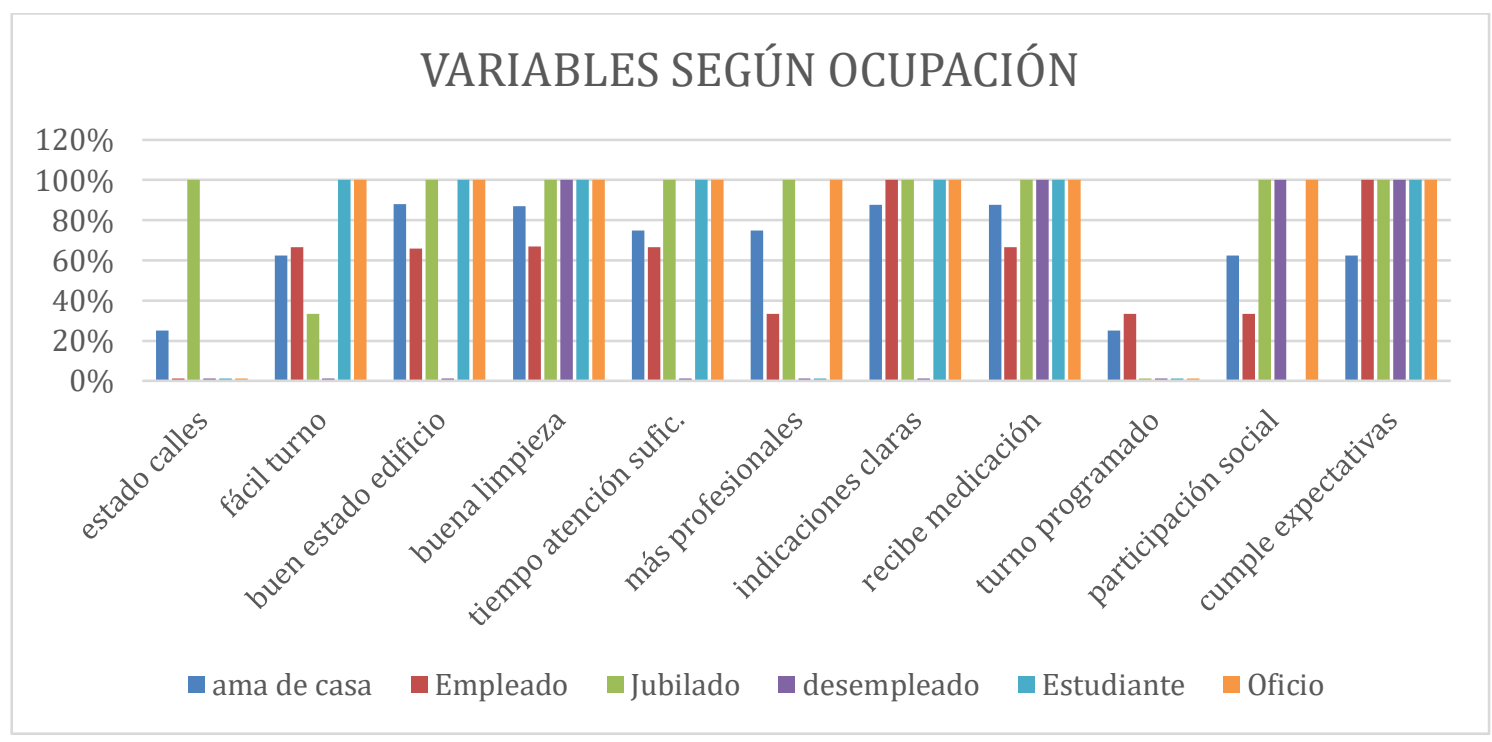

Gráfico N²1

\subsection{6-Análisis de las respuestas según la escolaridad de los entrevistados}

No se observaron diferencias en la calificación del CAPS si se tiene en cuenta la escolaridad de los entrevistados, al momento de analizar las respuestas. Todos los usuarios externos opinaron que las calles y veredas se encontraban en regular y mal estado, salvo para un tercio de los que cursaron educación $1^{\circ}$ y $2^{\circ}$ incompletas que refirieron como bueno el estado de las mismas. Al $100 \%$ de los que tienen escuela primaria incompleta y estudios secundarios y terciarios completos les resultó fácil sacar un turno. En cambio, al $66 \%$ de las personas que no terminaron la secundaria y al 33\% que completó la educación primaria les fue difícil. Sobre el estado del edificio, en general, los entrevistados opinaron que era bueno, excepto para el $100 \%$ del grupo con $2^{\circ}$ incompleta y un tercio de los que finalizaron el secundario que lo definieron como regular. Cuando se les preguntó sobre la limpieza del CAPS todos la calificaron como buena, salvo un tercio de las personas que terminaron la educación secundaria. Idéntica fue la respuesta sobre el tiempo de atención. La totalidad de las categorías con $1^{\circ}$ completa e incompleta y el $66 \%$ de la categoría con $2^{\circ}$ incompleta estuvieron de acuerdo con agregar otras especialidades que necesita el barrio, como odontología, cardiología y estimulación temprana. El resto, en su mayoría, opinó que no hacía falta. Sobre las indicaciones de los profesionales o de la enfermera sólo el $33 \%$ de los UE con $1^{\circ}$ incompleta expresó que no las entiende. El $66 \%$ de las personas que completaron la escuela $1^{\circ}$ y todos los que cursaron estudios superiores recordaron haber sido citados con un turno programado. Al preguntarles si les interesaría participar en la sociedad de fomento del barrio, un tercio de los usuarios con $1^{\circ}$ completa y $2^{\circ}$ incompleta y $66 \%$ de los que completaron la educación secundaria explicaron que no podían, no tenían tiempo o no 
les interesaba. Un tercio de los entrevistados que no completaron la educación primaria y secundaria expresaron que el centro de salud no cubría sus expectativas.

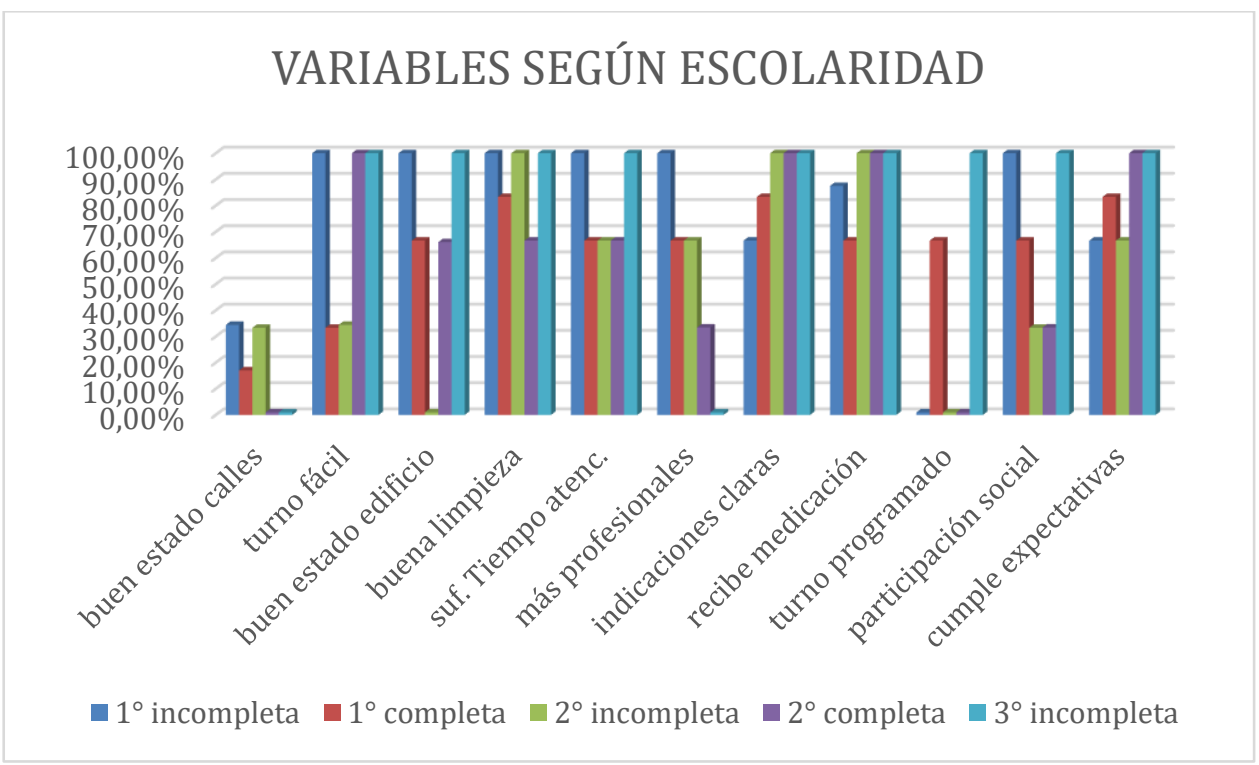

Gráfico N²2

\subsection{7-Análisis de las respuestas según el estado civil de los entrevistados}

Cuando se analizaron las respuestas según el estado civil de las personas entrevistadas se observaron diferencias en las evaluaciones del estado de las calles y veredas de acceso al CAPS. La mayoría valoró el estado de las mismas como regular o malo, pero el $100 \%$ de los divorciados opinó que era bueno. En cuanto al trámite para obtener un turno, los solteros dijeron que era fácil, al igual que la mitad de los casados y divorciados. En cambio, el $100 \%$ de los viudos admitió que era difícil. Los mismos que calificaron la limpieza como regular cuando el resto de los usuarios, en su mayoría, contestó que era buena. Sólo el $66 \%$ de los solteros solicitó la incorporación de más profesionales, los demás encuestados respondieron que no hacía falta. Al preguntarles si entendían las indicaciones de los médicos o de las enfermeras todos respondieron que sí, a excepción, de la mitad de los divorciados que no las comprendieron. No consiguieron la medicación en el CAPS que les había sido recetada el $50 \%$ de los divorciados. El $100 \%$ de los viudos y divorciados contestaron que en alguna oportunidad fueron citados con un turno programado. Sobre la posibilidad de participar en la sociedad de fomento del barrio todos se mostraron interesados, en cambio la mitad de los casados enumeró motivos por los que no podía colaborar. En referencia a las expectativas de los usuarios externos, la mayoría aseguró que estaban satisfechos, salvo por la mitad de los divorciados. 


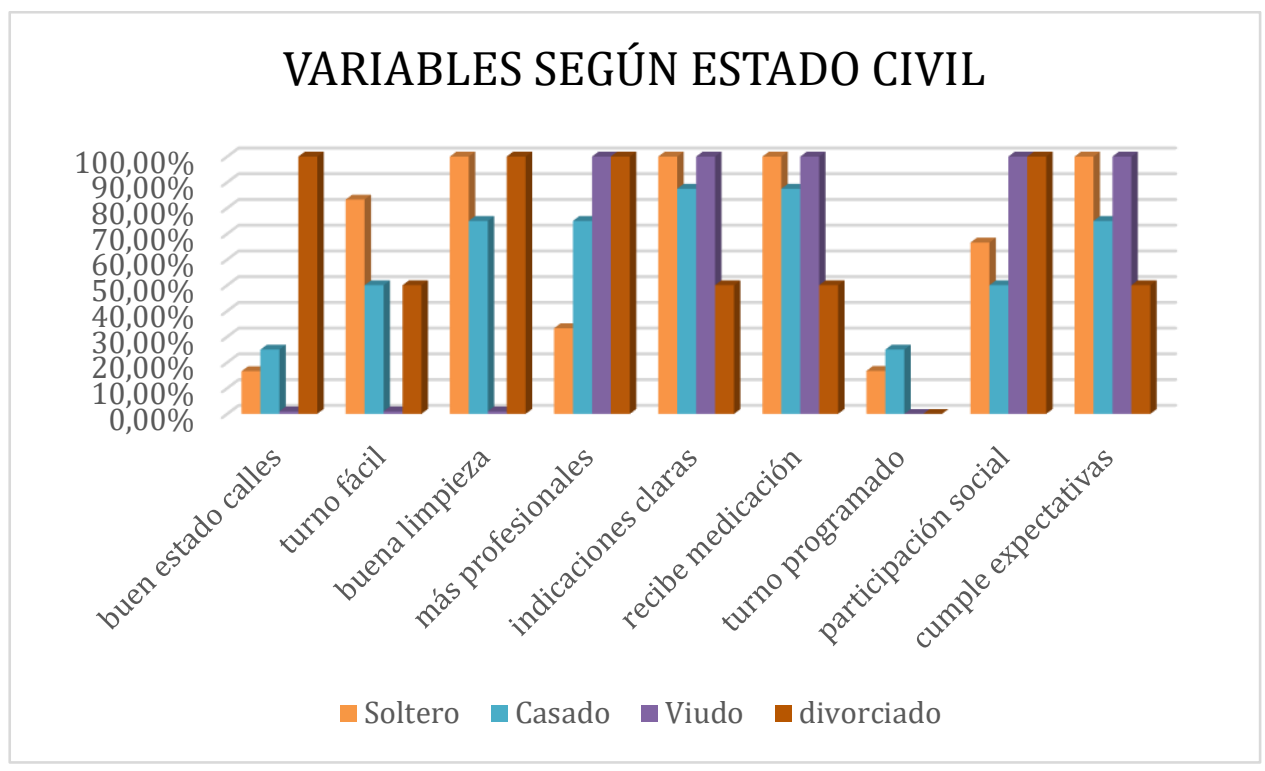

Gráfico $\mathrm{N}^{\circ} 23$

\section{5-Análisis de las variables del grupo focal}

Se realizó un grupo focal en el CAPS Entre Ríos Norte entre: las 2 enfermeras, obstétrica, promotora de salud, pediatra, fonoaudióloga, mucama, administrativa, y asistente social. En total 9 personas, $60 \%$ del personal. Todas las participantes fueron del género femenino, con edades entre 35 y 55 años, con más de 6 años de antigüedad en el centro de salud y con distintos regímenes de trabajo. Algunas pertenecen al Programa Médicos Comunitarios, otras son empleadas bajo relación de dependencia del municipio y una integra una cooperativa de limpieza.

Sobre los objetivos del CAPS, todas aseguraron conocerlos y estuvieron de acuerdo con los mismos, sin embargo, se quejaron de que no se los hubieran explicitado. "Yo diría que no hay políticas de salud. Te pregunto cuál es la política de salud de este centro. No sabemos. Nadie nos informó. Antes te exigían que des charlas, que salgas al barrio, que cada fecha del calendario había que preparar un afiche o un taller, hacíamos el PROSANE. El concepto era, no que la gente llegue al centro de salud, sino que el centro vaya al barrio. Eso es lo que cambió." Repitieron muchas veces la palabra compromiso, como un objetivo propio. Refirieron que se necesita del compromiso de todos, trabajadores y autoridades para mejorar la salud de la comunidad.

Todas las participantes opinaron que las calles y veredas de acceso al centro de salud están en malas condiciones. "Hicieron el asfalto a todos los otros CAPS ¿Por qué a nosotros no? Son 2 cuadras. Me cuesta a mí a veces llegar y vengo en auto, imagínate la gente que viene caminando, en moto o bicicleta."

La mayoría de las trabajadoras evaluó como regular a malo el estado del edificio. "No es adecuada la distribución de los consultorios y hay filtraciones de humedad." "Es muy chico, tiene humedad y problemas de mantenimiento." "A veces la calefacción no funciona y en algunas partes la iluminación y ventilación no es adecuada." "Las estufas funcionan todas, el problema está en las chapas que hace que se llueva la cocina y el pasillo." "Las paredes llenas de humedad y sucias, habría que pintarlas."

Expresaron quejas sobre la limpieza: "Nunca limpian los vidrios de las ventanas", "Cuando llego a la mañana tengo que repasar los muebles porque está todo lleno de tierra, y no es mi trabajo." 
En cuanto a la forma de otorgar los turnos, algunas estuvieron conformes y otras no. "Para mí está bien como se dan los turnos, así está más organizado." "Me parece que tienen que respetar más los turnos, si la doctora no puede venir a atenderlas un día, tendría que citarlas para el día siguiente, no puede abandonarlas." "Yo lo que hago cuando un profesional no atiende es pasar los turnos para la semana siguiente, pero puede pasar que tampoco venga, porque es el arreglo que tiene con el municipio. Primero atiende las urgencias del hospital y si puede y le queda tiempo y no está muy cansada entonces viene al CAPS." "Ahora que los damos el mismo día, la gente no tiene que esperar."

Con respecto al instrumental de trabajo, las opiniones estuvieron divididas. "En mi área de trabajo no dispongo de material, sólo artículos de librería y muy escasos. El resto lo traigo yo de mi casa para poder trabajar mejor." "Yo no tengo problemas porque mi trabajo es administrativo y no requiere de mucho material. Me dan las lapiceras, los marcadores y las hojas que tengo que completar." "En cambio yo tengo un problema y es que el espacio no es adecuado, se escucha lo que se habla adentro del consultorio desde el pasillo y los otros consultorios, aunque hablemos bajo y algunas personas hablan fuerte y no tengo cómo controlarlo." "Yo cuento con todo lo que necesito para trabajar, tengo la camilla, la balanza, el tensiómetro, el estetoscopio, no me falta nada.

Sobre el sistema de información, en general, refirieron que era deficiente y propusieron ideas para mejorarlo. "Tendríamos que tener una cartelera donde esté toda la información al alcance de todos." "Necesitamos computadoras con internet para tener toda la información actualizada, informatizarnos." "Si, hay que actualizamos, nuestro sistema de información está caduco" "Yo formaría un grupo de WhatsApp para que estemos todos los trabajadores comunicados. Cuando estás preocupada por una paciente que no vino o queres citar una paciente y no te acordás donde vive, podes preguntar por el WhatsApp y tal vez la vio la enfermera o la pediatra atendió al hijo, o sea, el que sabe algo te avisa y la podés contactar."

Existieron diferencias de opinión con respecto a los conflictos entre los trabajadores. "Yo comparo con otros lugares donde trabajo y para mi acá no hay conflictos. Puede ser que estoy poco tiempo en el CAPS y por eso no los vea." "Yo creo que los conflictos son porque no hay reuniones y por culpa de los jefes que no hacen su trabajo". "Estoy de acuerdo, los jefes tendrían que hacer reuniones para que hablemos de nuestros problemas para poder solucionarlos." También hubo distintas opiniones sobre la resolución de los mismos. "Los jefes tendrían que hacer reuniones para que nos pongamos de acuerdo." "Lo que pasa es que no existe un tiempo y un espacio destinado a tal fin, para hablar sobre los conflictos." "Tendríamos que tener al menos una reunión por mes para hablar sobre todos los problemas." "Yo creo que es mejor que los problemas los solucionemos entre compañeros sin que se metan los jefes." "Yo considero que, de ser necesario, si tengo que intervenir en una reunión para solucionar los conflictos, podría hacerlo y tendría lugar para mis opiniones."

La mayoría estuvo de acuerdo con agregar otras especialidades como odontología y Estimulación Temprana al equipo de salud del CAPS. Además, acordaron que era necesario aumentar las horas de atención de algunos profesionales.

Sobre el trabajo interdisciplinario y en red todas las participantes opinaron que debería mejorarse. "Trabajar en equipo que es más fácil, más placentero." "Estaría bueno que pudiéramos reunirnos una vez por semana para hablar sobre nuestros pacientes, y no a las apuradas o por teléfono como ahora." "Las asistentes sociales de las escuelas vienen a verme, pero no hay nada organizado de como trabajar juntas."

Todas las usuarias internas reconocieron en el grupo focal que habían recomendado el CAPS y casi todas aseguraron que habían solicitado atención para ellas mismas o para un familiar. "Yo me hago atender y lo recomiendo a familiares y amistades." "Me atendí algunas veces y vine con familiares y amigos sobre todo para vacunarse." "Yo digo que no todos los profesionales son para recomendar, pero la mayoría sí." "Yo también lo 
recomiendo, vine con mis nietas para que las atiendan y cada vez que tuve una urgencia también me atendí yo." "Como tengo mi médico por la obra social yo no me atendí nunca, pero si lo recomiendo." "Yo si me atendí y también mi hijo porque para mí la atención es muy buena y se hace lo mejor que se puede."

Las participantes del grupo focal refirieron cierto nivel de satisfacción con su trabajo, pero también algún grado de disconformidad. En su mayoría, atribuyeron la insatisfacción a la ausencia de gestión. Reclamaron que los gestores establezcan objetivos y planifiquen para orientar al equipo de salud y para aunar los esfuerzos de todos los trabajadores,

\section{7- DISCUSIÓN Y CONCLUSIONES}

El presente estudio mostró que la percepción de los usuarios externos e internos sobre la atención del centro de salud Entre Ríos Norte es muy buena y buena. La satisfacción fue mayor al $80 \%$ para ambos usuarios y este porcentaje coincide con otros trabajos sobre percepción de calidad. Por ejemplo, el estudio de Gonzalez Pastora sobre satisfacción de los usuarios en atención primaria que obtuvo $85 \%$ de satisfacción, la Encuesta de Satisfacción de Usuarios con los servicios de Atención Primaria del año 2000, que alcanzó el $88 \%$ de satisfacción y el trabajo de investigación de Arrondo, Barragán, Etchegoyen y Paganini en el cual el nivel de calidad global (expresado en porcentaje promedio de cumplimiento de los estándares) fue de $80 \pm 15 \%$ en los centros de salud de la provincia de Buenos Aires.

Cerca del $90 \%$ de los entrevistados percibió que el CAPS resuelve los problemas de salud de las personas y mejora su estado de salud. Este porcentaje está levemente por encima del obtenido en el estudio de Reyes Morales y otros, sobre "Percepción de los usuarios sobre la calidad de la atención ambulatoria en servicios de salud en México," que alcanzó el 80\% solamente. Por esta valoración positiva de los encuestados es que casi el $100 \%$ de los mismos, lo recomienda y decide atenderse en el CAPS. Esta calificación coincide con otros trabajos de investigación como el de Martinez Duque en Bogotá dónde el 100\% de los pacientes manifestaron adherencia institucional y el de Szwako y Vera en Paraguay dónde el $98 \%$ de los encuestados contestó que recomendaría al centro de salud.

La mayoría de los usuarios consideró que el personal fue amable. Respondieron positivamente sobre la amabilidad de las enfermeras el $95 \%$ y sobre los profesionales el 92\%. Resultado similar a la investigación de la Dra. Mélida Bravo Tapia, que obtuvo 100\% entre trato "bueno" y "muy bueno" del personal.

El $87 \%$ de los usuarios internos y el $80 \%$ de los externos calificaron como "fácil" la obtención de un turno. Este valor es superior al de la Encuesta de satisfacción de los usuarios con los servicios de Atención Primaria 2000 de Alfaro Latorre y colaboradores dónde un $75 \%$ de los entrevistados, consideraron que conseguir cita con su médico fue "fácil". En las entrevistas abiertas las personas que consideron difícil sacar un turno lo atribuían al hecho de que debía hacerse personalmente, concurriendo al CAPS, porque no cuenta con la modalidad de turno por teléfono o internet.

Sobre el tiempo de atención, existió cierta discrepancia de percepción entre los usuarios. Como "suficiente" respondió el $95 \%$ de los usuarios externos, en cambio sólo el $73 \%$ de los internos. Esta diferencia se puede explicar observando las respuestas del grupo focal realizado con los trabajadores del CAPS, dónde se evidenció que algunos profesionales reclamaban más horas de atención para mejorar su desempeño. De todas maneras, resultó excesivo el valor positivo en las respuestas de los usuarios externos, si comparamos con el trabajo de investigación de Szwako y Vera dónde el $81 \%$ de los entrevistados (pacientes), 
respondió que "siempre" es suficiente. Puede que haya existido un sesgo en la interpretación de la pregunta de parte de los encuestados. Es un punto a corregir en los cuestionarios cerrados.

En el trabajo de Galvis, "Calidad de Atención de Salud Percibida por el Usuario del área de consulta de Medicina de familia del ambulatorio Tipo III Venezuela, Mérida, diciembre 2005" la casi totalidad de los encuestados calificaron la accesibilidad geográfica como muy buena y excelente. Por el contrario, en este estudio, la mitad de los usuarios externos y el 93\% de los trabajadores contestaron que el estado de calles y veredas era "regular" y "malo." Esta discrepancia en ambas investigaciones puede interpretarse según las declaraciones realizadas en las entrevistas abiertas y el grupo focal dónde afirmaron que las calles de acceso y las veredas son de tierra y que se vuelven intransitables en días lluviosos porque tienen poco mantenimiento. Aseguraron también, que tanto los trabajadores como los que consultan deben llegar por sus propios medios al CAPS porque Bragado no cuenta con transporte público. Probablemente, el personal no profesional que debe concurrir todos los días a trabajar y en general, se transporta en bicicleta o motocicleta, es el que más sufre la inaccesibilidad.

Es importante tener en cuenta para luego hacer las recomendaciones, que todos los entrevistados concordaron en que no se realizan actividades de prevención y solicitaron la incorporación de otros profesionales como, odontólogos, cardiólogos, maestras de estimulación temprana, etc. para completar los equipos de salud. Estas definiciones surgieron también muy claras en las entrevistas abiertas y el grupo focal.

Se observaron diferencias en las respuestas sobre el estado del edificio, los UE lo calificaron como "muy bueno" y "bueno", en cambio, los UI como "regular". La discrepancia de opinión puede atribuirse a que la mayoría de los problemas del edificio como, humedad en las paredes, techos que se llueven, cañerías que no funcionan, no son observables a simple vista. La sala de espera donde la gente pasa el mayor tiempo está en muy buenas condiciones y fue refaccionada hace pocos meses. Los trabajadores pudieron observar mejor el deterioro edilicio y lo expresaron en el grupo focal.

Sobre la limpieza, los UE la consideraron como "muy buena" y "buena" en cambio, los UI como "buena" y "regular". La valoración de los UE fue similar a otros estudios, como el de Martinez Duque dónde el $71 \%$ opinó que la limpieza era buena y el 13\% muy buena. La baja calificación de los UI se interpreta por las expresiones de los trabajadores en el grupo focal dónde se quejaron porque "no se limpiaban los vidrios de las ventanas" y no se repasaban todos los días los muebles "que se llenaban de tierra."

Los usuarios externos respondieron que estaban conformes con la atención y que casi siempre obtenían la medicación o método anticonceptivo recetado. Cabe aclarar que el centro de salud cuenta con el Programa Remediar y Programa Nacional de Salud Sexual y Procreación responsable y además recibe los medicamentos más necesarios del laboratorio de monodrogas del municipio.

Todos los usuarios internos percibieron su trabajo como importante, dijeron que "casi siempre" dispusieron del instrumental y los insumos necesarios para su desempeño, y que se sintieron reconocidos por sus superiores, aunque no recibieron incentivos. Aceptaron la existencia de conflictos entre los trabajadores y aproximadamente la mitad de los UI estuvieron de acuerdo con la forma de resolverlos. En el grupo focal expresaron que no cuentan con normas o protocolos para la resolución de los conflictos, que no se reúnen para tal fin y que el personal los resuelve como puede o quedan sin resolver. 
La mitad de los UI aseguró desconocer el sistema de información del centro de salud. Actualmente, los centros de salud no tienen computadoras ni servicio de internet, aunque las autoridades han planificado informatizarlos, y en ciertos CAPS ya comenzaron.

En cuanto a las variables sociodemográficas, más del 70\% de los usuarios externos y más del $80 \%$ de los usuarios internos entrevistados, se identificaron con el género femenino. Esta diferencia significativa se repite en varios trabajos de investigación como, por ejemplo, el de Barrero Castro en Colombia dónde el $68,2 \%$ de las encuestas las respondieron mujeres. Ese alto porcentaje explica que en la categoría ocupación de las entrevistas cerradas a los usuarios externos la mitad contestaran "amas de casa". En general, en la población donde se desarrolló esta investigación la mujer es quien se encarga, principalmente, del cuidado de los niños. Por lo tanto, ellas realizan el mayor número de consultas, ya sea para control del embarazo, control de sus hijos, cuando los niños se enferman y para su propia atención. En cuanto al personal, las tareas administrativas, de limpieza y de enfermería en casi su totalidad las realizan mujeres. También profesiones como obstetricia, fonoaudiología y psicopedagogía son ejercidas en un $100 \%$ por personas del género femenino. Esto se repite en todos los CAPS de Bragado

En el estudio de Barrero Castro el $44.65 \%$ de los encuestados respondieron estar casados, un $24.16 \%$ manifestaron estar solteros, un $23.24 \%$ dijeron estar en unión libre, mientras que sólo un $3,98 \%$ reportaron estar separados o divorciados y un $3.98 \%$ que eran viudos. En este estudio se incurrió en el error de no incluir la opción "unión libre" o "de hecho," por lo cual quedó sobrevalorada la categoría "soltero". De los usuarios externos el $66 \%$ contestó "soltero" en la entrevista cerrada al no tener la opción correcta, que los incluyera.

Cuando se analizaron las respuestas de las entrevistas cerradas al usuario externo según las distintas variables sociodemográficas, no se encontraron diferencias significativas que estén relacionadas con una u otra variable. Además, no son comparables las categorías ya que no son uniformes. Por ejemplo, dos tercios de los encuestados fueron del género femenino y solteros, más de la mitad respondió ser amas de casa, etc. De todas maneras, no se observaron relaciones entre las características sociodemográficas y una valoración positiva o negativa.

Se hallaron diferencias con respecto a las respuestas de los usuarios internos en relación a las distintas variables sociodemográficas. En cuanto a la edad, los más jóvenes calificaron mejor el estado del edificio, la limpieza y el trabajo intersectorial, pero sintieron menos reconocimiento. Aseguraron mayor conflictividad entre trabajadores y demostraron tener menos conocimiento del sistema de información que los mayores. Si relacionamos las respuestas de los $\mathrm{UI}$ con el género de los mismos encontramos, que el género femenino sintió mayor reconocimiento y afirmó en mayor proporción que contaba con el instrumental necesario para su labor. Además, las mujeres demostraron más conocimiento del sistema de información y aseguraron más que los hombres que el CAPS resuelve los problemas de salud del barrio. En cambio, sobre el seguimiento de los pacientes fue más alta la valoración del género masculino. En cuanto a la escolaridad de los usuarios internos se observó, que los que completaron solamente la escuela primaria calificaron mejor la limpieza, no observaron conflictos y todos desconocían el sistema de información. Sintieron más reconocimiento que los otros grupos, pero refirieron mayor dificultad para conseguir el instrumental para su trabajo. Si comparamos por puesto de trabajo, la única diferencia que se encontró, fue que los profesionales declararon mayor conflictividad que los no profesionales. Si cotejamos según la antigüedad, presentaron menor satisfacción los que hace menos tiempo que trabajan en el centro de salud y si lo hacemos por cantidad de horas de trabajo, tuvieron menos satisfacción los que cumplen menos horas en el CAPS. 


\section{8- RECOMENDACIONES}

Las similitudes encontradas en este trabajo en la percepción de los usuarios externos e internos sobre algunas de las dimensiones de la calidad, resultan muy útiles para tener en cuenta al momento de definir objetivos, establecer prioridades de acción sobre la estructura y el funcionamiento del centro de salud y para planificar con la finalidad de mejorar el grado de satisfacción de todos los usuarios.

Del presente estudio surgen las siguientes recomendaciones. Es primordial mejorar el acceso al centro de salud, si es posible, asfaltando las calles ya que la mayoría de las personas que se acercan al CAPS para consultar y algunos trabajadores lo hacen caminando, en bicicleta o motocicleta. El edificio, aunque en buenas condiciones, requiere mantenimiento periódico como cualquier inmueble. Deben establecerse prioridades de reparación y cuidados continuos. Es necesario completar los equipos de salud con otros profesionales como odontólogos, maestras de Estimulación Temprana, etc. y fomentar el trabajo interdisciplinario e intersectorial. Es importante comenzar cuanto antes con actividades de prevención. Un centro de atención primaria de la salud que no realiza prevención, no cumple con su principal objetivo de mejorar en forma integral la salud de la comunidad que asiste. Deben establecerse protocolos para la resolución de los conflictos y para la gestión del CAPS. Es imperativo informatizar el centro de salud y capacitar a todo el personal sobre el sistema de información.

\section{9-REFERENCIAS BIBLIOGRÁFICAS}

1. Aguirre Gas, H. (1990). Evaluación y garantía de la calidad de la atención médica. Salud Pública México, 32(2):623-9.

2. Alba, A. C. (2014). Análisis comparativo de los sistemas de salud de Cuba, Canadá y Colombia. Bogotá. Colombia: Universidad Nacional de Colombia.

3. Alfaro Latorre, M. Etreros Huerta, J. Ruiz Martínez, A. Sendagorta Camino, A. Terol García, E. (2001). Encuesta de satisfacción de los usuarios con los servicios de Atención Primaria 2000. Madrid: Ministerio de Sanidad y Consumo Instituto Nacional de la Salud.

4. Arrondo, Barragán, Etchegoyen, Paganini. (2016). Evaluación de calidad de atención en centros de atención primaria de salud. 7(26): 14-19

5. Basta., A. H. (2007). Mecanismos de evaluación de la Atención Médica. En H. L. Barragán, Fundamentos de Salud Pública (pág. 619; 630). La Plata: EDULP.

6. Barrero Castro (2017). Percepción de la calidad de la atención en salud de los usuarios de consulta externa atendidos en la IPS Mediccol SAS 2017. [En línea] https://repositorio.ucm.edu.co > jspui > bitstream > handle

7. Bravo Tapia, M. (2011). Percepción de la calidad de atención que tienen los usuarios de la consulta externa del Subcentro de Salud de Amaguaña. Quito. Universidad Técnica Particular de Loja.

8. Bunge, L. E. (2012). Satisfacción de los Usuarios con los Servicios de Salud Mental para Niños y Adolescentes Desde la Perspectiva del Paciente y el Cuidador. Buenos Aires. Universidad de Palermo.

9. CEPAL/CELADE. (2010). Censo de población, hogares y Viviendas. Argentina.

10. Clotet, J. (1993). Por Qué Bioética, in Bioética, Revista Publicada por el Consejo Federal de Medicina, Brasilia, Vol. 1, N. 1, p. 16

11. Clotet, J. (2001). Bioética. Porto Alegre: EDIPUCRS. 
12. Corbella, A. Saturno, P. (1990). La garantía de la calidad en atención primaria de la salud. Scielo.sld.cu, 397-9.

13. Deming, W. E. (1986). Out of the Crisis. MIT Press.

14. Díaz, Vilma F. Fernandez, Lucía A. Jaramillo, G. Tobar, E. (14 de agosto de 2014). Grado de satisfacción del usuario interno del centro de salud familiar Gil de Castro, durante el año 2003. Recuperado el 24 de 08 de 2016, de SCRIBD: https://es.scribd.com/document/236763652/Grado-de-Satisfaccion-UsuariosCentro-de-Salud-Familia

15. Donabedian. (1966). Evaluating the quality of medical care. The Milbank Memorial Fund Quarterly. Vol. 44, №3, part 2, pp. 166-203, publicado nuevamente en junio 2005, Vol. 83, № 4, pp. 691-729.

16. Donabedian, A. (1984). La Calidad de la atención médica, definición y métodos de evaluación. México: La Prensa Médica Mexicana.

17. Donabedian, A. (1992). Evaluación de la calidad de la atención médica. Investigación sobre Servicios de Salud: una antología. Publicación científica N ${ }^{\circ} 534$ OPS, 382, 389.

18. Donabedian, A. (2001). Criterios y estándares para evaluar y monitorear la calidad. Revista de Calidad Asistencial, V16-S68; S78.

19. Donabedian, A. (2001). Los siete pilares de la calidad. Revista Calidad Asistencial, S96- S100.

20. Galvis, J. (2006). "Calidad de Atención de Salud Percibida por el Usuario del área de consulta de Medicina de familia del ambulatorio Tipo III Venezuela, Mérida, diciembre 2005". Mérida: Universidad Católica Andrés Bello. Dirección de Posgrado.

21. Gilmore, Carol M. Novaes, H. (1996). Gerencia de la calidad. Washington, D.C: OPS.

22. Gonzalez, C. G. (2009). Nivel de satisfacción de los pacientes que asisten al servicio de urgencias frente a la atención de enfermería en una institución de primer nivel de atención en salud, en Mistrato Risaralda. Febrero a abril de 2009. Santa Fe de Bogotá: Pontificia universidad Javeriana. Facultad de enfermería.

23. Hamui Sutton Fuentes García Aguirre Hernández Ramírez de la Roche (2013). Expectativas y experiencias de los usuarios del Sistema de Salud en México: Un estudio de satisfacción con la atención médica. México: Universidad Nacional Autónoma de México.

24. Jara, D. R. (2002). Encuesta de satisfacción del personal de salud. Lima. Perú: Dirección General de Salud de las Personas. Ministerio de Salud.

25. JC. Gonzalez Pastora, L. Juandó Perxachsb, M. Quesada Sabatéc, P. Solanas Saurad. (Noviembre 1998). Satisfacción de los usuarios en atención primaria. Elsevier, Vol. 22. Núm 8. Páginas 514-520.

26. Laurenza, D. M. (30 de julio de 2013). Calidad de la atención de la salud desde la perspectiva del paciente. Análisis de los resultados de una encuesta realizada en centros de atención primaria del ámbito público. actacientifica.servicioit.cl/biblioteca/gt/GT19/GT19_. Argentina: Ministerio de Salud de la Nación.

27. Lima Quintana, L. Levcovich, M. Díaz Muñoz, A. R. (2012). Las reformas de los sistemas de salud del Reino Unido, Estados Unidos y Países Bajos de la década del ' 90 al siglo XXI. Buenos Aires: Fundación Sanatorio Güemes.

28. Mariño, E. del Salto (2014). Evaluación de la calidad de atención y satisfacción del usuario que asiste a la consulta en el departamento médico del Instituto Nacional Mejía en el periodo 2012. Quito: Universidad Central del Ecuador.

29. Martinez Duque Percepción de la satisfacción en la atención en salud en usuarios del servicio de consulta externa, de los hospitales San Antonio de Chia y Santa Rosa de Tenjo, marzo de 2016. [En línea]

https://repository.udca.edu.co > Percepción de la satisfacción, Tenjo 
30. Massip Perez; Ortiz Reyes; Llantá Abreu; Peña Fortes; Infante Ochoa. (2008). La evaluación de la satisfacción en salud: un reto a la calidad. Revista cubana de Salud Pública, v.34 n.4. pág. 1,11.

31. Mozobancyk, L. S. (2006). Satisfacción de Usuarios de centros de Atención Primaria. Buenos Aires: Informe Final Académico | Beca Carrillo - Oñativia.

32. OMS. (2008). Informe sobre la salud en el mundo 2008. La atención primaria de salud, más necesaria que nunca. Ginebra, Suiza: OMS.

33. Organización Panamericana de la Salud. Calidad en la Atención y Seguridad del Paciente. [En línea] Septiembre de 2011.

http://new.paho.org/hq/index.php?option=com content\&task=view\&id=3412\&lte $\underline{\mathrm{mid}=1557}$

34. Outomuro, Delia. (2013). Estimación del tiempo de consulta ambulatoria en clínica médica. Revista Médica Chile, 141: 361-366.

35. Paganini, J. (2001). Las Estrategias para la calidad y la eficiencia en Salud. La Plata: Facultad de Ciencias Médicas. INUS.

36. Paganini, J.M. (2001). La Salud y la Equidad. ISQUA: Publicación Científica №1, Vol.12. $\mathrm{N}^{\circ} 5$; pág. $1,13$.

37. Paganini, J. M. La Salud y la equidad. Fundamentos conceptuales, definiciones, propuestas de acción. www.inus.org.ar/documentacion/. Recuperado el 10 de 11 de 2016, de www.inus.org.ar/documentación/.../La salud y la equidad.pdf

38. Paganini, J. M. La gestión integral de la calidad, una estrategia para la equidad en salud. Recuperado el 10 de 11 de 2016, de www.cenas.org.ar/antigua/ART\%203.pdf.

39. Paganini, J. M. (2016). Las Ciencias de la Salud Colectiva. Relaciones Lógicas Sistémicas para la equidad y Calidad. CABA: Leviatán.

40. Passos Nogueira, R. (1997). Perspectivas de la gestión de calidad total en los servicios de salud. Washington, D.C: OPS Serie PALTEX Sociedad y Salud $2.000 \mathrm{~N}^{\circ} 4$

41. Peñaranda, F. Rendón, CE. (2013). Determinismo-indeterminación y el debate de los determinantes-determinación social de la salud. Colombia. Rev. Fac. Nac. Salud Pública 31 (supl 1): S47-S56.

42. Reyes Morales, Flores-Hernández, Sauceda-Valenzuela, Vértiz-Ramírez, JuárezRamírez, J Wirtz, Pérez-Cuevas. (2013). Percepción de los usuarios sobre la calidad de la atención ambulatoria en servicios de salud en México. Revista Salud Pública México. Vol. 55 Supl. 2

43. Santacruz Varela, Javier y Rodríguez Suárez, Javier. (2011). Marco general de la seguridad del paciente. México: Comisión Nacional de Arbitraje Medido. OPS OMS.

44. Sonis, A. (2001). Equidad y salud. Arch.argent.pediatr, 99(3)/253.

45. Starfield, B. (1992). Medición de los logros de la atención primaria. Investigaciones sobre servicios de salud: una antología. OPS, Publicación Científica No. 534 capítulo 67 pág. $761 ; 769$.

46. Summers, Donna C. S. (2006). Administración de la calidad. México: Pearson Educación.

47. Szwako Andrés, Federico Vera (2017). Percepción de la calidad de atención médica en consultorios de la Cátedra de Medicina Familiar del Hospital de Clínicas, 
Asunción Paraguay. Año 2013 Rev. Salud Pública Paraguay 2017; Vol. 7 N²; Julio Diciembre, 2017.

48. Zurro, M. A. Jodar Sola, G. (2011). Atención Primaria de la Salud y Atención Familiar y comunitaria. España: ELSEVIER.

\section{9-ANEXOS}

\section{1-ENTREVISTA ABIERTA (GUÍA DE COTEJO)}

\begin{tabular}{|l|}
\hline Género \\
\hline Edad \\
\hline Motivo de consulta \\
\hline ¿Cuál es tu opinión en general sobre este centro de salud? \\
\hline ¿Te parece cómodo? ¿Está limpio? \\
\hline ¿Qué opinas del edificio? ¿ ¿e las calles de acceso y las veredas? \\
\hline ¿Es fácil conseguir un turno para atenderte? ¿Siempre lo conseguís? \\
\hline ¿Qué opinas de la atención del personal? ¿Son amables? ¿Todos? \\
\hline ¿Elegís este centro? ¿Por qué? \\
\hline ¿Siempre te atendes acá? ¿Con todos los profesionales? \\
\hline ¿Sentís que en este centro estás bien atendido? ¿Qué soluciona tus problemas de salud? \\
\hline ¿Tiene todo lo que necesitan vos y tu familia? \\
\hline ¿Lo recomendas? \\
\hline ¿Estás conforme en general? ¿Por qué? \\
\hline ¿Volverías? \\
\hline ¿Qué cambiarías o mejorarías? ¿Por qué? \\
\hline
\end{tabular}

\section{2- ENTREVISTA ABIERTA AL USUARIO EXTERNO}

\begin{tabular}{|l|}
\hline Edad: \\
\hline Género: \\
\hline Ocupación: \\
\hline Escolaridad: \\
\hline Estado civil: \\
\hline ¿Cómo calificaría a este centro de salud? \\
\hline ¿Qué opina del estado de las calles y veredas para llegar hasta acá? \\
\hline ¿Es fácil o difícil sacar un turno? ¿Para quién? \\
\hline ¿Qué opina del edificio, la sala de espera? ¿Qué cambiaría? \\
\hline ¿Le parece limpio? \\
\hline ¿El personal y los profesionales son amables? ¿Son respetuosos? ¿Lo tratan bien? \\
\hline ¿Le alcanza el tiempo que dura la consulta? ¿Necesita más tiempo con el profesional? \\
\hline ¿Habría que agregar otros profesionales? ¿Cuáles? \\
\hline ¿Entiende cuando el médico le da las indicaciones o tratamiento? ¿Se las escribe? ¿Se entiende la letra? \\
\hline ¿Le explica bien? \\
\hline ¿Le entregan medicación o métodos anticonceptivos? \\
\hline ¿Le han dado turnos programados o lo han citado a través de la promotora de salud? \\
\hline ¿Ha participado de alguna actividad que organizó el centro de salud? ¿Hacen campañas de prevención? \\
\hline
\end{tabular}




\begin{tabular}{|l|}
\hline ¿Lo han invitado? \\
\hline Si se formara una comisión barrial para colaborar con la salita, ¿le interesaría? \\
\hline ¿Siente que el centro de salud resuelve sus problemas de salud? ¿Encuentra respuesta cuando consulta? \\
\hline ¿Mejoró su salud desde que se atiende acá? ¿Es necesario este CAPS para la salud del barrio? \\
\hline ¿Siente que el centro de salud cumple con sus expectativas? ¿Qué le cambiaría? o ¿Le cambiaría algo? \\
\hline
\end{tabular}

\section{3- ENTREVISTA CERRADA USUARIO EXTERNO}

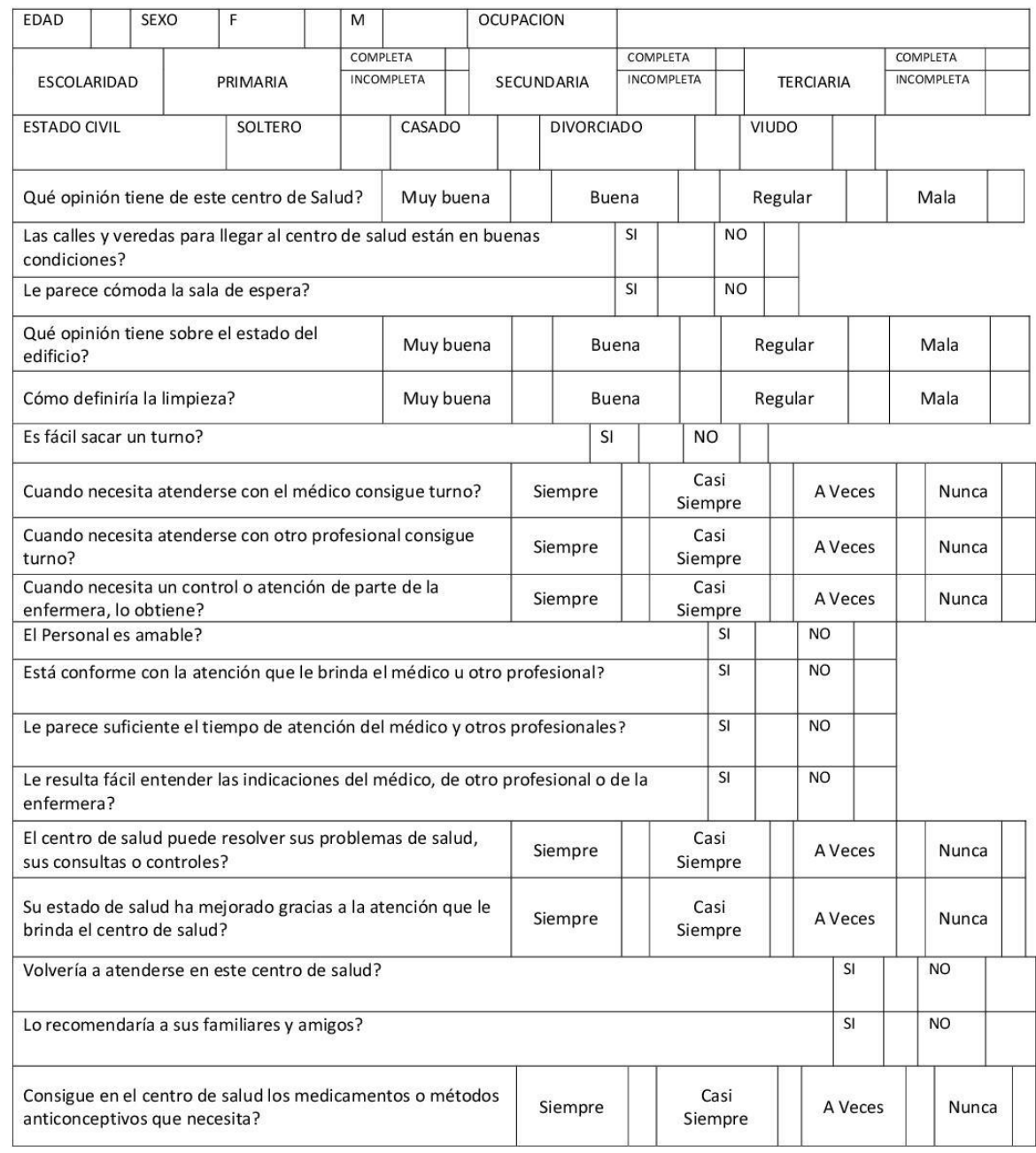

\section{4-ENTREVISTA CERRADA AL USUARIO INTERNO}




\begin{tabular}{|c|c|c|c|}
\hline \multicolumn{4}{|l|}{ Edad } \\
\hline \multicolumn{4}{|l|}{ Género } \\
\hline Escolaridad & \multicolumn{2}{|l|}{$1^{\circ}$ completa } & $1^{\circ}$ incompleta \\
\hline $2^{\circ}$ completa & $2^{\circ}$ incompleta & $3^{\circ}$ completa & $3^{\circ}$ incompleta \\
\hline \multicolumn{2}{|l|}{ Puesto de trabajo } & profesional & $\begin{array}{l}\text { No } \\
\text { profesional }\end{array}$ \\
\hline \multicolumn{4}{|c|}{ Marque la alternativa que identifique el número de años que Ud. se desempeña en este establecimiento } \\
\hline Menos de un año & 1 a 5 años & 6 a 10 años & $\begin{array}{l}\text { Más de } \\
\text { 10años }\end{array}$ \\
\hline \multicolumn{4}{|c|}{ Marque la alternativa que identifique el número de horas por las que está contratado } \\
\hline \multicolumn{2}{|c|}{ Hasta 6 horas } & $\begin{array}{l}\text { Más de } \\
\text { 10horas }\end{array}$ & $\begin{array}{l}\text { Más de } \\
\text { 30horas }\end{array}$ \\
\hline \multicolumn{2}{|c|}{ ¿Conoce Ud. los Objetivos y Metas del Centro de Salud? } & Si & No \\
\hline \multicolumn{4}{|c|}{ ¿Qué opina del estado en que se encuentran las calles y veredas de acceso al centro de salud? } \\
\hline Muy bueno & bueno & regular & malo \\
\hline \multicolumn{2}{|c|}{ ¿Le parece bien cómo se dan los turnos? } & $\mathrm{Si}$ & No \\
\hline \multicolumn{4}{|c|}{ Cómo califica el estado del edificio, la iluminación, la ventilación y la calefacción } \\
\hline Muy bueno & bueno & regular & malo \\
\hline \multicolumn{4}{|c|}{ ¿Qué opina de la limpieza? } \\
\hline Muy bueno & bueno & regular & malo \\
\hline \multicolumn{2}{|c|}{$\begin{array}{l}\text { ¿Siente que el personal es amable y respetuoso con las personas que } \\
\text { consultan? }\end{array}$} & $\mathrm{Si}$ & No \\
\hline \multicolumn{4}{|c|}{ De acuerdo al trabajo que Ud. desempeña, el instrumental de que dispone es } \\
\hline \multicolumn{2}{|c|}{ Adecuado } & \multicolumn{2}{|l|}{ Inadecuado } \\
\hline \multicolumn{2}{|c|}{ ¿Le parece suficiente el tiempo de atención que puede dedicar al paciente? } & $\mathrm{Si}$ & No \\
\hline \multicolumn{2}{|c|}{ ¿Reconoce Ud. la existencia de conflictos, o problemas en el Centro de Salud? } & $\mathrm{Si}$ & No \\
\hline \multicolumn{2}{|c|}{ ¿Está Ud. conforme con la forma de resolver los conflictos o problemas? } & $\mathrm{Si}$ & No \\
\hline \multicolumn{2}{|c|}{$\begin{array}{l}\text { ¿Puede participar en el análisis de los diferentes problemas del Centro de Salud } \\
\text { y buscar soluciones en forma conjunta con los demás trabajadores? }\end{array}$} & $\mathrm{Si}$ & No \\
\hline \multicolumn{2}{|c|}{ ¿Considera Ud. que la labor que realiza, es reconocida por sus superiores? } & $\mathrm{Si}$ & No \\
\hline \multicolumn{2}{|c|}{ ¿Cómo considera usted su trabajo? } & Importante & $\begin{array}{l}\text { Sin } \\
\text { importancia }\end{array}$ \\
\hline \multicolumn{2}{|c|}{$\begin{array}{l}\text { ¿Considera Ud. que en el Centro de Salud existen sistemas de incentivo a la } \\
\text { labor que se realiza? }\end{array}$} & $\mathrm{Si}$ & No \\
\hline \multicolumn{2}{|c|}{ ¿Conoce Ud. los sistemas de información existentes en el Centro de Salud? } & $\mathrm{Si}$ & No \\
\hline \multicolumn{2}{|c|}{ ¿Se realizan actividades de prevención? } & $\mathrm{Si}$ & No \\
\hline \multicolumn{2}{|c|}{ ¿Se trabaja en forma interdisciplinaria? } & $\mathrm{Si}$ & No \\
\hline \multicolumn{2}{|l|}{ ¿Se trabaja en red? } & $\mathrm{Si}$ & No \\
\hline \multicolumn{2}{|c|}{ ¿Se realiza seguimiento del paciente? } & $\mathrm{Si}$ & No \\
\hline \multicolumn{2}{|c|}{$\begin{array}{l}\text { ¿Considera que con su trabajo ha colaborado para mejorar la salud de la } \\
\text { comunidad? }\end{array}$} & $\mathrm{Si}$ & No \\
\hline ¿Considera que el & d resuelve la mayoría de las consultas? & $\mathrm{Si}$ & No \\
\hline $\begin{array}{l}\text { ¿Usted, se atende } \\
\text { familiares y amigo }\end{array}$ & ndido en este centro? ¿Lo ha recomendado a & $\mathrm{Si}$ & No \\
\hline ¿Se siente satisfec & ajo en este centro de salud? & $\mathrm{Si}$ & No \\
\hline
\end{tabular}

